NIST Special Publication 1041

\title{
CFAST - Consolidated Model of Fire Growth and Smoke Transport (Version 6)
}

\section{User's Guide}

\author{
Richard D. Peacock \\ Walter W. Jones \\ Paul A. Reneke \\ Glenn P. Forney
}




\title{
CFAST - Consolidated Model of Fire Growth and Smoke Transport (Version 6)
}

\section{User's Guide}

\author{
Richard D. Peacock \\ Walter W. Jones \\ Paul A. Reneke \\ Glenn P. Forney \\ Fire Research Division
} Building and Fire Research Laboratory

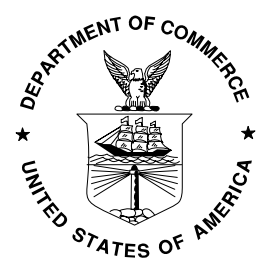

U.S. Department of Commerce Carlos M. Gutierrez, Secretary

Technology Administration Phillip J. Bond, Under Secretary for Technology

National Institute of Standards and Technology Hratch G. Semerjian, Acting Director 
Certain commercial entities, equipment, or materials may be identified in this document in order to describe an experimental procedure or concept adequately. Such identification is not intended to imply recommendation or endorsement by the National Institute of Standards and Technology, nor is it intended to imply that the entities, materials, or equipment are necessarily the best available for the purpose.

National Institute of Standards and Technology Special Publication 1041 Natl. Inst. Stand. Technol. Spec. Publ. 1041, 109 pages (August 2005)

CODEN: NSPUE2 WASHINGTON: 2005

For sale by the Superintendent of Documents, U.S. Government Printing Office Internet: bookstore.gpo.gov — Phone: (202) 512-1800 — Fax: (202) 512-2250 Mail: Stop SSOP, Washington, DC 20402-0001 



\section{Contents}

Chapter 1 Introduction $\quad 1$

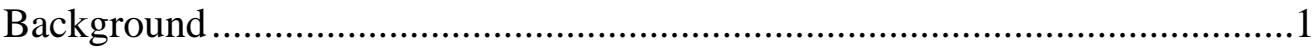

Chapter 2 Getting Started 3

Installation from the CFAST Web Site..........................................................

Computer Hardware Requirements..............................................................4

Computer Operating System and Software Requirements ..............................4

Verifying Correct Installation and Operation ................................................4

$\begin{array}{ll}\text { Chapter } 3 \text { Running CFAST } & 6\end{array}$

Creating a CFAST Input Data File ..........................................................6

File Naming and Location .....................................................................10

Starting a CFAST Calculation .............................................................11

Running CFAST from CEdit ..........................................................11

Running CFAST from a Command Prompt .....................................12

Chapter 4 Setting up the Input File for CFAST 14

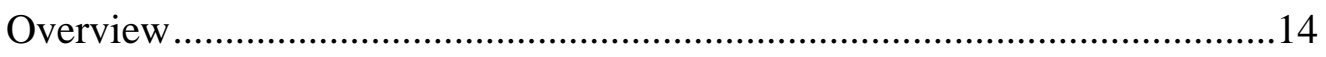

Simulation Environment ........................................................................16

Naming the Calculation, the Title Input ..........................................16

Setting Time Limits and Output Options.........................................17

Ambient Conditions .........................................................................18

Compartment Geometry.........................................................................20

Defining Compartment Size and Position.........................................22

Modeling the Compartment as a Tall Shaft or Long Corridor.............23

Thermal Properties of Boundaries .....................................................25

Compartment Connections...................................................................26

Defining Horizontal Natural Flow Connections (Doors, Windows) ...27

Defining Vertical Natural Flow Connections (Ceiling or Floor Holes,

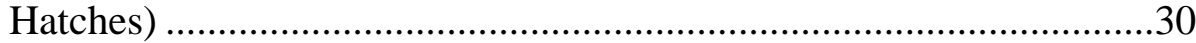

Defining Mechanical Ventilation Connections...................................32

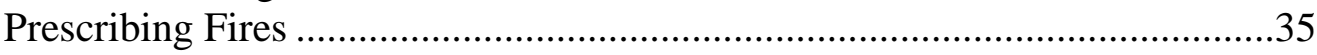

Defining Fire Objects...................................................................38

Associating Fire Objects with One or More Instances of the Fire in the

Compartments of the Simulation ....................................................41

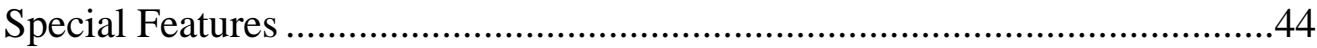

Sprinklers and Detectors ...........................................................44 
Defining Targets ...................................................................45

Defining Compartment Area...........................................................47

Inter-compartment Heat Transfer (Conduction) ..................................48

The Ceiling Jet - An Additional Zone..............................................50

Scenario and Software Limits ..............................................................51

Chapter 5 Output $\quad 52$

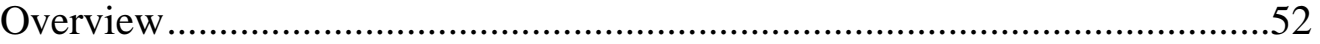

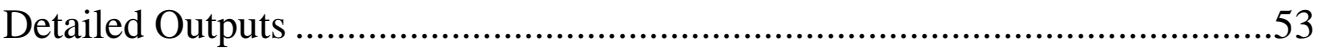

Output for Initialization ...........................................................53

Output for Main Output Variables.....................................................59

Output for Wall Surface and Targets ................................................60

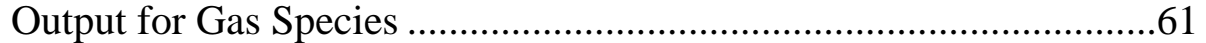

Output for Vent Flows ...................................................................62

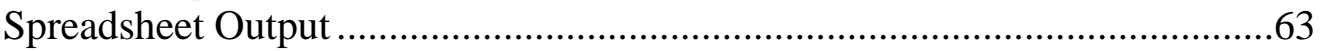

Primary Output Variables (project.n.csv) ..........................................63

Species Output (project.s.csv).......................................................64

Vent Flow (project.f.csv) ..............................................................64

Temperatures and flux (project.w.csv) .............................................65

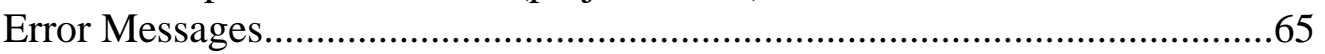

$\begin{array}{ll}\text { References } & 69\end{array}$ 


\section{Acknowledgement}

The CFAST model has been under development for more than 20 years. The primary developers are Walter Jones, Richard Peacock, Glenn Forney, Rebecca Portier, Paul Reneke, John Hoover, and John Klote.

There have been contributions through research and published papers at Worcester Polytechnic Institute, University of California at Berkeley, VTT of Finland and CITCM of France. An important guide to development of the model has been from many people around the world who have provided ideas, suggestions, comments, detailed questions, opinions on what should happen in particular scenarios, what physics and chemistry are needed and what types of problems must be addressed by such a model in order to be useful for real world applications.

In addition to support by NIST, at least two outside organizations have provided support for the development of the model, its documentation, and validation. At the U.S. Navy, Naval Research Laboratory, Jean Bailey, John Hoover, and Pat Tatem provided support for model development, including the vertical flow and corridor flow algorithms. The U.S. Nuclear Regulatory Commission (NRC) has supported experiments to validate CFAST as part of an international collaboration to study the application of fire models to nuclear power plants. NRC has also partially funded the development of the Windows version of CFAST, the documentation described in this document and the evaluation of the model per ASTM E1355. 



\section{Disclaimer}

This software was developed at the National Institute of Standards and Technology by employees of the Federal Government in the course of their official duties. Pursuant to Title 17 Section 105 of the United States Code this software is not subject to copyright protection within the United States and is in the public domain. The software is an experimental system. NIST assumes no responsibility whatsoever for its use by any party. This software is provided "as is." You accept the software "as is” and acknowledge that NIST makes no warranty of any kind, express, implied or statutory, including, without limitation, the implied warranty of merchantability, fitness for a particular purpose, non-infringement and data accuracy. NIST does not represent or warrant that the operation of the software will be uninterrupted or error-free, or that any defects will be corrected. NIST does not warrant or make any representations regarding the use of the software or the results thereof, including but not limited to the correctness, accuracy, reliability, or usefulness of the software. You may freely use, copy or distribute this software.

Users are warned that CFAST is intended for use only by those competent in the field of fire safety and is intended only to supplement the informed judgment of the qualified user. The software package is a computer model which may or may not have predictive value when applied to a specific set of factual circumstances. Lack of accurate predictions by the model could lead to erroneous conclusions with regard to fire safety. All results should be evaluated by an informed user.

\section{Intent and Use}

The algorithms, procedures, and computer programs described in this report constitute a methodology for predicting some of the consequences resulting from a prescribed fire. They have been compiled from the best knowledge and understanding currently available, but have important limitations that must be understood and considered by the user. The program is intended for use by persons competent in the field of fire safety and with some familiarity with personal computers. It is intended as an aid in the fire safety decision-making process. 



\section{Chapter 1 Introduction}

\section{Background}

CFAST is a two-zone fire model used to calculate the evolving distribution of smoke, fire gases and temperature throughout compartments of a building during a fire. These can range from very small containment vessels, on the order of $1 \mathrm{~m}^{3}$ to large spaces on the order of $1000 \mathrm{~m}^{3}$. This guide describes how to obtain the model, verify its correct installation, create input data in an appropriate form, and analyze of the output of a simulation.

The modeling equations used in CFAST take the mathematical form of an initial value problem for a system of ordinary differential equations (ODEs). These equations are derived using the conservation of mass, the conservation of energy (equivalently the first law of thermodynamics), the ideal gas law and relations for density and internal energy. These equations predict as functions of time quantities such as pressure, layer height and temperatures given the accumulation of mass and enthalpy in the two layers. The CFAST model then consists of a set of ODEs to compute the environment in each compartment and a collection of algorithms to compute the mass and enthalpy source terms required by the ODEs. The formulation of the equations, their solution, and discussion of validation and verification of the code are presented in a companion document ${ }^{1}$..

All of the data to run the model is contained in a primary data file, together with databases for objects, thermophysical properties of boundaries, and sample prescribed fire descriptions ${ }^{2}$. These files contain information about the building geometry (compartment sizes, materials of construction, and material properties), connections between compartments (horizontal flow openings such as doors, windows, vertical flow openings in floors and ceilings, and mechanical ventilation connections), fire properties (fire size and species production rates as a function of time), and specifications for detectors, sprinklers, and targets (position, size, heat transfer characteristics, and flow characteristics for sprinklers). Materials are defined by their thermal conductivity, specific heat, density, thickness, and burning behavior. Throughout the discussion on the model inputs, notes are included to provide additional insight on the model's operation.

The outputs of CFAST are the sensible variables that are needed for assessing the environment in a building subjected to a fire. These include temperatures of the upper and lower gas layers within each compartment, the ceiling/wall/floor temperatures within each 
compartment, the visible smoke and gas species concentrations within each layer, target temperatures and sprinkler activation time.

Many of the outputs from the CFAST model are relatively insensitive to uncertainty in the inputs for a broad range of scenarios. However, the more precisely the scenario is defined, the more accurate the results will be. Not surprisingly, the heat release rate is the most important variable, because it provides the driving force for fire-driven flows. Other variables related to compartment geometry such as compartment height or vent sizes, while important for the model results, are typically more easily defined for specific design scenarios than fire related inputs.

The first public release of CFAST was version 1.0 in June of 1990. This version was restructured from $\mathrm{FAST}^{3}$ to incorporate the "lessons learned" from the zone model CCFM ${ }^{4}$, namely that modifications and additions to the model are easier and more robust if the components such as the physical routines are separated from the solver code used by the model. Version 2 was released as a component of Hazard 1.2 in $1994^{5}$. The first of the 3.x series was released in 1995 and included a vertical flame spread algorithm, ceiling jets and non-uniform heat loss to the ceiling, spot targets, and heating and burning of multiple objects in addition to multiple prescribed fires. Ignition was assigned based on a critical heat flux, a critical temperature, or a critical time input by the user. As CFAST evolved over the next five years, version 3 included smoke and heat detectors, suppression through heat release reduction, better characterization of flow through doors and windows, vertical heat conduction through ceiling/floor boundaries, and non-rectangular compartments. In 2000, version 4 was released and included horizontal heat conduction through walls, and horizontal smoke flow in corridors. Version 5 improved the combustion chemistry. Version 6 includes a new user interface written for Windows and revisions to the input file and model. The current version is 6.0 


\section{Chapter 2 Getting Started}

\section{Installation from the CFAST Web Site}

CFAST is documented by two publications, this user's guide and a technical reference guide $^{1}$. The technical reference guide describes the underlying physical principles, provides a comparison with other models, includes an evaluation of the model following the guidelines of ASTM E1355 ${ }^{6}$. This user's guide describes how to use the model and applies to version 6 and later. All the documentation is available on the web site.

All of the files associated with CFAST can be obtained at:

http://fire.nist.gov/cfast

Information about new versions, bug fixes, and documentation for the model and software are available on this web site. The CFAST distribution consists of a self-extracting set-up program for Windows-based PCs.

After downloading the set-up program to a PC, doubleclicking on the file's icon walks the user through a series of steps for installation of the program. The most important part of the installation is the creation of a directory (called c: \nistlcfast6 by default) in which the CFAST executable files, sample cases, and supplemental data files are installed.

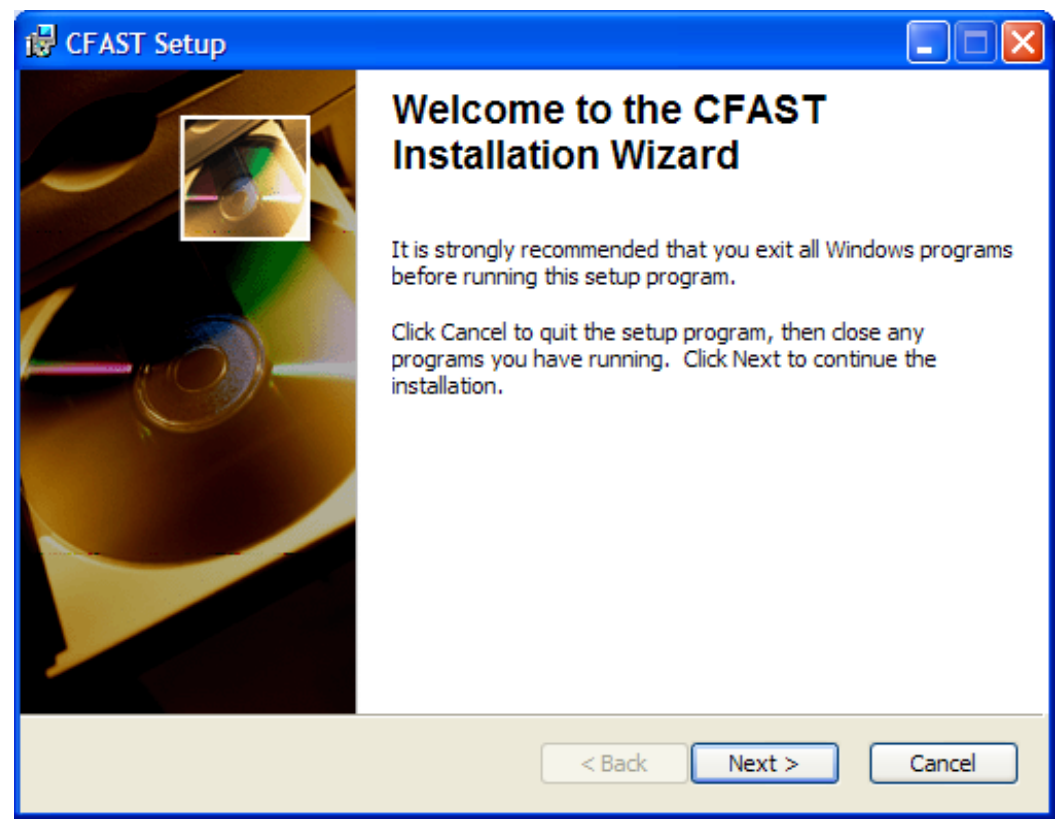




\section{Computer Hardware Requirements}

CFAST requires a relatively fast processor and a sufficient amount of random-access memory (RAM) for complex cases. The processor should be at least as fast as a $1 \mathrm{GHz}$ Pentium III, with more than 256 MB of memory for complex cases. Typical calculation times for a 2 compartment scenario can range from a few seconds to multiple hours, depending on the details of the scenario. Plus, a large hard drive is needed to store the output of calculations. It is not uncommon for a single calculation to generate output files as large as 1 GB.

\section{Computer Operating System and Software Requirements}

CFAST and the input editor CEdit run under Microsoft Windows. The latest version has been tested and runs on both Windows 2000 and Windows XP.

\section{Verifying Correct Installation and Operation}

Sample input files are provided with the program for new users who are encouraged to first run the sample calculations before attempting to create an input file. To run the model, browse to the location of the CFAST input files (default location is c: Inistlcfast6/data, and double click on the file named standard.in. This should open the file in the CFAST input editor, CEdit. The simple test case can be run from the program menu by selecting "Run!" and then "Model Simulation, CFAST"

This runs a very simple test case and it should be completed quickly. Additional details on running CFAST are included in the next chapter. To verify that the installation has been done correctly, the output of the model should appear as follows. 


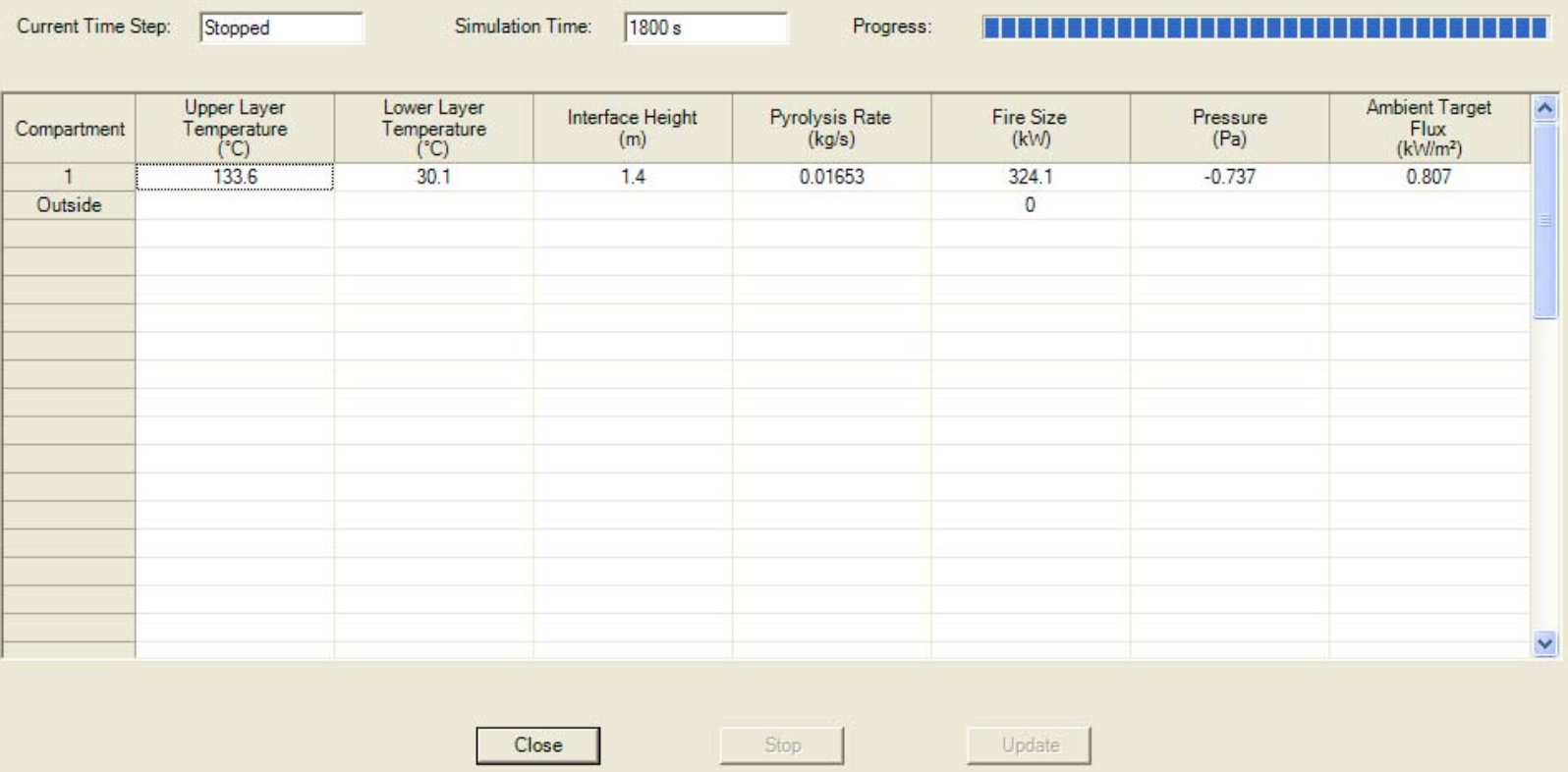

This case checks several attributes of the installation including the presence of the database files (see auxiliary files in the section on building input files). Additional explanation of the results of this run is described in Chapter 5. 


\section{Chapter 3 Running CFAST}

Running CFAST is relatively simple. All of the parameters that describe a given fire scenario are entered into a text file that is referred to as the "data" or "input" file. In this document, the data file is designated as filename.in, where "filename" stands for any character string that helps to identify the simulation. All of the output files associated with the calculation would typically have this common prefix. In addition to the input file, there are often several external files containing input parameters for the simulation. These files are referred to as "database" files, which contain parameters describing common materials and fuels.

The CFAST distribution includes a Windows-based input editor called CEdit that allows the user to enter details of a simulation in a standard Windows format, save the data file to disk, and run the simulation with CFAST from within the program. Typically, all simulations would be developed and run from within CEdit. For numerous, similar or lengthy simulations, the fire model CFAST can be run from a command prompt window.

It is suggested that a new user start with an existing data file, run it as is, and then make the appropriate changes to the input file for the desired scenario. By running a sample case, the user becomes familiar with the procedure and ensures that his/her computer is up to the task before embarking on learning how to create new input files.

\section{Creating a CFAST Input Data File}

All of the data to run the model is contained in an input data file. Also needed are databases for objects, thermophysical properties of boundaries, and sample prescribed fire descriptions provided with the model. These files contain information about the building geometry (compartment sizes, materials of construction, and material properties), connections between compartments (horizontal flow openings such as doors, windows), vertical flow openings in floors and ceilings, and mechanical ventilation connections), fire properties (fire size and species production rates as a function of time), and specifications for detectors, sprinklers, and targets (position, size, heat transfer characteristics, and flow characteristics for sprinklers). Materials are defined by their thermal conductivity, specific heat, density, thickness, and burning behavior (heat release rate, ignition properties, and species yields).

The input data file provides the program with parameters to describe the scenario under consideration. The parameters are organized into groups of related variables. Each line of the 
input data file contains inputs related to a single group and begins with a keyword that identifies the input. For example, compartment geometry is described by a set of lines (keyword COMPA) that define the width, depth, and height of each compartment. A description of the input parameters can be found in Chapter 4.

Typically, the input data file will be created with the input editor, CEdit, included with the CFAST distribution. A shortcut to the input editor is placed on the start menu during installation. To run, select Start, Program Files, and CFAST. Details of the program and its inputs are described in chapter 4.

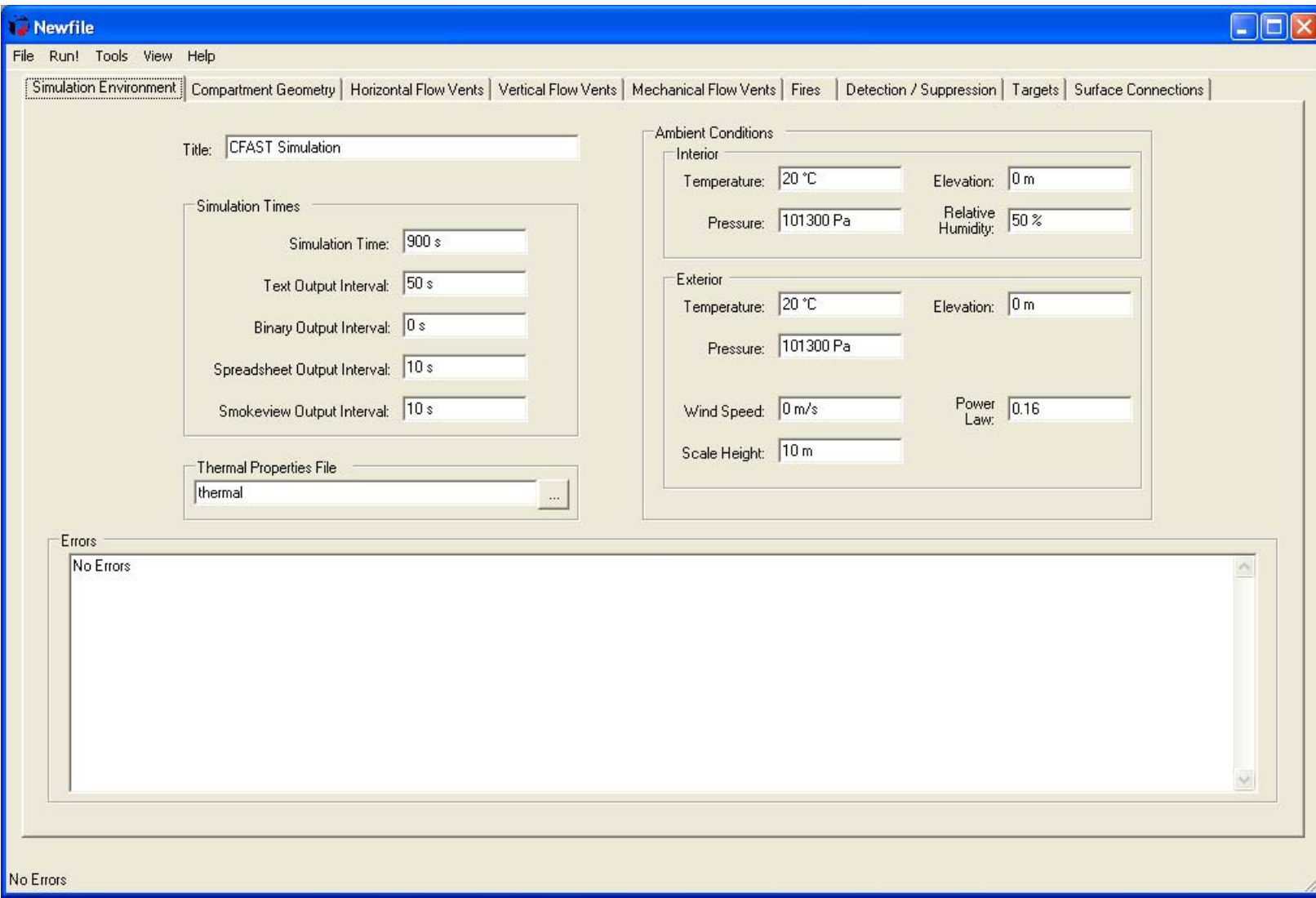

\begin{tabular}{l} 
Create Geometry File \\
Model Simulation, CFAST Ctrl+R \\
Simulation Visualization, Smokeview \\
\hline Show CFAST Window \\
$\checkmark$ Detailed Output File
\end{tabular}

The program includes a number of menu items for ancillary functions. In addition to the normal file menu items to open and save input data files or to exit the program, a "Run!” menu is included to execute or view the current simulation. Menu items include the following:

- Create Geometry File: used to create a geometry file for visualization with the program smokeview. The input data file is saved, if necessary, and CFAST is run with an option to only run through initialization. The resulting geometry can be viewed with the "Simulation Visualization, Smokeview" menu item, below. 
- Model Simulation, CFAST: runs the current input data file specification with the fire model CFAST. The input data file is saved, if necessary, and CFAST is run to completion. Additional details are described below in the section on starting a CFAST calculation. In order to visualize the results of the simulation with the program smokeview, the Smokeview Output Interval must be set to a non-zero value on the simulation Environment page. This is described in more detail in chapter 4.

- Simulation Visualization, Smokeview: runs the program smokeview with the previously defined smokeview geometry file. This allows the user to see the compartment geometry and connections or view the results of the simulation visually. Additional details on the use of smokeview are included in the user's guide for smokeview ${ }^{7}$.

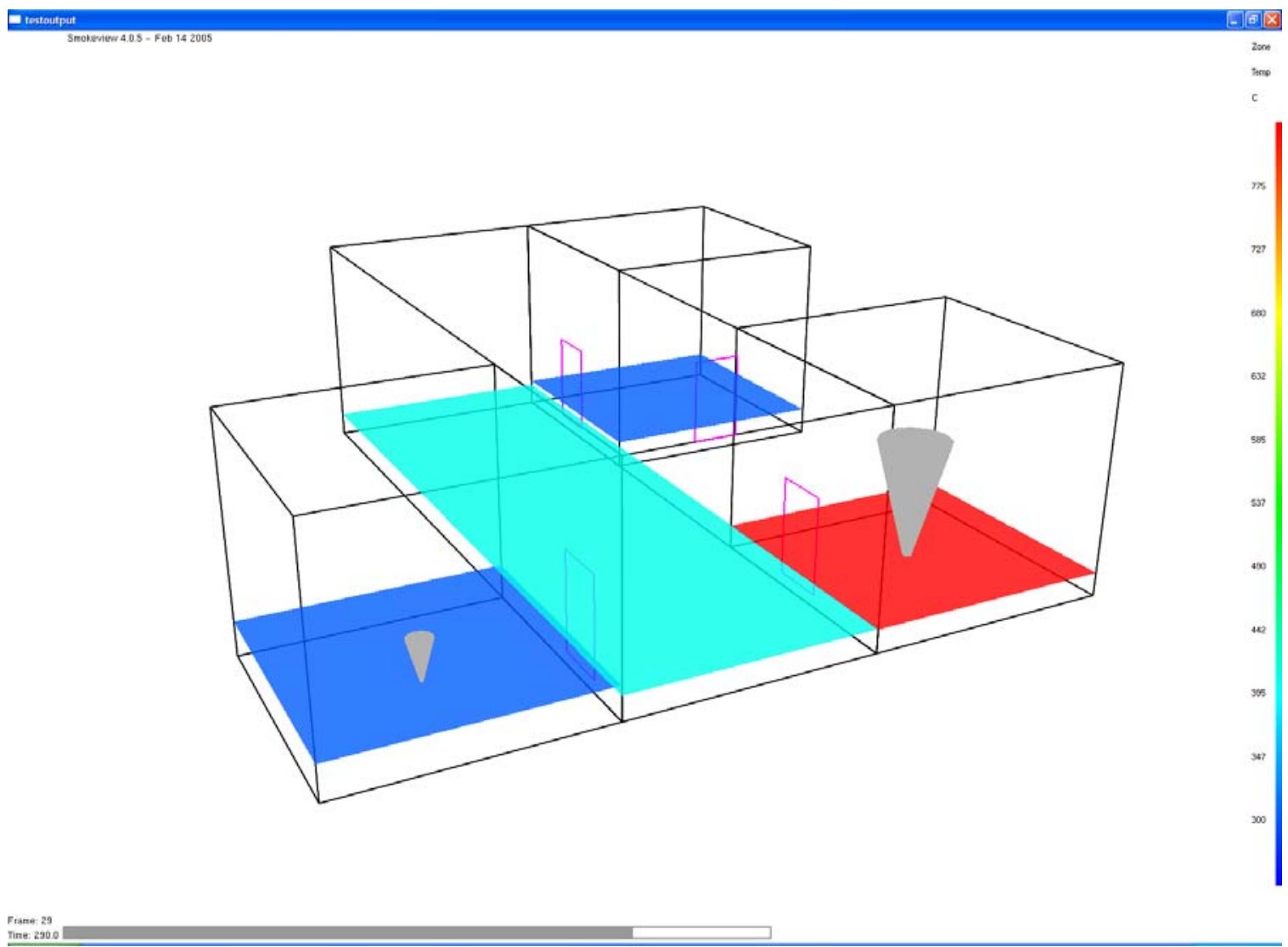

Two additional menu items can be selected to control details of the model simulation using CFAST.

- Show CFAST Window: If checked, this menu item allows the user to see the windows command prompt that is used to execute the CFAST model when the Model Simulation, CFAST menu item is used. By default, this is not checked. Normally, this can be left unchecked. For troubleshooting, this can be selected to see additional details of the calculation as it progresses. 
- Detailed Output File: If checked, this menu item directs the CFAST model to produce a detailed text output file. Details of the output are included in chapter 5.

Edit Thermal Properties

Select Engineering Units

Set Maximum Simulation Time Step
The "Tools" menu allows the user to view or change the database of material thermophysical properties used by the model and to select desired engineering units used in the input editor CEdit. Menu items include the following.

- Edit Thermal Properties: Heat transfer through compartment surfaces, to secondary fire objects, or other targets that may be specified depends on userspecified thermal properties for the materials. These may be view or changed by the user as desired. It is important to note that these are global parameters that are not tied to any particular simulation. Thus, if values are changed, the changed values will affect all future simulations or repeated runs of earlier simulations.

Materials properties include thermal conductivity, specific heat, density, thickness, and emissivity. Materials included in the database provided with the program are textbook values of common building and furnishing materials.

\begin{tabular}{|c|c|c|c|c|c|c|c|c|}
\hline \multicolumn{6}{|l|}{ Thermal Properties } & \multicolumn{3}{|c|}{$0 \square x$} \\
\hline Material & Short Name & Conductivity & Specific Heat & Density & Thickness & Emissivity & A & \\
\hline Acoustic Tile (1/8 in) & ACOUTILE & $5.8 \mathrm{E}-05$ & 1.34 & 290 & 0.003 & 0.9 & & \\
\hline Aluminum (1/8 in) & ALUM1/8 & 0.231 & 1.033 & 2702 & 0.003 & 0.9 & & \\
\hline Aluminum Alloy 2024-T6 (1/8 in) & ALUM2064 & 0.186 & 1.042 & 2770 & 0.003 & 0.9 & & \\
\hline Brick, Clay ( 3 in) & BRICK & 0.0015 & 0.96 & 2645 & 0.076 & 0.9 & & \\
\hline Brick, Common (3 in) & COMBRICK & 0.00072 & 0.835 & 1920 & 0.076 & 0.9 & & \\
\hline Calcium Silicate Board (1/2 in) & MARINITE & 0.00018 & 1.293 & 737 & 0.013 & 0.83 & & \\
\hline Cellulose Insulation, Wood or Paper Pulp ( $3.5 \mathrm{in})$ & CELLULOS & $3.9 \mathrm{E}-05$ & 1.38 & 45 & 0.088 & 0.9 & & \\
\hline Cement Mortar (1 in) & CEMENTMO & 0.00072 & 0.78 & 1860 & 0.025 & 0.9 & & \\
\hline \multirow[t]{2}{*}{ Concrete, Light Weight (6 in) } & CONCLITE & 0.000125 & 1.05 & 525 & 0.15 & 0.94 & $\checkmark$ & \\
\hline & \multicolumn{3}{|c|}{ aterial: Acoustic Tile (1/8 in) } & & & & & \\
\hline Short Name: ACOUTILE & \multicolumn{3}{|c|}{ Thermal Conductivity: $5.8 \mathrm{E}-05 \mathrm{~kJ} / \mathrm{kg}$} & \multicolumn{3}{|c|}{ Specific Heat: $1.34 \mathrm{~kJ} /{ }^{\circ} \mathrm{C}$} & & \\
\hline Density: $290 \mathrm{~kg} / \mathrm{m}^{\wedge} 3$ & \multicolumn{3}{|c|}{ Thickness: $\quad 0.003 \mathrm{~m}$} & \multicolumn{3}{|c|}{ Emissivity: 0.9} & & \\
\hline $\mathrm{HCl}(\mathrm{b} 1): \sqrt{0}$ & \multicolumn{3}{|c|}{$\mathrm{HCl}(\mathrm{b} 2): 0$} & \multicolumn{3}{|c|}{$\mathrm{HCl}(\mathrm{b} 3): 0$} & & \\
\hline \multirow[t]{3}{*}{$\mathrm{HCl}(\mathrm{b} 4): 0$} & \multicolumn{3}{|c|}{$\mathrm{HCl}(\mathrm{b} 5): 0$} & \multicolumn{3}{|c|}{$\mathrm{HCl}(\mathrm{b} 6): 0$} & & \\
\hline & \multicolumn{3}{|c|}{$\mathrm{HCl}(\mathrm{b} 7): 0$} & & & & & \\
\hline & OK & & Cancel & & & & & \\
\hline
\end{tabular}

In addition, a series of constants that define the absorption of $\mathrm{HCl}$ on compartment surfaces can be specified. Values for gypsum wallboard are included in the database supplied with the program.

- Select Engineering Units: The CFAST model uses input values and provides output in S.I. units. Within the input editor, CEdit, the user may select engineering 
units of choice for input and output. These values are saved in the windows registry and may be changed at any time.

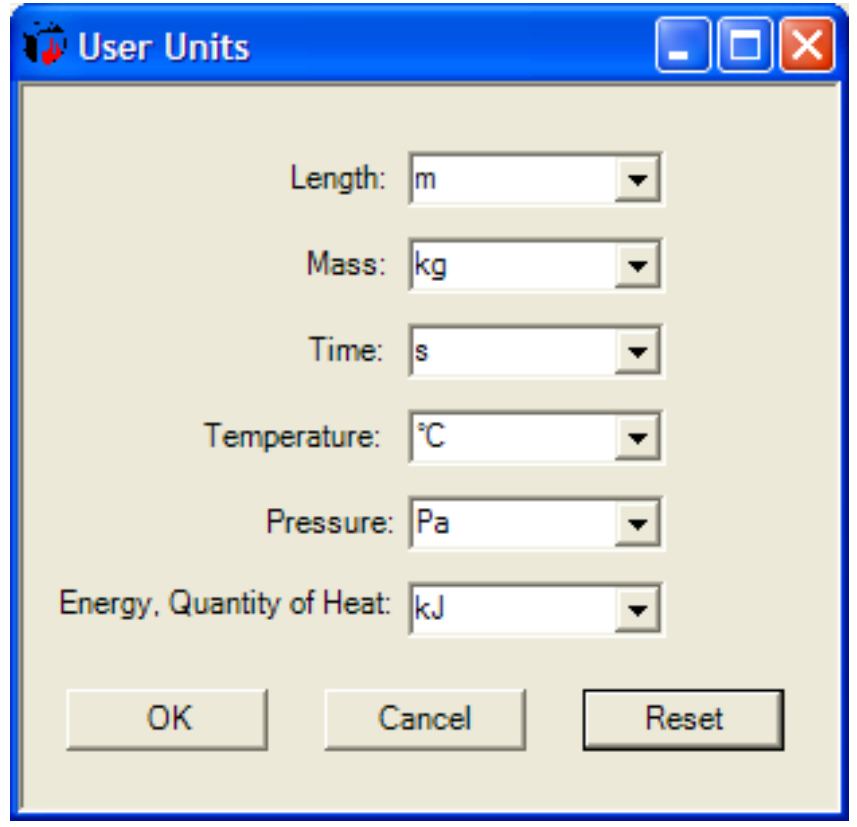

CFAST Input File CFAST Output File CFAST Log File

Help Topics $\quad$ F1 CFast Web Site About
The View menu allows the user to view and / or print the input data file, output file (if the simulation has been run and a text output file generated) and the log file of the simulation.

The Help menu accesses the online version of this user's guide, the CFAST web site, or an about dialog box that displays the user license and version of the program.

\section{File Naming and Location}

By default, the CFAST installation places all program files in the directory c:\NIST\CFAST6 and sample input data files in the directory c: $\mid$ NIST\CFAST6\DATA. While these locations can be changed during installation, the documentation in this user's guide assumes these locations. File naming conventions in CFAST limit the length of file names to the DOS standard of 8 characters plus a three character extension such as standard.in. By default, all input data files are assumed to be located in the data directory at c:\NIST\CFAST6\DATA and all output files are written to this directory as well.

In addition, there are several files that CFAST uses to communicate with its environment. They include 1) an input data file, required for every simulation, 2) the thermal properties database, 3) additional secondary fire source objects, 4) a binary data file containing all calculated values from the simulation, and 6) a series of spreadsheet files of important output variables. Documentation of the input data file is included as chapter 4 of this user's guide. 
The format of the configuration file, thermal database, and object databases are detailed in the appendices. Specification of the history and restart file is included in chapter 4.

In CFAST, simulations are arranged as projects with all the files associated with a single simulation sharing a common base file name. For a simulation with a base file name of "project", the built-in naming conventions would identify the files of the simulation as follows:

- input: project.in

- text output file: project.out

- $\quad$ spreadsheet output files: (Normal output) project.n.csv, (Species output) project.s.csv, (Flow output) project.f.csv, (Wall surface temperatures, targets and sprinklers) project.w.csv

- smokeview geometry file: project.smv

- smokeview plot file: project.plt

- binary output file: project.hi

\section{Starting a CFAST Calculation}

\section{Running CFAST from CEdit}

Typically, model simulations are run directly from the input editor, CEdit. To run the model, either open an existing input data file from the program menus with "File", "Open," or create a new input data file within CEdit. The model is run by selecting "Run!" and then "Model Simulation, CFAST.” 


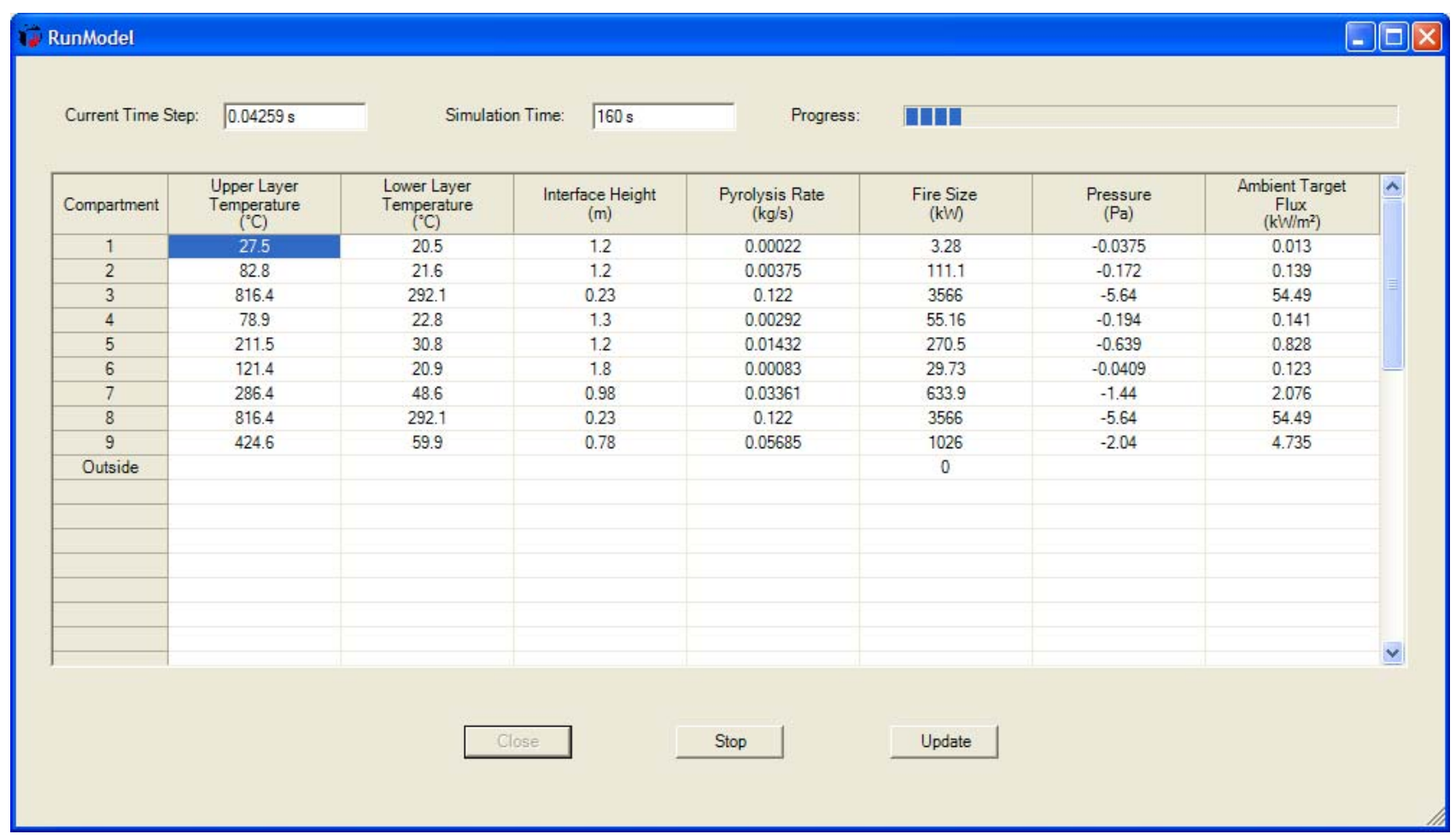

This opens a window that shows the progress of the simulation, with information on the environment in each compartment of the simulation. Several buttons are also available as follows:

Close Close The close button is disabled while the model is running. Once the simulation is complete (stopped by the user with the stop button), the close button closes the window and returns to the main input editor.

Stop The stop button halts execution of the simulation, but leaves the simulation window on the screen. The stop button is available only when the simulation is in progress.

Update Normally, model outputs are displayed and updated only at any of the time intervals specified on the environment page. For complex calculations, there may be a significant time period between display updates. The update button allows the user to see the current state of the calculation at any time. The update button is only available when the simulation is in progress.

\section{Running CFAST from a Command Prompt}

The model CFAST can also be run from a Windows command prompt. CFAST can now be run from any folder, and refer to a data file in any other folder. The fires and thermophysical properties have to be in either the data folder, or the executable folder. The data folder is checked first and then the executable folder.

[drive1:1][folder1\]cfast [drive2:1][folder2l]project 
The project name will have extensions appended as needed (see below). For example, to run a test case when the cfast executable is located in c:Inistlcfast6 and the input data file is located in c:Idata, the following command could be used:

c:Inistlcfast6lcfast c:Idataltestfire0 $\quad<<<$ note there is no extension.

If the command is entered as \bin \cfast \bin\dataltestfire0.in, then CFAST will try to open testfire0.in.in

The database files for thermal properties and fire objects may be located either in the folder with the input data file or in the folder with the cfast executable. The model checks first in the data file folder and then in the cfast executable folder. If the files do not exist in either location, the simulation is not run. By default, names for these files are thermal.csv for the thermal properties file and *.o for the fire object files.

Command line options

- $\mathrm{k}$ - no key board access

- i - initialization only

- $\mathrm{h}$ - output header

- c - compact output

- $\quad f$ - full output (c and $f$ are exclusive). Note the interaction of the $f$ and c option. The default for the console output is /c. The default for the file output is /f. This default action can be overwritten by explicitly including the /f or /c option. Output goes to the screen if the print interval (second entry on the TIMES line) is positive and to the output file if the interval is negative. 


\section{Chapter 4 Setting up the Input File for CFAST}

\section{Overview}

CFAST is a computer program that uses an input file and generates one or more output files. The first step in performing a calculation is to generate a text input file that provides the program with all of the necessary information to describe the scenario under consideration. The most important inputs determine the geometry of the compartments in the scenario and the connections between these compartments. Next, the fire, detection, and suppression characteristics of the scenario are defined. Finally, there are a number of parameters that customize the output from the model. Each line of the file contains a keyword label that identifies the input, followed by a number of numerical or text inputs corresponding to the particular input keyword. A simple input file is shown below. This example is used in the discussion of the output in Chapter 5.

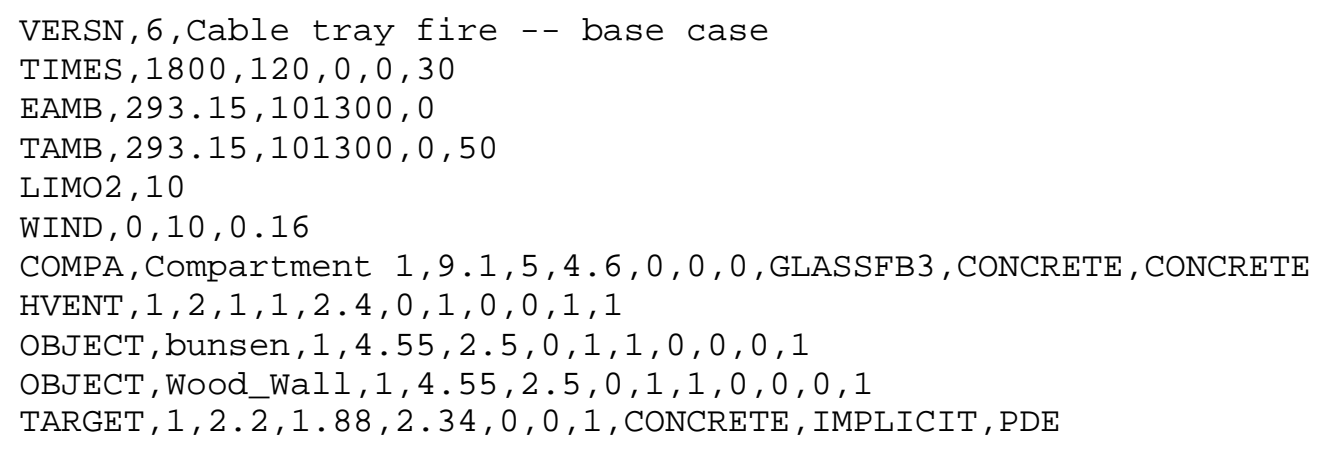

All of the inputs to the model are discussed in this chapter. Following the discussion that details each input, their engineering units and default values, notes are included that provided additional guidance or frequently addressed problems that may be encountered by the user. These notes take the form of a bulleted list such as: 
- The inputs may be integers (a simulation time of $1800 \mathrm{~s}$ ), real numbers (a mass loss rate of $0.0082 \mathrm{~kg} / \mathrm{s}$ ), or text (a floor material of CONCRETE), as appropriate. The input file is a comma-separated ASCII text file and may be edited with a spreadsheet program or any text editor. It is possible to use a word processor but it is important to save the file in ASCII text format and not in a word processing format. It is worthy to note that some word processors will save punctuation and other characters incorrectly for the simple ASCII text file used by CFAST. It is recommended that the input files be created with the input editor, CEdit, provided as part of the CFAST distribution. In addition to checking the input data for errors, it includes recommended limits for input values to assist in appropriate use of the model.

- Each line of input consists of a label followed by one or more alphanumeric parameters associated with that input label, separated by commas. The label must always begin in the first space of the line and be in capital letters. Following the label, the values may start in any column, and all values must be separated by a comma. Values may contain decimal points if needed or desired. They are not required.

- Inputs are in standard SI units. The maximum line length is 1024 characters, so all data for each keyword must fit in this number of characters.

The installation program creates a shortcut to the input editor on the Windows start menu labeled "CFAST" that points to the input editor. Once started, the user is presented with a series of tabbed-pages for the various inputs in a CFAST input data file.

Simulation Environment $\mid$ Compartment Geometry | Horizontal Flow Vents $\mid$ Vertical Flow Vents $\mid$ Mechanical Flow Vents | Fires | Detection / Suppression | Targets | Surface Connections

These tabbed-pages organize the inputs for CFAST simulations into several categories:

- Simulation Environment includes simulation time, specification of model outputs, and ambient conditions. Also included on the page are a constantly updated list of errors, warnings, and messages about the input file specification or model simulation.

- Compartment Geometry defines the size, construction characteristics, and position of the compartments in a simulation.

- Horizontal Flow Vents, Vertical Flow Vents, and Mechanical Flow Vents allows the user to connect compartments with doors and windows, ceiling and floor vents, or forced air ventilation systems.

- Fires include user specification of the initial fire source and any additional burning objects in one or more of the compartments of the simulation.

- Detection / Suppression defines any heat alarms and sprinklers in the compartments of the simulation. 
- Targets provide the ability calculate the temperature and net heat flux to objects placed and oriented arbitrarily in the structure.

- Surface Connections allows for more detailed description of the connections between compartments in the simulation to better simulate the transfer of heat from compartment to compartment in the simulation.

Each of these tabbed-pages is described in more detail below. In addition, a series of menus allow the user to open and save files; run the simulation, or access help and program information.

\section{Simulation Environment}

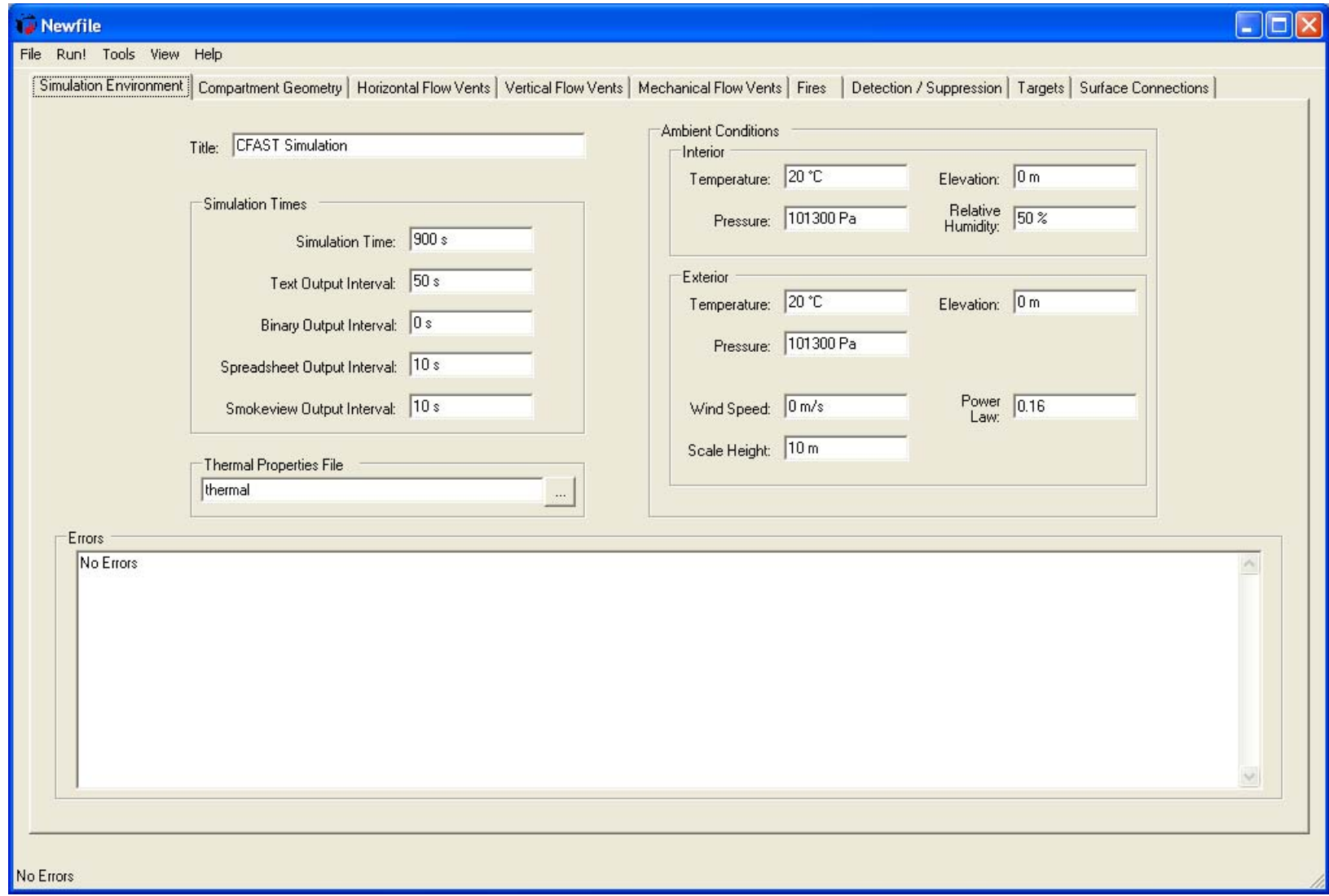

The Simulation Environment page defines the initial conditions and simulation time for the CFAST input file.

\section{Naming the Calculation, the Title Input}

The first thing to do when setting up an input file is to give the simulation a title. The first line in the CFAST input data file must be the CFAST version identification along with an optional short title for the simulation. This is a required input. The title command is the line that CFAST keys on to determine whether it has a correct data file. 
Title: CFAST Simulation

Title: The title is optional and may consist of letters, numbers, and/or symbols and may be up to 50 characters. It permits the user to label each run.

\section{Setting Time Limits and Output Options}

A TIMES line specifies the length of time over which the simulation takes place and how often output will be generated. This is a required input. There are one to four entries in this line

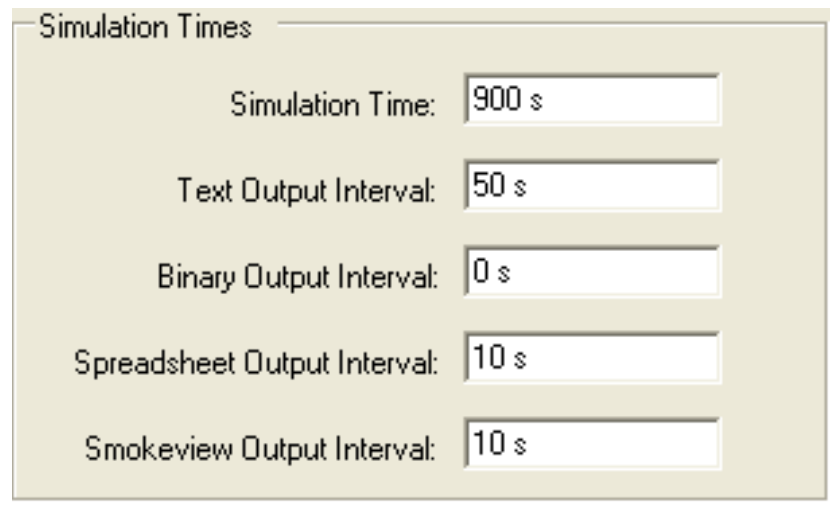

Simulation Time (default units: s, default value, 900 s): The length of time over which the simulation takes place. This is a required input which should be entered even if all other fields are not included. The maximum value for this input is $86400 \mathrm{~s}$ (1 day).

Text Output Interval (default units: s, default value, 50 s): The print interval is the time interval between each printing of the output values. If omitted or less than or equal to zero, no output values will occur.

Binary Output Interval (default units: s, default value: no output): CFAST can store all of the results of the model simulation in a binary-formatted file which can be saved for later analysis or output using utility programs that come with the CFAST software. This input defines the time interval between outputs of the model results in binary format.

Spreadsheet Output Interval (default units: s, default value, $10 \mathrm{~s}$ ): CFAST can output a subset of the results of the model simulation in a comma-delimited alphanumeric format which can be read by most spreadsheet software. This is designed to be imported into a spreadsheet for further analysis or graphing of the results of the simulation. This input defines the time interval between outputs of the model results in a spreadsheet-compatible format. A value greater than zero must be used if the spreadsheet file is to be used. 
Smokeview Output Interval (default units: s, default value: 10 s): CFAST can output a subset of the results in a format compatible with the visualization program smokeview. This input defines the time interval between outputs of the model results in a smokeview-compatible format. A value greater than zero must be used if the spreadsheet output is desired.

In addition to the input data file created specifically for a CFAST simulation, there are a number files that CFAST uses to define default values and other input information, and to output the results of the simulation for later analysis. They include 1) a thermal properties file, 2) files of predefined fire objects, 3) a binary history file, and 4) a spreadsheetcompatible output file.

The thermal properties file contains material properties for compartment surfaces, target objects that may be placed in compartments in the simulation to monitor surface temperature and heat flux to the objects, and fire objects, in addition to the main fire in the simulation that may ignite based on their surface temperature or incident flux onto the surface of the object. The predefined fire objects files contain definitions for a number of reference fires from the literature or developed by the user that may be included in a simulation. The thermal properties and fire objects files may be modified by the user. Details of the files are included in the appendices. There are default files included in the CFAST distribution.

- Thermal Properties File
thermal

Thermal Properties File: The name specifies a file from which the program reads data for names specified in the compartment, target, and object fire specifications. The default name is thermal.csv which is included with the CFAST distribution. The format of this file is detailed in the appendix.

\section{Ambient Conditions}

Ambient conditions define the environment at which the scenario begins. This allows the user to specify the temperature, pressure, and station elevation of the ambient atmosphere, as well as the absolute wind pressure to which the structure is subjected. Pressure interior to a structure is calculated simply as a lapse rate (related to the height above sea level) based on the NOAA/NASA tables ${ }^{8}$. This modification is applied to the vents which connect to the exterior ambient. The calculated pressure change is modified by the wind coefficient for each vent. This coefficient, which can vary from -1.0 to +1.0 , nominally from -0.8 to +0.8 , determines whether the vent is facing away from or into the wind. The pressure change is multiplied by the vent wind coefficient and added to the external ambient for each vent which is connected to the outside. There is an ambient for the interior and for the exterior of the structure. Three keywords define the ambient conditions: TAMB for the interior of the structure, EAMB for the exterior of the structure is EAMB, and WIND for the wind information. 


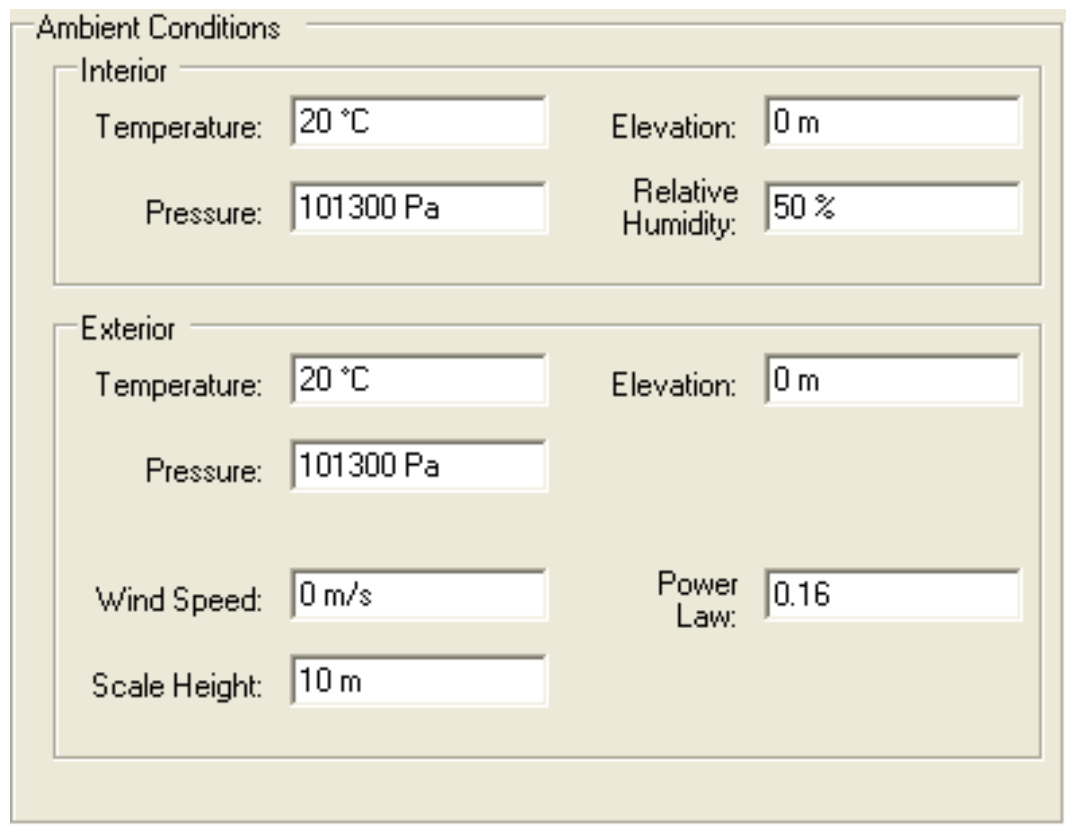

Ambient Temperature (default units: K, default value: $293.15 \mathrm{~K}$ ): Initial ambient temperature inside (for TAMB) or outside (For EAMB) the structure at the station elevation.

Ambient Pressure (default units: Pa, default value: $101300 \mathrm{~Pa}$ ): Initial values for ambient atmospheric pressure inside (for TAMB) and outside (for EAMB) the structure at the station elevation. Default value is standard atmospheric pressure at sea level $(0 \mathrm{~m}$ elevation) of $101.3 \mathrm{kPa}$. Input units are in $\mathrm{Pa}$. These values define standard conditions as defined in Standard Atmosphere as noted in the Handbook of Chemistry and Physics $^{9}$. There is a set of numerical approximations in the CFAST code which duplicate the pressure/temperature/altitude relationships in the handbook.

Elevation (defaults units: $\mathrm{m}$, default value: $0 \mathrm{~m}$ ): The height where the ambient pressure and temperature were specified. This is the reference datum for calculating the density of the atmosphere as well as the temperature and pressure inside and outside of the structure as a function of height.

Relative humidity (default units \% RH, default value: $50 \%$ ): The initial relative humidity in the system, only specified for the interior with the TAMB command. This is converted to kilograms of water per cubic meter.

The wind speed, scale height, and power law are used to calculate the wind coefficient for each vent connected to the outside. The wind velocity is specified at some reference height. The power law then provides a lapse rate for the wind speed. An assumption is that the wind speed is zero at the surface. The formula used to calculate the wind speed at the height of any vent is show below. The wind is applied to each external opening as a change in pressure outside of the vent.

Wind Speed (default units: m/s, default value $0 \mathrm{~m} / \mathrm{s}$ ): Wind speed at the reference elevation. 
Scale Height: (default units: $\mathrm{m}$, default value: $0 \mathrm{~m}$ )): Reference height at which the reference wind speed is measured.

Power Law Coefficient (default units: dimensionless, default value 0.16): The power law used to calculate the wind speed as a function of height. Default value is 0.16. Using the notation that $\mathrm{V}_{\mathrm{W}}$, is the wind speed at the reference height $\mathrm{H}_{\mathrm{w}}$, and $\mathrm{P}_{\mathrm{W}}$ is the power law, the exterior pressure is modified by $\delta P=C_{W} \rho V^{2}$ and $V=V_{W}\left(H_{i} / H_{W}\right)^{P_{W}}$ where $\mathrm{H}_{\mathrm{i}}$ is the position of the vent ${ }^{1}$.

- In order to see the effect of wind, the corresponding parameter for the ventilation keyword must be specified. The default for the wind vector is 0 , which turns off wind effects. Please see the HVENT command, below.

- The choice for station elevation, temperature and pressure must be consistent. Outside of that limitation, the choice is arbitrary. It is often convenient to choose the base of a structure to be at zero height and then reference the height of the structure with respect to that height. The temperature and pressure must then be measured at that position. Another possible choice would be the pressure and temperature at sea level, with the structure elevations then given with respect to mean sea level. This is also acceptable, but somewhat more tedious in specifying the construction of a structure. Either of these choices works though, so long as they are consistent. Usually, the station elevation is set to zero and the pressure to ambient. The effect of changing these values is small for small changes. There will be an effect for places at altitude such as Denver, Colorado, but even there the effect is not pronounced. Note that the equations implemented in the model are not designed to handle negative elevations and altitudes. It is suggested that the defaults be used.

- These three parameters are optional. If they are not included in the input file, default values are used.

\section{Compartment Geometry}


Simulation Environment Compartment Geometry | Horizontal Flow Vents / Vertical Flow Vents $\mid$ Mechanical Flow Vents $\mid$ Fires | Detection/Suppression | Targets | Surface Connections

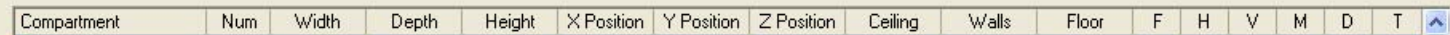
Compartment 1 \begin{tabular}{l|l|l|l|l|l|l|l|l|} 
Num Width & Depth & Height & XPosition & YPosition & ZPosition & Celing \\
\hline
\end{tabular} \begin{tabular}{l|l|l|l|l|l|l|l|l|} 
Walls & Floor & F & H & V & M & D & T & $\wedge$ \\
\hline
\end{tabular} Compa

1
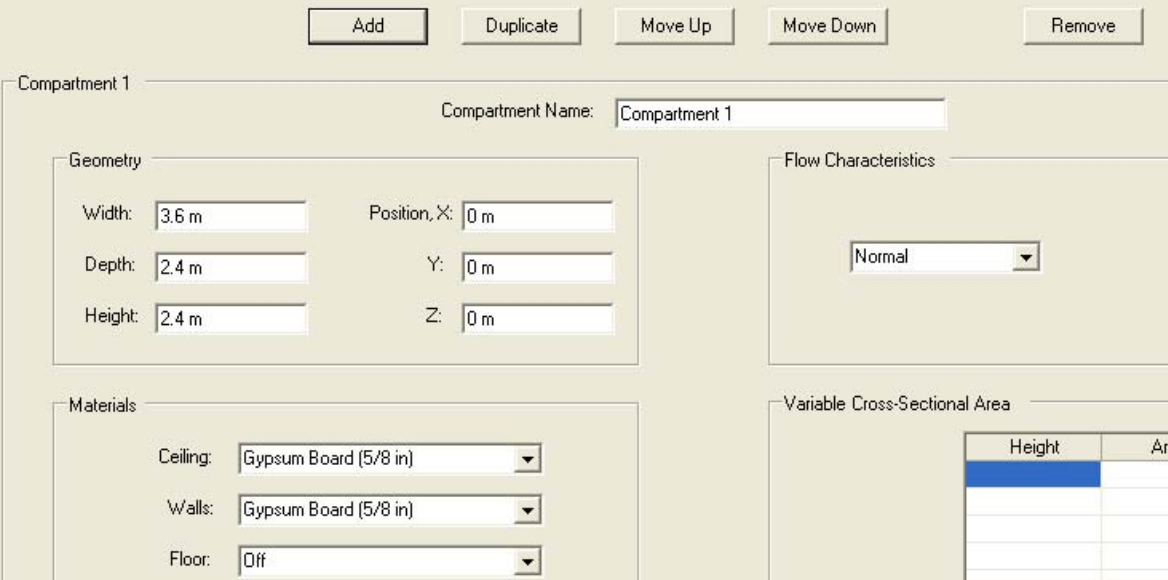

Flow Characteristics

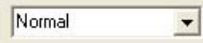

Variable Cross-Sectional Area

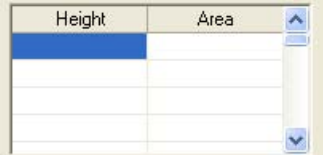

No Errors

The Compartment Geometry page defines the size, position, materials of construction, and flow characteristics for the compartments in the simulation. Initially, only the simulation environment page and the "Add" button on the compartment geometry page is enabled; all other pages are not available to the user for detailed inputs until a compartment has been added to the simulation.

Most of the tabbed pages in the program are of similar design, with a summary of the defined items in table form at the top of the page, a series of buttons to add, remove, or modify the item highlighted in the summary table, and a number of individual inputs below which details all of the inputs for the item selected in the summary table. The buttons included on the compartment geometry page are as follows:

Add Use the Add button to create a new compartment with default values for all entries.

Duplicate Use the Duplicate button to create a copy of the compartment currently selected in the summary table at the top of the page. The new compartment is added to the end of the list with the named changed to indicate it is a copy of the selected item.

Move Up $\quad$ Move Down $U$ Use the Move Up and Move Down buttons to change the order of the list of compartments in the summary table. This simply changes the automatically assigned compartment numbers for the compartments. Compartments can be ordered as desired. 

compartments in the summary table. Other compartments are renumbered once the compartment is deleted.

Compartment Name: Compartments are identified by a unique alphanumeric name. This may be a simple as a single character or number, or a description of the compartment.

\section{Defining Compartment Size and Position}

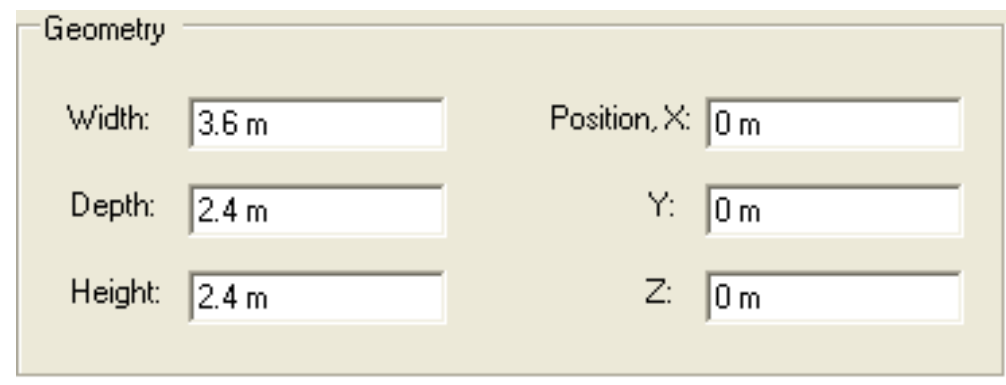

In order to model a fire scenario, the size and elevation of each compartment in the structure must be specified. For a compartment, the width, depth, compartment height and height of the floor of the compartment provide this specification. The maximum number of compartments for version 6 is thirty. The usual assumption is that compartments are rectangular parallelepipeds. However, the CFAST model can accommodate odd shapes as equivalent floor area parallelepipeds or with a cross-sectional area that varies with height.

At least one compartment must be specified in the input file. There are no defaults for compartment size. There are defaults for absolute positioning $(0,0,0)$. The fully mixed (single zone) and corridor models are turned off by default.

Compartments in CFAST are most typically defined by a width, depth, and height. If desired, the user can prescribe the cross-sectional area of the compartment as a function of height from floor to ceiling for other shapes. The absolute position of the compartment with respect to a single structure reference point can be defined to ease visualization or to allow exact placement of vents and surfaces relative to other compartments in a detailed calculation. This specification is important for utilizing the corridor flow algorithm

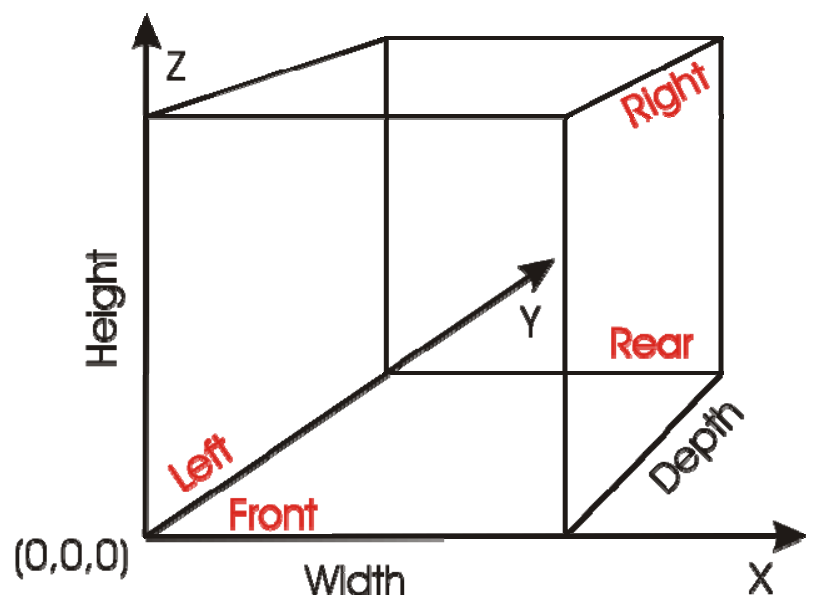
with the HALL command and for positioning the compartments for visualization in SMOKEVIEW.

The relevant CFAST keywords are COMPA to define the compartment size and materials, HALL or ONEZ to define flow characteristics in the compartment, and ROOMA / ROOMH 
to define a variable cross-sectional area for the compartment. The COMPA command is required for each compartment as a basic definition for the compartment, even if there are subsequent modifications by the HALL, ONEZ, ROOMA, or ROOMH keywords which follow. Details of the CFAST keywords are included in the appendix.

Width: specifies the width of the compartment as measured on the $\mathrm{X}$ axis from the origin $(0,0,0)$ of the compartment.

Depth: specifies the depth of the compartment as measured on the $\mathrm{Y}$ axis from the origin $(0,0,0)$ of the compartment.

Height: specifies the height of the compartment as measured on the $\mathrm{Z}$ axis from the origin $(0,0,0)$ of the compartment.

Absolute Width Position: specifies the absolute $x$ coordinate of the lower, left, front corner of the room.

Absolute Depth Position: specifies the absolute y coordinate of the lower, left, front corner of the room.

Absolute Floor Height: specifies the height of the floor of each compartment with respect to station elevation specified by the internal ambient conditions reference height parameter. The reference point

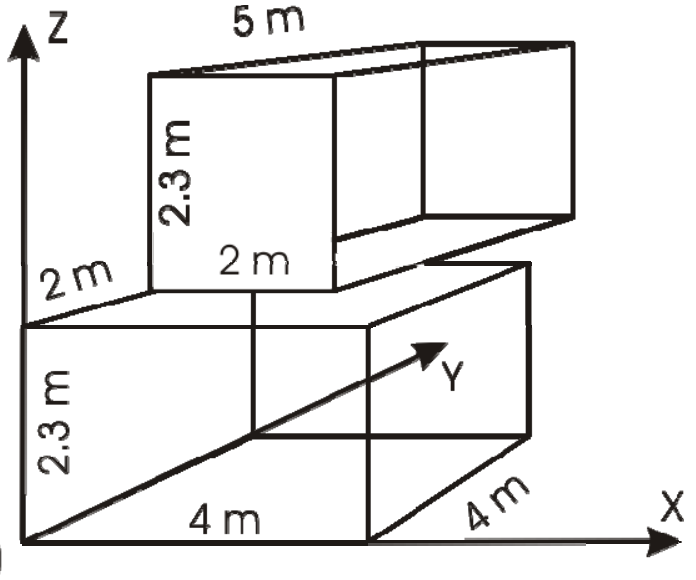
must be the same for all elevations in the input data. For example, the two rooms in the example would be located at $(0,0,0)$ and $(0,2,2 \cdot 3)$.

\section{Modeling the Compartment as a Tall Shaft or Long Corridor}

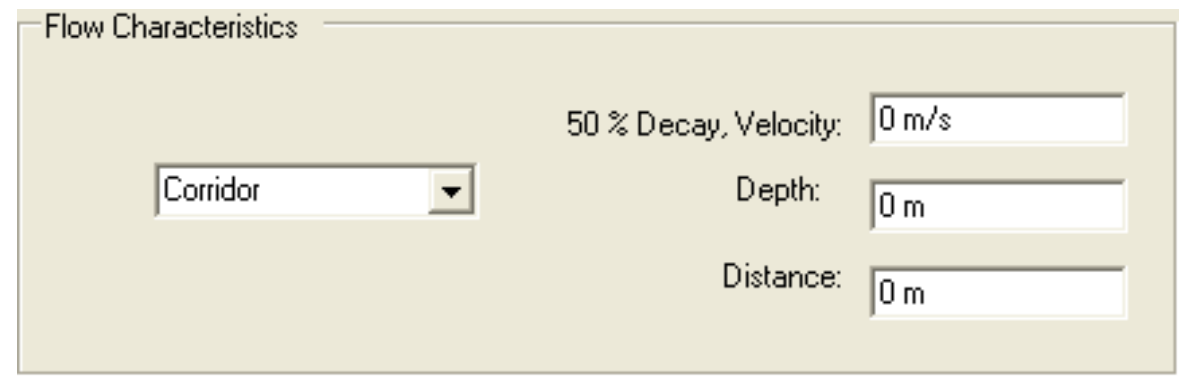

For tall compartments or those removed from the room of fire origin, the compartment may be modeled as a single, well-mixed zone rather than the default two-zone assumption. A single zone approximation is appropriate for smoke flow far from a fire source, where the two-zone layer stratification is less pronounced than in compartments near the fire. This is used in situations where the stratification does not occur. Examples are elevators, shafts, complex stairwells, and compartments far from the fire. 
For long hallways or corridors, there can be a significant delay time for the initial hot gas layer to travel along the ceiling to the far end of the compartment. By estimating the time required for a ceiling jet to travel in a corridor and the temperature distribution along the corridor, CFAST can delay flow into compartments connected to corridors until the ceiling jet has passed the connections to these compartments.

50 \% Decay Velocity: ceiling jet velocity at the distance from the reference point where the temperature falls off by $50 \%$. Default velocity and depth are calculated by the program based on the vent size, flow and layer thickness in the horizontal vent from which flow first enters the hallway, and on the width of the hallway ${ }^{1}$.

50 \% Decay Depth: ceiling jet depth at the distance from the reference point where the temperature falls off by $50 \%$.

$50 \%$ Decay Distance: distance from the reference point where the temperature falls off by $50 \%$.

- Since the algorithm depends on the flow into the hallway to determine default ceiling jet velocity and depth, the main fire compartment should not be specified as a hallway. In the main fire compartment, a stable layer will build before flow into the compartment through horizontal vents.

- The zone model concept best applies for an enclosure in which the width and length are not too different. If the horizontal dimensions of the room differ too much (i.e., the room looks like a corridor), the flow pattern in the room may become asymmetrical. If the enclosure is too shallow, the temperature may have significant radial differences. The width of the plume may at some height become equal to the width of the room and the model assumptions may fail in a tall and narrow enclosure. Therefore, the user should recognize approximate limits on the ratio of the length $(\mathrm{L})$, width $(\mathrm{W})$, and height $(\mathrm{H})$ of the compartment.

- If the aspect ratio (length/width) is greater than about 10 , the corridor flow algorithm should be used. This provides the appropriate filling time. Similarly, for tall shafts (elevators and stairways), a single zone approximation is more appropriate and the shaft option should be used. It was found experimentally that the mixing between a plume and lower layer due to the interaction with the walls of the shaft caused complete mixing. This is the flip side of the corridor problem and occurs at a ratio of the height to characteristic floor length of about 10 . The following quantitative limits are recommended:

\begin{tabular}{||c|c|c|c||}
\hline Group & Acceptable & $\begin{array}{c}\text { Special } \\
\text { consideration } \\
\text { required }\end{array}$ & $\begin{array}{c}\text { Corridor flow } \\
\text { or shaft } \\
\text { algorithm }\end{array}$ \\
\hline \hline$(\mathrm{L} / \mathrm{W})_{\max }$ & $\mathrm{L} / \mathrm{W}<3$ & $3<\mathrm{L} / \mathrm{W}<5$ & $\mathrm{~L} / \mathrm{W}>5$ \\
\hline$(\mathrm{L} / \mathrm{H})_{\max }$ & $\mathrm{L} / \mathrm{H}<3$ & $3<\mathrm{L} / \mathrm{H}<6$ & $\mathrm{~L} / \mathrm{H}>6$ \\
\hline$(\mathrm{W} / \mathrm{H})_{\min }$ & $\mathrm{W} / \mathrm{H}>0.4$ & $0.2<\mathrm{W} / \mathrm{H}<0.4$ & $\mathrm{~W} / \mathrm{H}<0.2$ \\
\hline
\end{tabular}




\section{Thermal Properties of Boundaries}

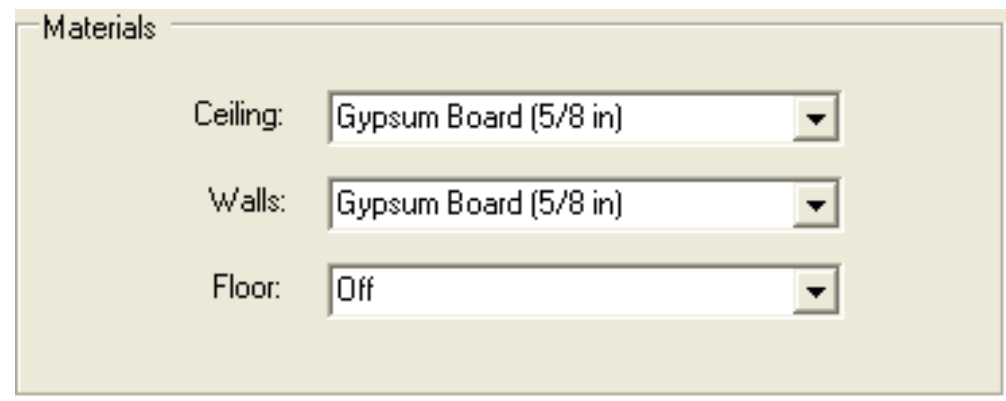

To calculate heat loss through the ceiling, walls, and floor of a compartment, the properties of the bounding surfaces must be known. This includes the thermophysical properties of the surfaces and the arrangement of adjacent compartments if calculation of intercompartment heat transfer is to be calculated.

The thermophysical properties of the surfaces which define compartments are described by specifying the thermal conductivity, specific heat, emissivity, density, and thickness of the enclosing surfaces for each material and then assigning the material to the ceiling, walls, and floor of a compartment. Currently, thermal properties for materials are read from a thermal data file unique to CFAST. The thermophysical properties are specified at one condition of temperature, humidity, etc. There can be as many as three layers per boundary, but they are specified in the thermal database itself. (See the explanation in the section on auxiliary files for additional details.)

The default name for the thermal properties database is thermal.csv. Another name can be used using the keyword THRMF in the input data file for the scenario of interest. This thermal data file is also used for targets and other objects

The bounding surfaces are the ceilings, walls and floors that define a compartment. These are referred to as thermophysical boundaries, since each participates in conduction and radiation as well as defining the compartments, unless these phenomena are explicitly turned off.

Ceiling Material (default value: Gypsum Board): material name from the thermal properties data file used for the ceiling surface of the compartment.

Wall Material (default value: Gypsum Board): material name from the thermal properties data file used for the wall surfaces of the compartment.

Floor Material (default value: Off): material name from the thermal properties data file used for the floor surface of the compartment.

- If the thermophysical properties of the enclosing surfaces are not included, CFAST will treat them as adiabatic (no heat transfer).

- If a name is used which is not in the database, the model should stop with an error message. The keyword in the data file simply gives a name (such as CONCRETE) 
which refers to the properties for that material in the thermal data file (see section 4.2.3 and Appendix A for details on the thermophysical database).

- Since most of the heat conduction is through the ceiling, and since the conduction calculation takes a significant fraction of the computation time, it is recommended that initial calculations be made using the ceiling only. Adding the walls generally has a small effect on the results, and the floor contribution is usually negligible. Clearly, there are cases where the above generalization does not hold, but it may prove to be a useful screening technique. A caveat in including floor properties is that the set of equations describing heat transfer becomes difficult to solve once the thermal wave from the compartments reaches the unexposed side of a floor. The back surfaces of compartments are assumed to be exposed to ambient conditions unless specifically specified (see the section on Intercompartment Heat Transfer (Conduction)) to specify heat transfer connections between compartments).

\section{Compartment Connections}

Flow through vents can be natural flow through doors, windows, or openings in ceilings and floors; or forced flow in a mechanical ventilation system. Natural flow comes in two varieties. The first is referred to as horizontal flow. It is the flow which is normally thought of in discussing fires. It encompasses flow through doors, windows and so on. The other is vertical flow and can occur if there is a hole in the ceiling or floor of a compartment. This latter phenomena is useful in some scenarios such as in a ship where openings in floors and ceilings through scuttles are common and in buildings with manual or automatic heat and smoke venting.

Flow through normal vents is governed by the pressure difference across a vent. There are two situations which give rise to flow through vents. The first is flow of air or smoke driven from a compartment by buoyancy. The second type of flow is due to expansion which is particularly important when conditions in the fire environment are changing rapidly. Rather than depending entirely on density differences between the two gases, the flow is forced by volumetric expansion.

In addition to natural flow, forced flow from mechanical ventilation can affect a fire as well. More important than affecting the fire, however, is the dispersal of the smoke and toxic gases from the fire to adjacent spaces, if ventilation continues to operate after a fire starts.

Atmospheric pressure is about $100000 \mathrm{~Pa}$. Fires produce pressure changes from $1 \mathrm{~Pa}$ to 1000 $\mathrm{Pa}$ and mechanical ventilation systems typically involve pressure differentials of about $1 \mathrm{~Pa}$ to $100 \mathrm{~Pa}$. In order to address pressure-induced flow, pressure differences of about $0.1 \mathrm{~Pa}$ out of $100000 \mathrm{~Pa}$ for the overall problem or $10^{-4} \mathrm{~Pa}$ for adjacent compartments must be tracked.

The keywords which describe the various flow regimes are:

- Windows and doors (horizontal flow through vertical vents): HVENT, specifies vent which connect compartments horizontally 
- Holes in a ceiling/floor (vertical flow through horizontal vents: VVENT, specifies a vent which connects compartments vertically

- HVAC specification: MVENT specifies a vent which connects compartments with a forced flow

For all three types of vents the size of the vent opening (expressed as a fraction of the original opening) may be changed:

- EVENT change the opening fraction of the specified vent at a chosen time.

Each of these commands is discussed in the sections that follow.

\section{Defining Horizontal Natural Flow Connections (Doors, Windows)}

Horizontal flow connections may include doors between compartments or to the outdoors as well as windows in the compartments. These specifications do not necessarily correspond to physically connecting the walls between specified compartments. Rather, lack of an opening simply prevents flow between the compartments. Horizontal flow connections may also be used to account for leakage between compartments or to the outdoors.

Horizontal connections can only be created between compartments that physically overlap in elevation at some point. These may include doors between compartments or windows in the compartments (between compartments or to the outdoors). Openings to the outside are included as openings to a compartment with a number one greater than the number of compartments described in the geometry section. The relevant CFAST keyword is HVENT. Details of the CFAST keywords are included in the appendix. 
Simulation Environment | Compartment Geometry Horizontal Flow Vents Vertical Flow Vents | Mechanical Flow Vents | Fires | Detection/Suppression | Targets | Surface Connections |
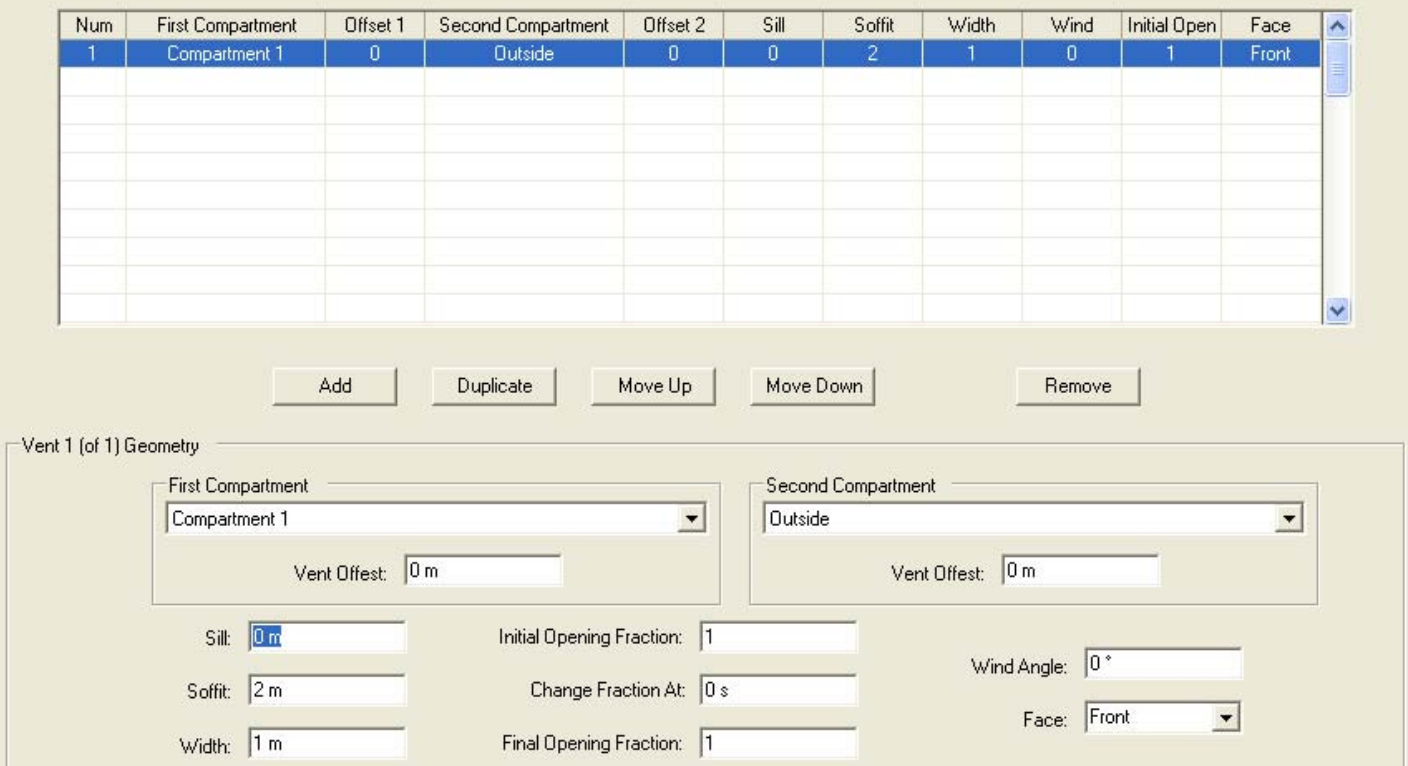

Most of the tabbed pages in the program are of similar design, with a summary of the defined items in table form at the top of the page, a series of buttons to add, remove, or modify the item highlighted in the summary table, and a number of individual inputs below which details all of the inputs for the item selected in the summary table. The buttons included on the horizontal flow vents page are as follows.

Add Use the Add button to create a new horizontal flow vent with default values for all entries.

Duplicate Use the Duplicate button to create a copy of the horizontal flow vent currently selected in the summary table at the top of the page. The new vent is added to the end of the list with the named changed to indicate it is a copy of the selected item.

Move Up $\quad$ Move Down $U$ Use the Move Up and Move Down buttons to change the order of the list of horizontal flow vents in the summary table. This simply changes the automatically assigned vent numbers for the vents. Vents can be ordered as desired.

Remove

Use the Remove button to delete the selected horizontal flow vent from the list of horizontal flow vents in the summary table. Other vents are renumbered once the compartment is deleted. 
First Compartment: First of the two compartments to be connected by a horizontal flow vent. Compartments are numbered automatically by the input editor and by the model in the order they are read from the input data file and/or the order they appear in the summary table on the compartment geometry page. Compartment numbers begin with 1 , so the first compartment is number 1 , the second 2 , and so forth.

Second Compartment: Second of the two compartments to be connected by a horizontal flow vent. Compartments are numbered automatically by the input editor and by the model in the order they are read from the input data file and/or the order they appear in the summary table on the compartment geometry page. Compartment numbers begin with 1 , so the first compartment is number 1 , the second 2 , and so forth.

Vent Number: It is possible to define a total of 25 horizontal flow connections between any pair of compartments. A number from 1 to 25 uniquely identifies the connection. Normally, this number is automatically assigned by the input editor based on the order they appear in the summary table on the horizontal flow vents page.

Sill (default units: m, default value: none): Sill height is the height of the bottom of the opening relative to the floor of the compartment selected as the first compartment.

Soffit (default units: $\mathrm{m}$, default value: none): Position of the top of the opening relative to the floor of the compartment selected as the first compartment.

Width (default units: m, default value: none): The width of the opening.

Horizontal flow vents may be opened or closed during the fire. The relevant CFAST keyword is EVENT. The initial format of EVENT is similar to HVENT specifying the connecting compartments and vent number. Each EVENT line in the input file details the open/close time dependent characteristics for one horizontal flow vent by specifying a fractional value and a time. The default is 1.0 which is a fully open vent. A value of 0.5 would specify a vent which is halfway open.

Initial Opening Fraction: Flow through horizontal vents is calculated based on the area of the vent. Normally, the vent is fully open. If desired, the user may specify a fraction between 0 and 1 that allows the vent to be partially or fully closed at the beginning of the simulation. In the model calculation, the vent width is multiplied by this fraction. The opening fraction may be changed at any time in the simulation through the use of the EVENT command.

Change Opening Fraction At Time: Time during the simulation at which to change the opening fraction.

Final Opening Fraction: for horizontal flow vents, the fraction specifies the fractional width opening of the vent. Fractional values must be between 0 and 1.

Wind: The wind coefficient is the cosine of the angle between the wind vector and the vent opening. This applies only to vents which connect to the outside. The range of values is -1.0 to 1.0 with a default value of zero. In the input editor, this is specified as the angle between the face of the vent and the wind direction. 
There are also two parameters which are used to locate the compartments relative to each other. These are used to incorporate additional three dimensional information of the relative location of the vents with respect to each other. In the compartment view of CFAST, the orientation is that the rotation/translation point of the compartment is the back/bottom/left. In this view, both parameters would be with respect to the left hand side of the respective compartments. This allows the corridor filling model to incorporate a delay time for filling based on the separation between the vents. These parameters are needed only if the HALL command is used.

First Compartment Offset: Horizontal distance between the centerline of this vent and the reference point in the first compartment.

Second Compartment Offset: Horizontal distance between the centerline of this vent and the reference point in the second compartment.

- The soffit and sill specifications are with respect to the first compartment specified and is not necessarily symmetric since the elevation of the second compartment may be different than the first. Reversing the order of the compartment designations does make a difference.

\section{Defining Vertical Natural Flow Connections (Ceiling or Floor Holes, Hatches)}

This section of the input data file describes these vertical flow openings. Examples of these openings are scuddles in a ship, or a hole in the roof of a residence. Combined buoyancy- and pressure-driven (i.e., forced) flow through a vertical flow vent is possible when the connected spaces adjacent to the vent are filled with gases of different density in an unstable configuration, with the density of the top space larger than that of the bottom space. With a moderate cross-vent pressure difference, the instability leads to a bi-directional flow between the two spaces. For relatively large cross-vent pressure difference the flow through the vent is unidirectional, from the high- to the low-pressure space.

Connections can exist between compartments or between a compartment and the outdoors. Openings to the outside are included as openings to a compartment with a number one greater than the number of compartments defined in the scenario. These connections are described by the VVENT keyword. Each VVENT line in the input file describes one vertical vent. There are four parameters which include each of the connected compartments, the shape of the opening, and the effective area of the vent. 
Simulation Environment | Compartment Geometry | Horizontal Flow Vents Vertical Flow Vents | Mechanical Flow Vents $\mid$ Fires | Detection/Suppression| Targets | Surface Connections
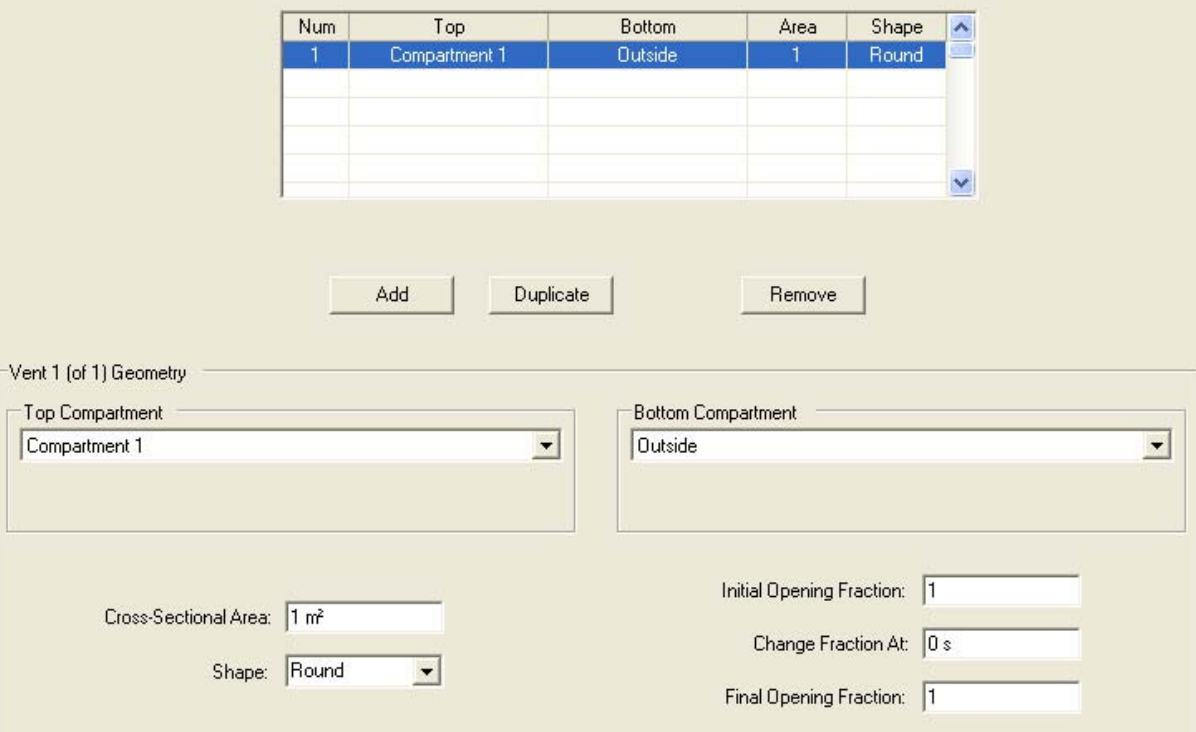

Most of the tabbed pages in the program are of similar design, with a summary of the defined items in table form at the top of the page, a series of buttons to add, remove, or modify the item highlighted in the summary table, and a number of individual inputs below which details all of the inputs for the item selected in the summary table. The buttons included on the vertical flow vents page are as follows.

Add $\quad$ Use the Add button to create a new vertical flow vent with default values for all entries.

Duplicate Use the Duplicate button to create a copy of the vertical flow vent currently selected in the summary table at the top of the page. The new vent is added to the end of the list with the named changed to indicate it is a copy of the selected item.

Remove Use the Remove button to delete the selected vertical flow vent from the list of vertical flow vents in the summary table. Other vents are renumbered once the compartment is deleted.

Top Compartment: The top or first of the two compartments to be connected by a vertical flow vent. The vent is through the floor of this compartment. Compartments are numbered automatically by the input editor and by the model in the order that they 
are read from the input data file and/or the order they appear in the summary table on the compartment geometry page. Compartment numbers begin with 1 , so the first compartment is number 1 , the second 2 , and so forth.

Bottom Compartment: The bottom or second of the two compartments to be connected by a horizontal flow vent. The vent is through the ceiling of this compartment. Compartments are numbered automatically by the input editor and by the model in the order they are read from the input data file and/or the order they appear in the summary table on the compartment geometry page. Compartment numbers begin with 1 , so the first compartment is number 1 , the second 2 , and so forth.

Cross-sectional Area (default units: $\mathrm{m}^{2}$, default value: none): specifies the cross-sectional area of the vent connecting the two compartments.

Shape: The shape factor is 1 for circular openings and 2 for square openings.

Initial Opening Fraction: Flow through vertical vents is calculated based on the area of the vent. Normally, the vent is fully open. If desired, the user may specify a fraction between 0 and 1 that allows the vent to be partially or fully closed at the beginning of the simulation. In the model calculation, the vent area is multiplied by this fraction. The opening fraction may be changed at any time in the simulation through the use of the EVENT command.

Change Opening Fraction At Time (default units: s, default value: none): Time during the simulation at which to change the opening fraction.

Final Opening Fraction: for vertical flow vents, the fraction specifies the fractional crosssectional area of the vent. Fractional values must be between 0 and 1.

- Although obvious, note that the top or first compartment must be the compartment on top of the bottom or second compartment.

- Vertical connections can only be created between compartments that could be physically stacked based on specified floor and ceiling elevations for the compartments. Some overlap between the absolute floor height of one compartment and the absolute ceiling height of another compartment is allowed. However, whether the compartments are stacked or overlap somewhat, the ceiling/floor absolute elevations must be within $0.01 \mathrm{~m}$ of each other. The check is not done when the connection is to the outside.

\section{Defining Mechanical Ventilation Connections}

Fan-duct systems are commonly used in buildings for heating, ventilation, air conditioning, pressurization, and exhaust. Generally, systems that maintain comfortable conditions have either one or two fans. Residences often have a systems with a single fan. Further information about these systems is presented in Klote and Milke ${ }^{10}$ and the American Society of Heating, Refrigerating and Air Conditioning Engineers ${ }^{11}$. 
The model for mechanical ventilation used in CFAST is based on the theory of networks and is based on the model developed by Klote ${ }^{12}$ This is a simplified form of Kirchoff's law which says that flow into a node must be balanced by flow out of the node. The equations used describe the relationship between the pressure drop across a duct, the resistance of a duct, and the mass flow. The pressure can be changed by conditions in a compartment, or a fan in line in the duct system. Resistance arises from the finite size of ducts, roughness on duct surfaces, bends and joints. In CFAST, default values are used for the duct properties, and thus mechanical ventilation connections are simply described by the connections to the two compartments and a fan whose throughput is a constant volumetric flow up to a userspecified pressure drop across the fan, dropping to zero at high backwards pressure on the fan.

Simulation Environment | Compartment Geometry | Horizontal Flow Vents | Vertical Flow Vents Mechanical Flow Vents | Fires | Detection/Suppression | Targets | Surface Connections
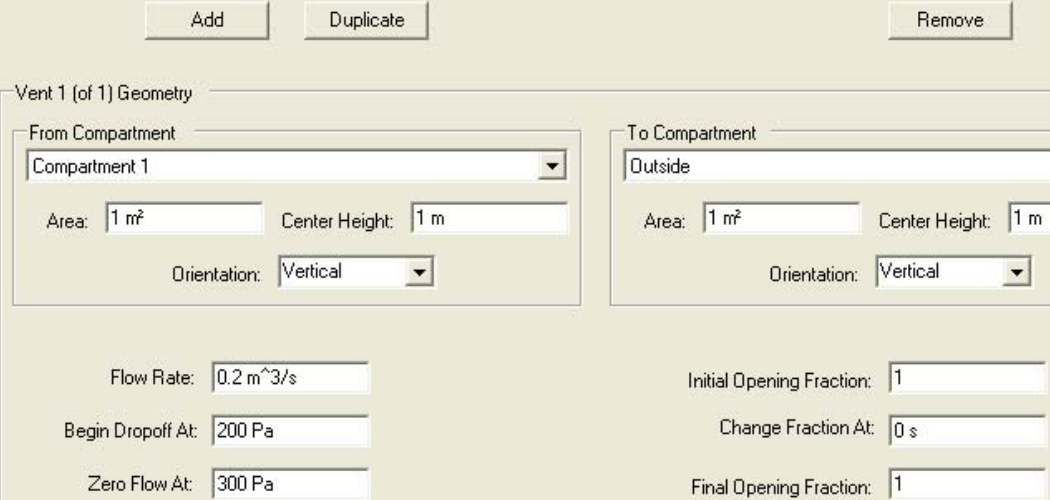

No Errors

Most of the tabbed pages in the program are of similar design, with a summary of the defined items in table form at the top of the page, a series of buttons to add, remove, or modify the item highlighted in the summary table, and a number of individual inputs below which details all of the inputs for the item selected in the summary table. The buttons included on the mechanical flow vents page are as follows.

Add Use the Add button to create a new mechanical flow vent with default values for all entries. 
Duplicate Use the Duplicate button to create a copy of the mechanical flow vent currently selected in the summary table at the top of the page. The new vent is added to the end of the list with the named changed to indicate it is a copy of the selected item.

Remove Use the Remove button to delete the selected mechanical flow vent from the list of mechanical flow vents in the summary table. Other vents are renumbered once the compartment is deleted.

From Compartment: The first compartment to which the mechanical ventilation system diffuser is connected. Fan flow is from this compartment. Compartments are numbered automatically by the input editor and by the model in the order they are read from the input data file and/or the order they appear in the summary table on the compartment geometry page. Compartment numbers begin with 1 , so the first compartment is number 1 , the second 2 , and so forth.

From Compartment Area (default units: $\mathrm{m}^{2}$, default value: none): Cross-sectional area of the opening into the compartment. The area will be truncated if the midpoint (height) is set such that the height plus or minus the effective length is above the compartment ceiling or below the floor.

From Compartment Height (default units: m, default value: none): Height of the duct opening above the floor of the compartment measured from the midpoint of the register.

From Compartment Orientation: The orientation of the diffuser relative to the floor of the compartment. A horizontal diffuser implies vertical flow through the ceiling or floor of the compartment. A vertical diffuser implies horizontal flow through a wall of the compartment.

To Compartment: The bottom or second of the two compartments to be connected by a horizontal flow vent. The vent is through the ceiling of this compartment. Compartments are numbered automatically by the input editor and by the model in the order they are read from the input data file and/or the order they appear in the summary table on the compartment geometry page. Compartment numbers begin with 1 , so the first compartment is number 1, the second 2, and so forth.

To Compartment Area (default units: $\mathrm{m}^{2}$, default value: none): Cross-sectional area of the opening into the compartment. The area will be truncated if the midpoint (height) is set such that the height plus or minus the effective length is above the compartment ceiling or below the floor.

To Compartment Height (default units: m, default value: none): Height of the duct opening above the floor of the compartment measured from the midpoint of the register.

To Compartment Orientation: The orientation of the diffuser relative to the floor of the compartment. A horizontal diffuser implies vertical flow through the ceiling or floor of the compartment. A vertical diffuser implies horizontal flow through a wall of the compartment. 
Flow Rate (default units: $\mathrm{m}^{3} / \mathrm{s}$, default value: none): Constant flow rate of the forced-air flow from the first compartment to the second compartment.

Begin Drop Off Pressure (default units: Pa, default value: $200 \mathrm{~Pa}$ ): The description of the fan includes a drop off in flow beginning at a pressure specified by the user. Above this pressure drop, the flow gradually drops to zero flow.

Zero Flow Pressure (default units: Pa, default value: $300 \mathrm{~Pa}$ ): Specifies the pressure above which the flow through the mechanical ventilation connection is zero.

Initial Opening Fraction: Flow through mechanical vents is calculated based on the area of the vent. Normally, the vent is fully open. If desired, the user may specify a fraction between 0 and 1 that allows the vent to be partially or fully closed at the beginning of the simulation. In the model calculation, the fan flow rate is multiplied by this fraction. The opening fraction may be changed at any time in the simulation through the use of the EVENT command.

Change Opening Fraction At Time (default units: s, default value: none): Time during the simulation at which to change the opening fraction.

Final Opening Fraction: for mechanical flow vents, the fraction specifies the fractional fan flow rate for the vent. Fractional values must be between 0 and 1.

- CFAST does not include provisions for reverse flow through a fan. Calibrations for backward flow are not provided by fan manufacturers and the equations incorporated in CFAST do not allow for such flow. The problem is simply that in this flow regime, the fan has stalled, and will soon fail.

\section{Prescribing Fires}

A simulated fire in CFAST is implemented as a source of fuel mass which is released at a prescribed rate (the pyrolysis rate). Energy is released by the fuel and combustion products are created as it burns. The model incorporates two distinct types of fires: heat source and constrained. In the heat source specification, the fire simply energy at a rate prescribed by the user; no calculation or tracking of products of combustion is included. In the constrained fire, species production is calculated based on production yields prescribed by the user. In addition, for the constrained fire, the pyrolysis rate and resulting energy and species generation may be limited by the oxygen available for combustion. When sufficient oxygen is available for combustion, the heat release rate for the constrained fire is the same as for the unconstrained fire.

The model can simulate multiple fires in one or more compartments of the building. These fires are treated as totally separate entities, with no interaction of the plumes. These fires are generally referred to as "objects" and can be ignited at a prescribed time, temperature or heat flux.

CFAST does not include a pyrolysis model to predict fire growth. Rather, pyrolysis rates for each fire are prescribed by the user. While this approach does not directly account for 
increased pyrolysis due to radiative feedback from the flame or compartment, in theory these effects could be prescribed by the user as described in this section. In an actual fire, this is an important consideration, and the specification used should consider the experimental conditions as closely as possible.

\section{Unconstrained Fire}

An unconstrained fire releases energy based on the pyrolysis rate of the fuel. This type of fire is applicable to fuels for which there is always sufficient oxygen in the fuel for combustion to take place and when the concentrations of products of combustion are not of interest.

\section{Constrained Fire}

A constrained fire releases energy based on the pyrolysis of fuel, but may be constrained by the oxygen available for combustion depending on the compartment conditions. Complete burning will take place only where there is sufficient oxygen. When insufficient oxygen is entrained into the fire plume, unburned fuel will be transported from zone to zone until there is sufficient oxygen and a high enough temperature to support combustion. In general, CFAST uses a simple definition of a combustion reaction that includes major products of combustion for hydrocarbon fuels:

$$
\begin{aligned}
& \mathrm{C}_{n} \mathrm{H}_{o} \mathrm{O}_{p} \mathrm{~N}_{q} \mathrm{Cl}_{r}+m_{1}\left(\mathrm{O}_{2}+3.76 \mathrm{~N}_{2}\right) \rightarrow m_{2} \mathrm{CO}_{2}+m_{3} \mathrm{CO}+m_{4} \mathrm{H}_{2} \mathrm{O}+m_{5} \mathrm{HCl} \\
& +m_{6} \mathrm{HCN}+3.76 m_{1} \mathrm{~N}_{2}+\text { soot }+(\text { total unburned hydrocarbo } n s)+\text { heat }
\end{aligned}
$$

where the coefficients $m_{1}, m_{2}$, etc. represent appropriate molar ratios for a stoichiometric balance of the equation. For complete combustion of the simplest hydrocarbon fuel, methane reacts with oxygen to form carbon dioxide and water. The only input required is the pyrolysis rate and the heat of combustion. For fuels that contain oxygen, nitrogen, or chlorine, the reaction becomes more complex. In this case, production yields for the species are prescribed by the user. Stoichiometry is used to insure conservation of mass and elements in the reaction. The species which are calculated are oxygen, carbon dioxide, carbon monoxide, water, total unburned hydrocarbons (tuhc), and soot. Gaseous nitrogen is included, but only acts as a diluent. Production of hydrogen cyanide and hydrogen chloride are tracked solely based on user prescribed yields.

The heat release rate for a constrained fire may be reduced below its prescribed value based upon the oxygen available for combustion. For the constrained fire, the burning rate may be less than the pyrolysis rate and cannot be simplified as in the case of the unconstrained fire. As fuel and oxygen are consumed, heat is released and various products of combustion are formed.

\section{Constraint on the Fire by Limiting Combustion by Available Oxygen (LOI)}

For a constrained fire, the heat release rate is limited by available oxygen. This limit is applied in three places: The first is burning in the portion of the plume which is in the lower layer of the room of fire origin; the second is the portion of the plume in the upper layer, also in the room of origin; the third is in the vent flow which entrains air from a lower layer into an upper layer in an adjacent compartment. The unburned hydrocarbons are tracked in this 
model. Combustion of $\mathrm{CO}$ to $\mathrm{CO}_{2}$ is not included in the model. Actual combustion chemistry is not considered in CFAST due to the complexities associated with detailed kinetics and transport.

\section{Visibility}

There are two calculations involving radiation in this model. One is for energy balance and is based on broadband radiation absorption. The amount of radiation absorbed in sensitive to the species present, specifically water vapor, soot and carbon dioxide.

The other is for visibility of egress signs. This calculation is based solely on the soot concentration and is reported as optical depth (per meter). The conversion factor is based on the recent work by Mulholland and Croarkin ${ }^{13}$. The value for converting mass density in $\mathrm{kg} / \mathrm{m}^{3}$ to optical depth is $3817 \mathrm{~m}^{2} / \mathrm{kg}$. The value reported is intended specifically for assessing the visibility of egress signs, based on the work of $\mathrm{Jin}^{14}$. It is not applicable to the far blue or red regions of the spectrum and so should not be used for assessing optical detection of fires through smoke.

Since chemical species are tracked only for a constrained fire, the optical depth for an unconstrained fire is fixed at $0.5 \mathrm{~m}^{-1}$ for the upper layer and $0.05 \mathrm{~m}^{-1}$ for the lower layer.

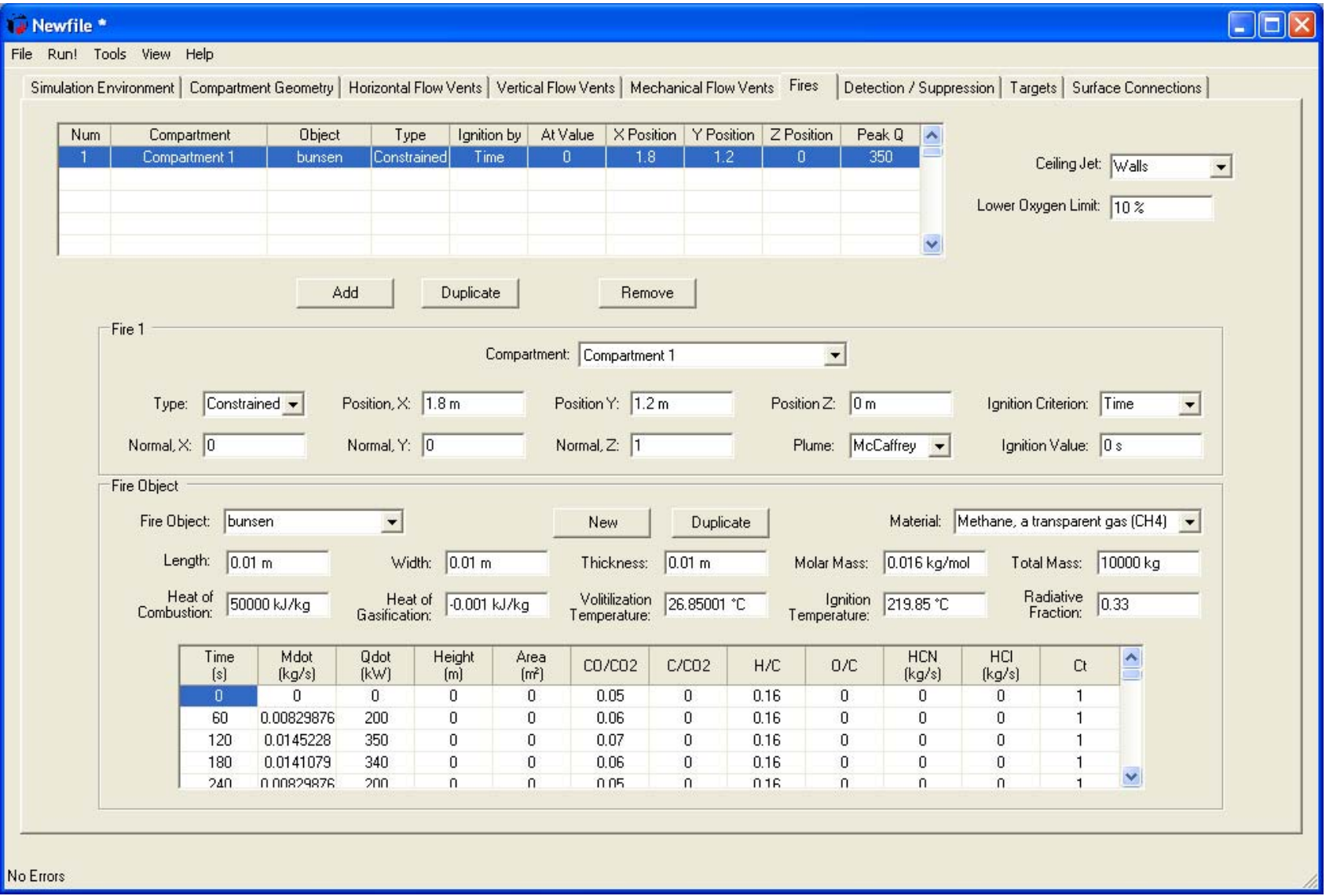

Most of the tabbed pages in the program are of similar design, with a summary of the defined items in table form at the top of the page, a series of buttons to add, remove, or modify the item highlighted in the summary table, and a number of individual inputs below which 
details all of the inputs for the item selected in the summary table. The buttons included on the fires page are as follows.

\section{Add}

Use the Add button to create a new fire with default values for all entries.

Duplicate Use the Duplicate button to create a copy of the fire currently selected in the summary table at the top of the page. The new fire is added to the end of the list with the named changed to indicate it is a copy of the selected item.

Remove Use the Remove button to delete the selected fire from the list of mechanical flow vents in the summary table. Other vents are renumbered once the compartment is deleted.

\section{Defining Fire Objects}

Fires in CFAST are defined as a series of individual fire objects which are then placed as desired in compartments in a simulation.

Each fire object defines the time dependent variables of the fire are described by the mass loss rate, rate of heat release, fuel height, and fuel area inputs. Species production rates are specified in a manner similar to the fire, entering the rates as a series of points with respect to time. The species which are followed by CFAST are: carbon dioxide, carbon monoxide, hydrogen cyanide, hydrogen chloride, nitrogen, oxygen, soot, total unburned hydrocarbons and water. There is a separate calculation of the concentration-time product Ct.

Each fire object is defined in a separate comma-separated spreadsheet file with an extension of “.o”. As many fire objects as desired may be defined by the user. One special fire object is named "mainfire.o" as is assumed to be a main fire source for the scenario, if included. The only difference between the main fire and other object fire is that the main fire is assumed to ignite at a user specified time. Other fire objects can ignite based on time, temperature or heat flux conditions.

\begin{tabular}{|c|c|c|c|c|c|c|c|c|c|c|c|c|c|}
\hline \multicolumn{14}{|l|}{ Fire Object } \\
\hline Fire Object: & bunsen & $\nabla$ & & & New & \multicolumn{2}{|c|}{ Duplicate } & & Material: $\mathrm{M}$ & \multicolumn{3}{|c|}{ Methane, a transparent gas $[\mathrm{CH} 4]$} & $\nabla$ \\
\hline Length: & $0.01 \mathrm{~m}$ & Width: & \multicolumn{2}{|c|}{$0.01 \mathrm{~m}$} & Thickness: & \multicolumn{2}{|l|}{$0.01 \mathrm{~m}$} & Molar Mass: & $0.016 \mathrm{~kg} / \mathrm{mol}$ & \multicolumn{2}{|c|}{ Total Mass: } & \multicolumn{2}{|l|}{$10000 \mathrm{~kg}$} \\
\hline $\begin{array}{c}\text { Heat of } \\
\text { Combustion: }\end{array}$ & $50000 \mathrm{~kJ} / \mathrm{kg}$ & $\begin{array}{r}\text { Heat of } \\
\text { Gasification: }\end{array}$ & \multicolumn{2}{|c|}{$-0.001 \mathrm{~kJ} / \mathrm{kg}$} & $\begin{array}{l}\text { Volitilization } \\
\text { Temperature: }\end{array}$ & \multicolumn{2}{|c|}{$26.85001^{\circ} \mathrm{C}$} & $\begin{array}{l}\text { Ignition } \\
\text { Temperature: }\end{array}$ & $219.85^{\circ} \mathrm{C}$ & \multicolumn{2}{|c|}{$\begin{array}{l}\text { Radiative } \\
\text { Fraction: }\end{array}$} & \multicolumn{2}{|l|}{0.33} \\
\hline $\begin{array}{c}\text { Time } \\
\text { (s) }\end{array}$ & $\begin{array}{l}\text { Mdot } \\
{[\mathrm{kg} / \mathrm{s}]}\end{array}$ & $\begin{array}{l}\text { Qdot } \\
\text { (kw) }\end{array}$ & $\begin{array}{c}\text { Height } \\
\text { (m) }\end{array}$ & $\begin{array}{l}\text { Area } \\
\left(\mathrm{m}^{2}\right]\end{array}$ & $\mathrm{CO} / \mathrm{CO} 2$ & $\mathrm{C} / \mathrm{CO} 2$ & $\mathrm{H} / \mathrm{C}$ & $0 / C$ & $\begin{array}{c}\mathrm{HCN} \\
{[\mathrm{kg} / \mathrm{s}]}\end{array}$ & $\begin{array}{c}\mathrm{HCl} \\
{[\mathrm{kg} / \mathrm{s}]}\end{array}$ & $\mathrm{Cl}$ & 슴 & \\
\hline 0 & 0 & 0 & 0 & 0 & 0.05 & 0 & 0.16 & 0 & 0 & 0 & 1 & & \\
\hline 60 & 0.00829876 & 200 & 0 & 0 & 0.06 & 0 & 0.16 & 0 & 0 & 0 & 1 & & \\
\hline 120 & 0.0145228 & 350 & 0 & 0 & 0.07 & 0 & 0.16 & 0 & 0 & 0 & 1 & & \\
\hline 180 & 0.0141079 & 340 & 0 & 0 & 0.06 & 0 & 0.16 & 0 & 0 & 0 & 1 & & \\
\hline $2 \Delta \pi$ & ก กกรว 9876 & 2กก & n & ก & กतम & n & ก1א & n & n & $n$ & 1 & $\underline{v}$ & \\
\hline
\end{tabular}

New Use the New button to create a new fire object with default values for all entries. No time-dependent values are included in the new fire. 
Duplicate Use the Duplicate button to create a copy of the fire object currently selected in the summary table at the top of the page. The new fire object is added to the list with the named changed to indicate it is a copy of the selected item.

Fire Object Name: The name from the collection of fire objects for the desired object. This corresponds to the name of the fire object file, without the extension. Specifying a name not found in the database causes CFAST to stop with an appropriate error message.

Material (default value: none): material name from the thermal properties data file used for the object. The material properties are used to calculate heat transfer into the object from its surroundings.

Length (default units: $\mathrm{m}$, default value: none): specifies the length of the object. The choice of dimension to be designated as length, width, or thickness is arbitrary. Heat flux to the object surface is assumed to be incident to the surface defined by the length and width dimensions.

Width (default units: $\mathrm{m}$, default value: none): specifies the width of the object.

Thickness (default units: $\mathrm{m}$, default value: none): specifies the thickness of the object.

Molar Mass (default units $\mathrm{kg} / \mathrm{mol}$, default value: $0.016 \mathrm{~kg} / \mathrm{mol}$ ) This is the conversion factor from mass density to molecular density for "Total Unburned Hydrocarbon," the fuel vapor. It is used only for conversion to parts-per-million and has no effect on the model itself.

Total Mass (default units: kg, default value: $10000 \mathrm{~kg}$ ): Total mass of the object.

Heat of Combustion (default units: J/kg, default value: $50000000 \mathrm{~J} / \mathrm{kg}$ ): The energy released per kilogram of mass burned.

Heat of Gasification (default units: J/kg, default value: none): The sum of the sensible and latent heat required to vaporize a unit mass of material.

Volatilization Temperature (default units: K, default value: ambient): The temperature of the vapor as it is emitted from a fuel source. Typically, the initial fuel temperature is the same as the ambient temperature specified on the ambient conditions window. This may not be true if significant conductive or radiative heat transfer affects the fuel. This affects the enthalpy since temperatures below the lower layer ambient cause the plume to cool. The effect is not large, but it is noticeable.

Ignition Temperature (default units: $\mathrm{K}$, default value: volatilization temperature plus $100 \mathrm{~K})$ : The lower temperature limit on the burning of fuel in a gas layer. Since CFAST does not support a combustion kinetics model, this is the algorithm used for fires out of vents.

Radiative Fraction: The fraction of the energy produced in combustion that is radiated from the fire and plume. Within CFAST, the radiative fraction defaults to $0.30^{15}$; i.e., $30 \%$ of the fire's energy is released via radiation. For other fuels, the work of Tewarson ${ }^{16}$, McCaffrey ${ }^{17}$, or Koseki ${ }^{18}$ is available for reference. The typical range for the radiative fraction is from about 0.05 to 0.4 . 
All of the time dependent variables depend on a predefined time line. The time input specifies a sequence of time points that define the timing of the fire. An entry indicates a point on the time-line when the mass loss rate, fuel height and other time dependent values are specified for the fire. This time is independent of the simulation time which is specified by the TIMES line. If the simulation time is longer than the total duration of the fire, the final values specified for the fire (mass loss rate, fuel height, fuel area, and species) are continued until the end of the simulation.

The units for species (HCR, etc.) are kilograms per kilogram. However, the meaning is different for fuel properties and species production rates. The input for CT is the kilograms of "toxic" combustion products produced per kilogram of fuel pyrolyzed. Input for HCR is the mass ratio of hydrogen to carbon ratio in the fuel. Input for $\mathrm{O} 2$ is the mass ratio of oxygen to carbon as it becomes available from the fuel. Input the ratio of the mass of carbon to carbon dioxide produced by the oxidation of the fuel for OD. The input for $\mathrm{CO}$ is the ratio of the mass of carbon monoxide to carbon dioxide produced by the oxidation of the fuel.

Time (default units: s, default values: none): specify a sequence of time points that define the timing of the main fire. An entry indicates a point on the time-line when the mass loss rate, fuel height and other time dependent values are specified for the fire.

Pyrolysis Rate (Mdot) (default units: kg/s, default values: none): Pyrolysis rate of the fire as a series of time points consistent with the time specification.

Heat Release Rate (QDot) (default units: W, default values: none): Heat release rate of the fire as a series of time points consistent with the time specification.

Fire Height (default units: m, default values: none): Time-based values for height of the base of the fire. Actual height of the base of the fire is the sum of the value specified by MAINF for the main fire or OBJFL for object fires and this height specification for a particular time in the fire development.

Area of the Base of the Fire (default units: $\mathrm{m}^{2}$, default values: none): Cross-sectional area of the base of the fire.

CO/CO2 (default units: $\mathrm{kg} / \mathrm{kg}$, default values: none): species yields ratios of carbon monoxide to carbon dioxide produced in the pyrolysis of the fuel.

H/C (default units: kg/kg, default values: none): the hydrogen component of the pyrolyzed fuel. This is the ratio of hydrogen to carbon produced in the pyrolysis of the fuel.

O/C (default units: $\mathrm{kg} / \mathrm{kg}$, default values: none): Oxygen component of the pyrolyzed fuel. $\mathrm{O} 2$ is the ratio of oxygen to carbon produced in the pyrolysis of the fuel. The $\mathrm{O} 2$ input thus represents excess oxygen available from the fuel for combustion. For normal fuels, this input should be set to zero.

HCN (default units: kg/kg, default values: none): Yield of hydrogen cyanide per mass of fuel produced in the pyrolysis of the fuel.

$\mathbf{H C l}$ (default units: $\mathrm{kg} / \mathrm{kg}$, default values: none): Yield of hydrogen chloride per mass of fuel produced in the pyrolysis of the fuel. 
Ct (default units: $\mathrm{kg} / \mathrm{kg}$, default values: none): Yield of a fictitious toxic species per mass of fuel produced in the pyrolysis of the fuel. For "normally toxic" materials, this takes a value of 1 and is typically changed by an order of magnitude for particularly toxic or non-toxic materials. It is not part of the mass balance for the fuel and system, but it just carried along as a transported species in flow through the structure. $\mathrm{Ct}$ is used as a measure of toxicity of a material. Typically the integrated $\mathrm{Ct}$ versus time product is calculated. For normal materials, a concentration-time product of $900 \mathrm{mg} \mathrm{min} / \mathrm{m}^{3}$ is an indication of incapacitation.

- With the three parameters, heat of combustion (HOC), the pyrolysis and heat release rate are over specified. The model uses the last two of the three to obtain the HOC parameter.

- By default, the fire is placed in the center of the compartment on the floor. If values for any of the three variables are invalid (i.e., less than zero or greater than the compartment dimension in the appropriate direction), the location for that direction defaults to the center of the appropriate direction.

- In the input editor, time-dependent data are entered in a simple spreadsheet. Normal windows copy (Ctrl-C), cut (Ctrl-X), and paste (Ctrl-V) keyboard shortcuts are available for data editing. In addition, Alt-Ins will insert a complete row above the currently-selected row in the spreadsheet and Alt-Del will delete the current row in the spreadsheet.

\section{Associating Fire Objects with One or More Instances of the Fire in the Compartments of the Simulation}

Fire objects are placed in defined positions within a compartment of a simulation and oriented with a normal vector to the surface of the object. Ignition of an object may be at a specified time, a specified net incident heat flux on the surface of the object, or at a specified surface temperature of the object. The relevant CFAST keywords are MAINF for a simple point-source fire, OBJECT for a complex fire object, and HEATF for a heat source.

The OBJECT keyword allows the specification of additional objects to be burned in the fire scenario. Positioning of the object within a compartment is specified in the same manner as for the main fire.

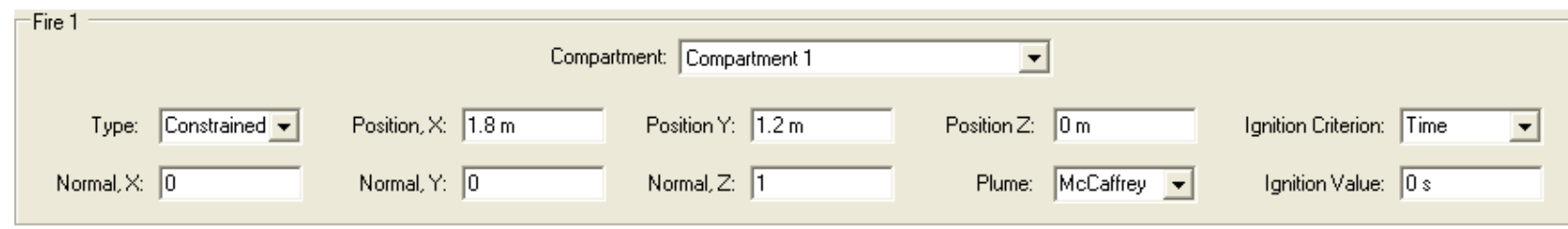

Compartment of Fire Origin: specifies the compartment that contains the main fire for the simulation. Any compartment defined is valid. 
Type: constrained or heat source. For a constrained fire, species are tracked and heat release rate is limited by the oxygen available for combustion. For a heat source, the fire is a source of heat only, no mass is released, and species concentrations are not calculated by the model.

Width (X) Position (default units: m, default value: compartment width / 2): Position of the center of the base of the fire measured in the $\mathrm{x}$ direction from the front lower left corner of the compartment origin $(0,0,0)$ in the compartment of fire origin.

Depth (Y) Position (default units: m, default value: compartment depth / 2): Position of the center of the base of the fire measured in the y direction from the front lower left corner of the compartment origin $(0,0,0)$ in the compartment of fire origin.

Height (Z) Position (default units: $\mathrm{m}$, default value: $0 \mathrm{~m}$ ): Position of the center of the base of the fire measured in the $\mathrm{z}$ direction from the front lower left corner of the compartment origin $(0,0,0)$ in the compartment of fire origin. Actual height of the base of the fire is the sum of the value specified by FPOS and by FHIGH for a particular time in the fire development.

Normal Vector X Component: specifies a vector of unit length perpendicular to the exposed surface of the object. (Depth) component is in the direction from the rear wall of the object compartment. Default value is a horizontal, upward facing object, unit vector $=(0,0,1)$

Normal Vector Y Component: specifies a vector of unit length perpendicular to the exposed surface of the object. (Breadth) component is in the direction from the left wall of the object compartment. Default value is a horizontal, upward facing object, unit vector $=(0,0,1)$

Normal Vector $\mathbf{Z}$ Component: specifies a vector of unit length perpendicular to the exposed surface of the object. (Breadth) component is in the direction from the floor of the object compartment. Default value is a horizontal, upward facing object, unit vector $=(0,0,1)$

Plume Type: specifies the algorithm used to calculate entrainment of air into the plume. At present, only a plume based on the work of McCaffrey is allowed.

Ignition Criterion Type: The type of ignition condition specified by the Ignition Criterion Value. Acceptable values are 1 for time, 2 for object surface temperature, and 3 for incident flux to object surface.

Ignition Criterion Value: The numerical value at which ignition will occur. If it is less than or equal to zero, the default is taken. For constrained and heat source fires, the default is and ignition at time of zero.

- Object fires are used to include additional burning objects in a simulation. For additional details, see the CFAST technical reference guide ${ }^{1}$,or Babrauskas and Grayson $^{19}$. 


\section{Calculating Normal Vectors}

The general equations for determining the normal vectors in the $\mathrm{x}, \mathrm{y}$, and $\mathrm{z}$ directions are:

Normal vector in the $\mathrm{x}$ direction, $\mathrm{x}=\mathrm{x} /\left(\mathrm{x}^{2}+\mathrm{y}^{2}+\mathrm{z}^{2}\right)^{.5}$

Normal vector in the $y$ direction, $y=y /\left(x^{2}+y^{2}+z^{2}\right)^{5}$

Normal vector in the $\mathrm{z}$ direction, $\mathrm{z}=\mathrm{z} /\left(\mathrm{x}^{2}+\mathrm{y}^{2}+\mathrm{z}^{2}\right)^{.5}$

The simplest way to calculate the unit vector is to draw an imaginary line at right angles (i.e., $90^{\circ}$ angle) from the exposed surface of the target and to extend this imaginary line until it hits the walls, floor or ceiling of the compartment in which it is located. This imaginary line is actually a vector that starts at the surface of the exposed target and terminates on a wall, floor, or ceiling. Once the start point and the end point of a vector are known, the unit vector for this imaginary line may be calculated as follows:

$$
\begin{aligned}
& \mathrm{x}=\left(\mathrm{x}_{\text {end }}-\mathrm{x}_{\text {start }}\right) /\left(\left(\mathrm{x}_{\text {end }}-\mathrm{x}_{\text {start }}\right)^{2}+\left(\mathrm{y}_{\text {end }}-\mathrm{y}_{\text {start }}\right)^{2}+\left(\mathrm{z}_{\text {end }}-\mathrm{z}_{\text {start }}\right)^{2}\right)^{0.5} \\
& \mathrm{y}=\left(\mathrm{y}_{\text {end }}-\mathrm{y}_{\text {start }}\right) /\left(\left(\mathrm{x}_{\text {end }}-\mathrm{x}_{\text {start }}\right)^{2}+\left(\mathrm{y}_{\text {end }}-\mathrm{y}_{\text {start }}\right)^{2}+\left(\mathrm{z}_{\text {end }}-\mathrm{z}_{\text {start }}\right)^{2}\right)^{0.5} \\
& \mathrm{z}=\left(\mathrm{z}_{\text {end }}-\mathrm{z}_{\text {start }}\right) /\left(\left(\mathrm{x}_{\text {end }}-\mathrm{x}_{\text {start }}\right){ }^{2}+\left(\mathrm{y}_{\text {end }}-\mathrm{y}_{\text {start }}\right)^{2}+\left(\mathrm{z}_{\text {end }}-\mathrm{z}_{\text {start }}\right)^{2}\right)^{0.5}
\end{aligned}
$$

As an example, assume the following scenario:

- A square shaped target object is located in the middle of the floor of a compartment.

- The target is constructed from no-combustible materials except the top.

- The square shaped material is $1 \mathrm{~m}$ in depth, $1 \mathrm{~m}$ in breadth, and $1 \mathrm{~m}$ high.

- The reference point $(0,0,0)$ in the compartment is the lower left hand side of the rear wall.

- The compartment is 3 meters in the $\mathrm{x}$ direction (i.e., the distance from the rear wall to the front wall of the compartment), 4 meters in the y direction (i.e., the distance from the left wall to the right wall of the compartment), and 5 meters in the $\mathrm{z}$ direction (i.e., the distance from the floor to the ceiling of the compartment).

Since the only side of the target that is combustible is the top surface of the target object, an imaginary line is draw perpendicular (i.e., at a $90^{\circ}$ angle) from the top surface of the target object and extended until it reaches the outer boundary of the compartment. In this case, since the top of the target object is facing the ceiling, the imaginary line would run straight up to the ceiling, running parallel to the four walls of the compartment, and terminating at the ceiling at the point $(1.5 \mathrm{~m}, 2 \mathrm{~m}, 5 \mathrm{~m})$. Since the vector starts at point (1.5-m, 2-m, 1-m) and terminates at (1.5-m, 2-m, 5-m), the unit vectors can be calculated as follows:

$$
\begin{aligned}
\mathrm{x} & =\left(\mathrm{x}_{\text {end }}-\mathrm{x}_{\text {start }}\right) /\left(\left(\mathrm{x}_{\text {end }}-\mathrm{x}_{\text {start }}\right)^{2}+\left(\mathrm{y}_{\text {end }}-\mathrm{y}_{\text {start }}\right)^{2}+\left(\mathrm{z}_{\text {end }}-\mathrm{z}_{\text {start }}\right)^{2}\right)^{.5} \\
& =(1.5-1.5) /\left((1.5-1.5)^{2}+(2-2)^{2}+(5-1)^{2}\right)^{.5}=0 \\
\mathrm{y} & =\left(\mathrm{y}_{\text {end }}-\mathrm{y}_{\text {start }}\right) /\left(\left(\mathrm{x}_{\text {end }}-\mathrm{x}_{\text {start }}\right)^{2}+\left(\mathrm{y}_{\text {end }}-\mathrm{y}_{\text {start }}\right)^{2}+\left(\mathrm{z}_{\text {end }}-\mathrm{z}_{\text {start }}\right)^{2}\right)^{.5} \\
& =(2-2) /\left((1.5-1.5)^{2}+(2-2)^{2}+(5-1)^{2}\right)^{.5}=0 \\
\mathrm{z} & =\left(\mathrm{z}_{\text {end }}-\mathrm{z}_{\text {start }}\right) /\left(\left(\mathrm{x}_{\text {end }}-\mathrm{x}_{\text {start }}\right)^{2}+\left(\mathrm{y}_{\text {end }}-\mathrm{y}_{\text {start }}\right)^{2}+\left(\mathrm{z}_{\text {end }}-\mathrm{z}_{\text {start }}\right)^{2}\right)^{.5}
\end{aligned}
$$




$$
=(5-1) /\left((1.5-1.5)^{2}+(2-2)^{2}+(5-1)^{2}\right)^{.5}=1
$$

In this case, the unit vector is in the $+\mathrm{Z}$ direction.

\section{Special Features}

\section{Sprinklers and Detectors}

Sprinklers and detectors are both considered detection devices by the CFAST model and are handled using the same input keywords. Detection is based upon heat transfer to the detector. Fire suppression by a user-specified water spray begins once the associated detection device is activated. A maximum of 20 sprinklers or detectors can be included for any input file and model run. These can be in one compartment or scattered throughout the structure. The DETEC keyword is used for both detectors and sprinklers. The first three parameters are required. The next three have defaults. The last three must be specified if this is a heat detector or sprinkler.

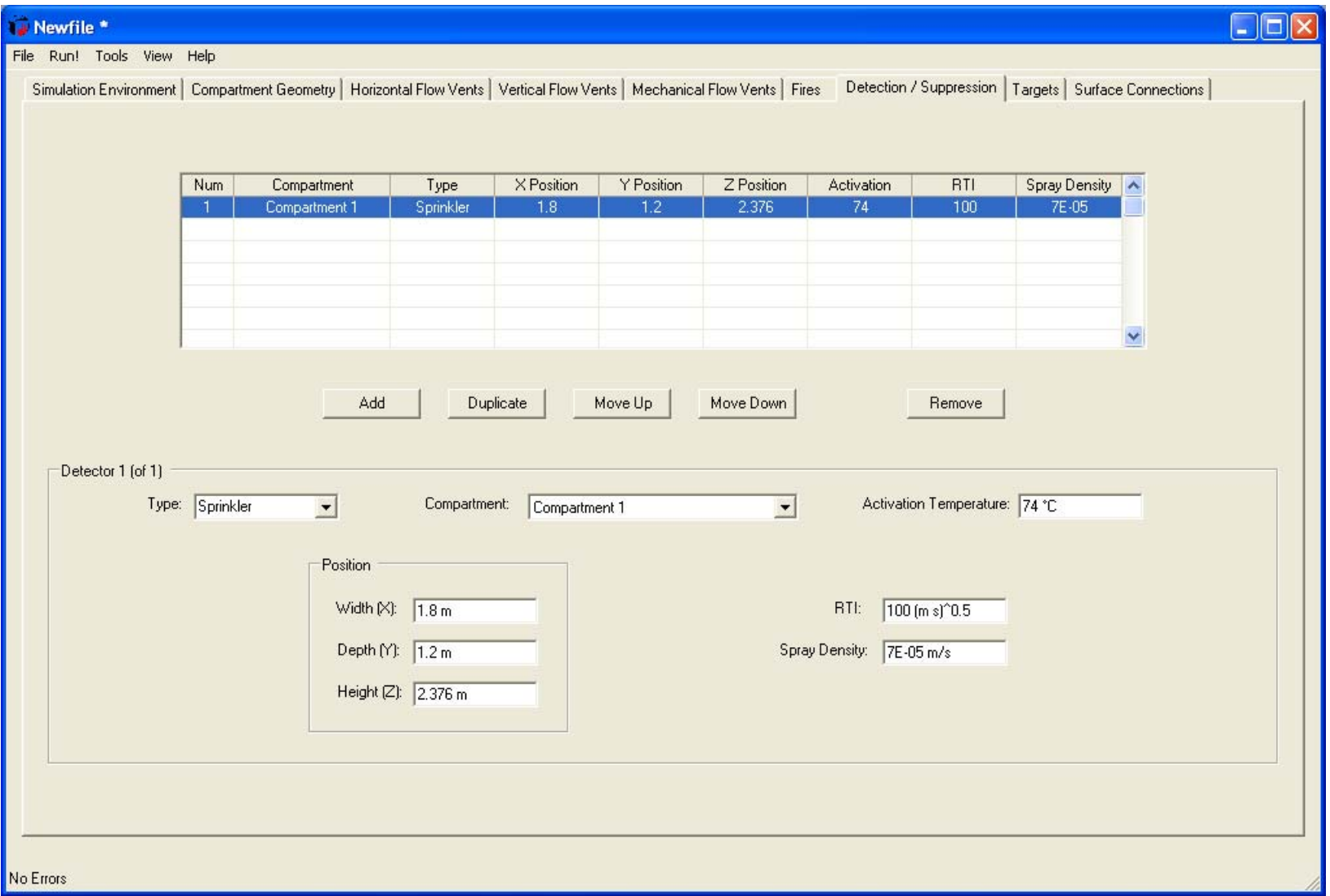

Type: type of detector, use 1 for smoke detector and 2 for heat detector or sprinkler.

Compartment the compartment in which the detector or sprinkler is located. 
Activation Temperature: the temperature at or above which the detector link activates.

Width (X) Position (default units: $\mathrm{m}$, default value: none): position of the object as a distance from the left wall of the compartment ( $\mathrm{X}$ direction).

Depth (Y) Position (default units: $m$, default value: none): position of the detector or sprinkler as a distance from the front wall of the compartment ( $\mathrm{Y}$ direction).

Height (Z) Position (default units: $m$, default value: none): position of the object as a distance from the floor of the compartment ( $\mathrm{Z}$ direction).

RTI (default units: $(\mathrm{m} \cdot \mathrm{s})^{1 / 2}$, default value: none): the Response Time Index (RTI) for the sprinkler or detection device.

Spray Density (default units: $\mathrm{m} / \mathrm{s}$, default value: none): the amount of water dispersed by a water spray-sprinkler. The units for spray density are length/time. These units are derived by dividing the volumetric rate of water flow by the area protected by the water spray. The suppression calculation is based upon an experimental correlation by Evans $^{20}$, and depends upon the RTI, activation temperature, and spray density to determine the behavior of the sprinkler.

- Often, the activation of smoke alarms is simulated with a temperature-based criterion. Davis and Notarianni ${ }^{21}$ studied the activation of heat and smoke alarms in small and large compartments. They conclude that a temperature rise of approximately $5^{\circ} \mathrm{C}$ corresponded to activation of ionization alarms for a range of fire sources and ceiling heights..

- Several cautions should be observed when using estimates of sprinkler suppression within the model: 1) the first sprinkler activated controls the effect of the sprinkler on the heat release rate of the fire. Subsequent sprinklers which may activate have no additional effect on the fire simulation. 2) The fire suppression algorithm assumes the effect of the sprinkler is solely to reduce the heat release rate of the fire. Any effects of the sprinkler spray on gas temperatures or mixing within the compartment are ignored. 3) The sprinkler always reduces the heat release rate of the fire. The ability of a fire to overwhelm an under-designed sprinkler is not modeled. 4) Since the dynamics of the sprinkler and direct effects of the spray on gas temperatures and velocities are not modeled, calculated times of activation of secondary sprinklers and / or detectors after the first sprinkler is activated should be not be modeled since the impact of the first sprinkler on the activation of additional sprinklers is not included in the CFAST model.

\section{Defining Targets}

CFAST can track and report calculations of the net heat flux striking arbitrarily positioned and oriented targets and the temperature of these targets. The relevant keyword used to specify targets is TARGE. 
In addition to any user-defined targets, there are always two targets that are automatically placed in any compartment containing a fire. Both are included for reporting purposes. The first is an "ambient target" and is intended to represent the net flux to a human body. This is used for the flux in the hazard calculation for tenability. The assumption is that the target will remain at ambient temperature, which is a surrogate for body temperature. The second determines the net flux to a horizontal target on the floor whose temperature is assumed to be the same as the floor surface. The calculation can be used to estimate the ignition of combustibles on the floor as a surrogate for estimating time to flashover, typically taken to be $20 \mathrm{~kW} / \mathrm{m}^{2}$. Thus if one of the target keywords is used, it will be in addition to these two predefined targets.

For all targets, heat flux is calculated to the surface specified by the user (with the normal vector). Conduction into the target is assumed to occur only from this surface.

File Run! Tools View Help

Simulation Environment | Compartment Geometry | Horizontal Flow Vents | Vertical Flow Vents | Mechanical Flow Vents | Fires | Detection/Suppression Targets | Surface Connections |
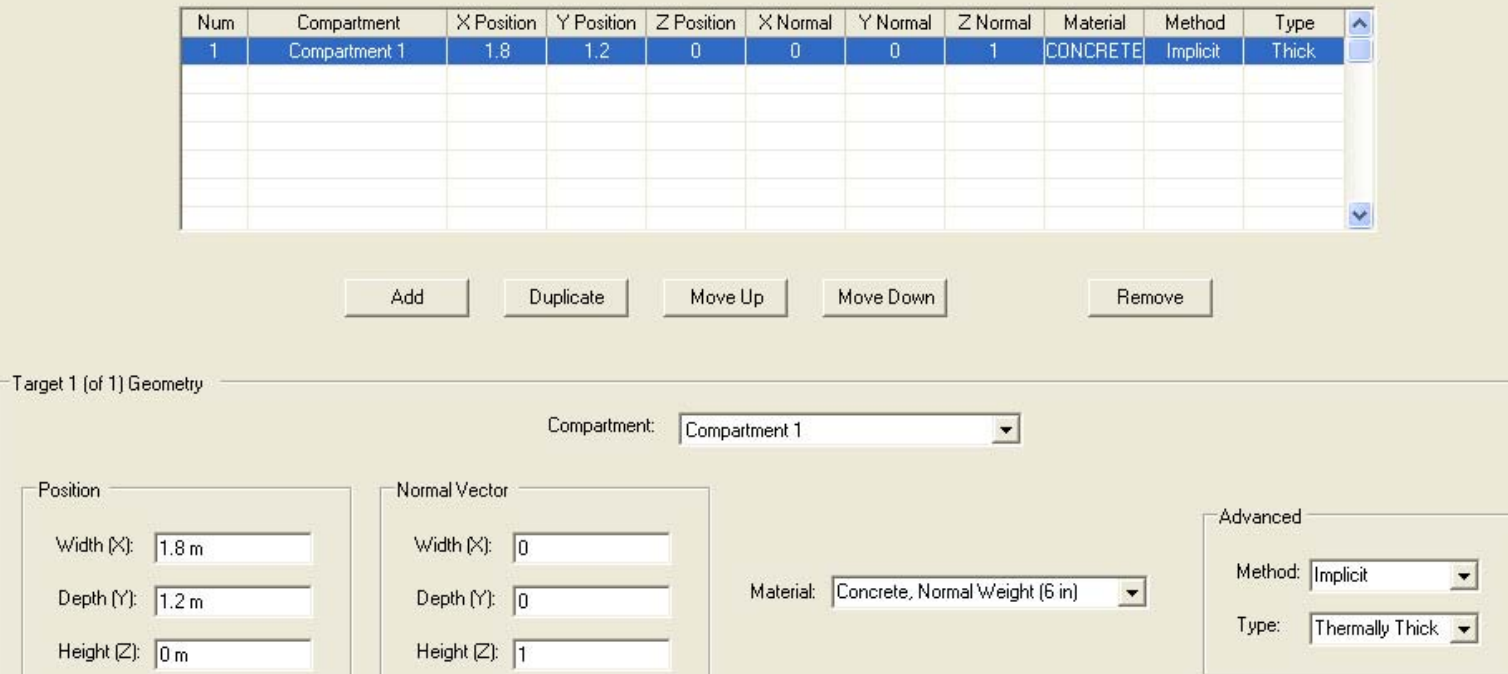

Compartment: The compartment in which the target is located.

Width (X) Position: Position of the target as a distance from the left wall of the target compartment (X direction).

Depth (Y) Position: Position of the target as a distance from the front wall of the target compartment (Y direction). 
Height (Z) Position: Height of the target above the floor ( $\mathrm{Z}$ direction).

Normal Vector X Component: specifies a vector of unit length perpendicular to the exposed surface of the target. (Width) component in the direction from the left wall of the target compartment. A value of 1 defines a vertical target facing into the compartment, unit vector $=(1,0,0)$.

Normal Vector Y Component: specifies a vector of unit length perpendicular to the exposed surface of the target. (Depth) component in the direction from the front wall of the target compartment. A value of 1 defines a vertical target facing to the right, unit vector $=(0,1,0)$.

Normal Vector Z Component: specifies a vector of unit length perpendicular to the exposed surface of the target. (Height) component in the direction from the floor of the target compartment. Default value is a horizontal, upward facing target, unit vector $=(0,0,1)$.

Material: Used to specify the wall material of the target. Any material from the thermal database used to represent wall materials may be used here. Since the transient heat conduction problem is not solved now for the target this parameter is not used.

Solution Method: Optional parameter that indicates the solution method. STEADY for steady state solution, EXPLICIT for explicit solution, IMPLICIT for implicit solution.

Material Solution Type: If METHOD is not STEADY, this parameter further indicates the equation type to be either ODE or PDE. For thermally thin materials, use ODE; for thermally thick materials, use PDE

- The TARGE keyword performs a heat transfer calculation between the compartment and the target. The steady state option assumes that the target material reacts instantly to changing conditions and computes the target temperature that would result in a balance of incoming and outgoing heat (i.e., a steady state). If a transient target temperature is modeled, then one can either assume that there is a temperature variation within the target or assume that the target is "thin" and can be modeled using only one temperature. If the target is assumed to be thin then the ODE option should be used set since this is how the equations are solved. If the target is assumed to be thick then the PDE option should set. Finally, if one of the two transient options are set (ODE or PDE), the numerical solution can be solved using an explicit or an implicit method. Typically, the implicit method will work in all cases. The explicit method is recommended only when the implicit method fails to come to a solution.

\section{Defining Compartment Area}

The Compartment Geometry page includes two additional entries that may be used for defining compartment properties for spaces which are not rectangular in area. Values are entered in a spreadsheet. The CFAST keywords ROOMA and ROOMH keywords allow the user to define non-rectangular rooms by specifying cross-sectional area as a function of 
height. One set of values is included for each compartment that has a variable cross-sectional area.

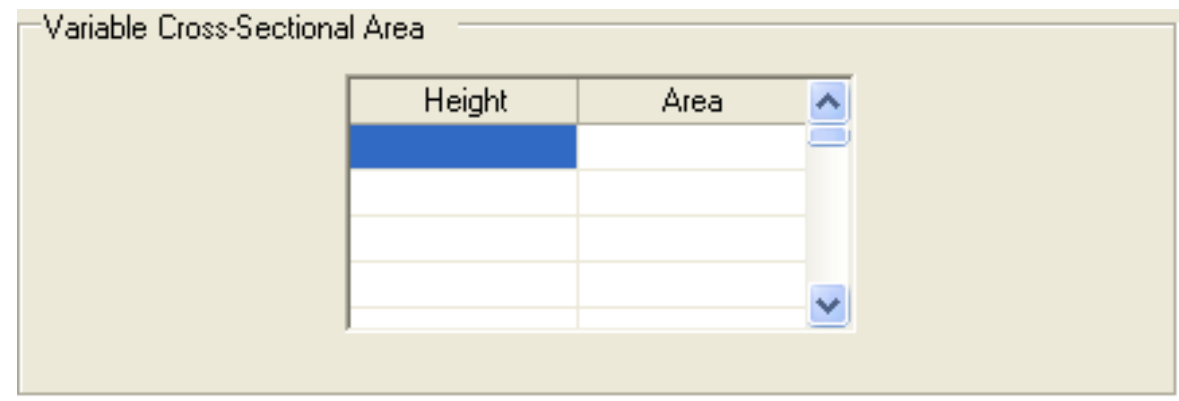

Height Value(s) (default units: m, default values: none): Values of height for the corresponding cross-sectional area values measured from the floor of the compartment. The values for the compartment correspond to cross-sectional area values included for the same compartment on the ROOMA command.

Area Value(s) (default units $\mathrm{m}^{2}$, default values: none): Values of cross-sectional area of the compartment as a function of height measured from the floor of the compartment. The values for the compartment correspond to height values included for the same compartment on the ROOMH command.

\section{Inter-compartment Heat Transfer (Conduction)}

The Surface Connections page allows the user to define heat transfer between compartments in a simulation. These may define vertical conduction through floors or ceilings or horizontal conduction through connecting wall surfaces.

There are two keywords that define physical connections which affect heat conduction between compartments. They are:

- VHEAT - ceiling/floor heat conduction (vertical heat flow)

- HHEAT - heat transfer between connected compartment walls (horizontal heat flow)

Energy can be transferred from compartment to compartment through solid boundaries (walls, ceilings and floors) by means of conduction. The heat transfer between connected compartments is modeled by merging the connected surfaces for the ceiling and floor compartments or for the connected horizontal compartments. The heat conduction problem is solved for the merged walls using a temperature boundary condition for both the near and far wall. As before, temperatures are determined by the solver so that the heat flux striking the wall surface (both interior and exterior) is consistent with the temperature gradient at that surface. This option is implemented with the VHEAT (for vertical heat transfer) and the HHEAT (for horizontal heat transfer) keywords. 
- Vertical Heat Transfer: Heat transfer between the ceiling and floor of specified compartments is included with the VHEAT keyword. Ceiling to floor heat transfer occurs between interior compartments of the structure or between an interior compartment and the outdoors. The model checks to make sure that the ceiling and floor are reasonably contiguous (within $0.01 \mathrm{~m}$ ). The assumption is made that this is true for the entire ceiling and floor.

- Horizontal Heat Transfer: Horizontal conduction between specified compartments is included with the HHEAT keyword. Conduction through vertical partitions (walls) occurs between interior compartments of the structure or between an interior compartment and the outdoors.

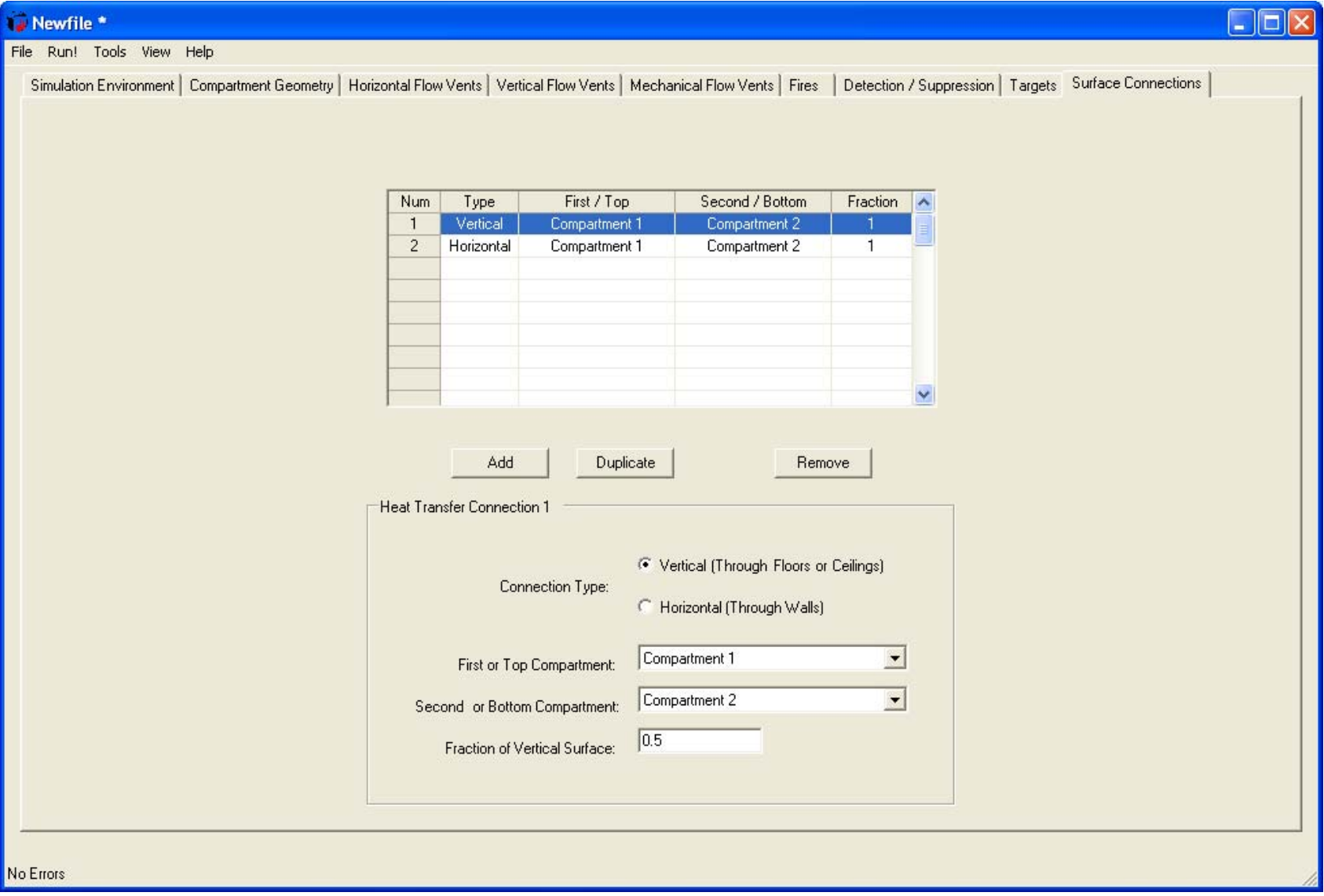

First Compartment: First of the connected compartments. Order of the inputs is not important.

Second Compartment: Second of the connected compartments. Order of the inputs is not important. 
Fraction: Specifies the fraction of the vertical surface areas of the compartments which are connected can be specified. The fraction specifies the fraction of the vertical surface area connecting the first and second compartment pair.

As an example, four cases were simulated by modeling all wall surfaces in a test case with gypsum and steel and by turning on and off the horizontal heat transfer option. The following table summarizes the results for these four cases. Each table entry gives the Upper room 1 temperature, upper room 2 temperature, upper wall temperature in room 1 and upper wall temperature in room 2.

\begin{tabular}{||l|l|l||}
\hline \hline & HHEAT Off & HHEAT Off \\
\hline \hline Steel walls & $1106 / 528.3 / 374.9 / 319$ & $1118 / 535.3 / 399.6 / 340.2$ \\
\hline Gypsum walls & $1147 / 545.4 / 462.9 / 338$ & $1148 / 545.8 / 464.1 / 339.3$ \\
\hline
\end{tabular}

The results are as one would expect. For each wall material turning HHEAT on leads to warmer calculated temperatures since the outside environment (where heat goes when HHEAT is off) is cooler than the adjoining room. The temperature differences are greater for steel than for gypsum since steel conducts heat more effectively.

\section{The Ceiling Jet - An Additional Zone}

Typically, zone models incorporate two zones in each compartment, one for the upper layer and one for the lower layer. A plume from a fire then pumps energy from the fire and lower layer into the upper layer. However, it has been observed that the heat loss from the upper layer to the ceiling and walls is higher than this paradigm would indicate. The cause is that a plume does not truly mix with the upper layer initially as indicated in the figure

This leads to higher convective heat transfer than the mixed model would indicate. CFAST has incorporated a model of this additional heat loss based on the work of Cooper. Heat loss by this mechanism to the ceiling is well established, the loss to walls is somewhat more uncertain due to the uncertainty of how far the plume descends below the ceiling.

Walls $\quad-$ To include ceiling jet effects in the calculation of the surface temperature of the ceiling, wall, or both surfaces, the CJET keyword is used. In the input editor, CEdit, this is included on the fires page. The ceiling jet calculation can be used for the ceiling, walls, or all surfaces. At present, this keyword effects only the calculation of the convective heating boundary condition for the conduction routines. If a particular surface is on, the ceiling jet algorithm is used to determine the convective heating of the surface. If the ceiling jet is off, the bulk temperature of the upper layer determines the convective heating.

- Using this option affects all fires and it is suggested that this option be turned on and set to "CEILING." 


\section{Scenario and Software Limits}

CFAST is intended for use with a wide variety of fire scenarios. A number of limits to the inputs in the software implementation of the model are noted below.

\begin{tabular}{||l|c||}
\hline Maximum simulation time in seconds & 86400 \\
\hline Maximum number of compartments & 30 \\
\hline Maximum number of fires which can be included in a single test case (including the main fire) & 31 \\
\hline Maximum number of fire definitions which can be included in a single fire database file & 30 \\
\hline Maximum number of data points for a single main or secondary object fire & 21 \\
\hline $\begin{array}{l}\text { Maximum number of material thermal property definitions which can be included in a single thermal } \\
\text { database file }\end{array}$ & 125 \\
\hline Maximum number of slabs in a single surface material in the thermal database file & 3 \\
\hline Total number of ducts in all mechanical ventilation systems which can be included in a single test case & 60 \\
\hline $\begin{array}{l}\text { Maximum total number of connections between compartments and mechanical ventilation systems which } \\
\text { can be included in a single test case }\end{array}$ & 62 \\
\hline $\begin{array}{l}\text { Maximum number of independent mechanical ventilation systems which can be included in a single test } \\
\text { case }\end{array}$ & 15 \\
\hline $\begin{array}{l}\text { Maximum number of targets which can be included in a single test case. In addition, the CFAST model } \\
\text { includes a target on the floor of each compartment in the simulation and one for each object fire in } \\
\text { simulation. }\end{array}$ & 90 \\
\hline \begin{tabular}{l} 
Maximum number of data points in a history or spreadsheet file \\
\hline
\end{tabular} & 900 \\
\hline
\end{tabular}




\section{Chapter 5 Output}

\section{Overview}

The output of CFAST are the sensible variables that are needed for assessing the environment in a building subjected to a fire. These include temperatures of the upper and lower gas layers within each compartment, the ceiling/wall/floor temperatures within each compartment, the visible smoke and gas species concentrations within each layer, target temperatures and sprinkler activation time. The amount of information can be very large, especially for complex geometries and long simulations.

The default output to the console is called the compact form, and shows the basic information about a scenario, including layer temperatures and the size of fires. Default text output provides a simple overview for the user to make sure the case runs as expected.

The compact output for each compartment is listed across the screen and the compartments are listed down the screen starting with compartment one and ending with the outside. The example below shows the initial and final conditions for a calculation: 


\begin{tabular}{|c|c|c|c|c|c|}
\hline Compartment & $\begin{array}{l}\text { Upper } \\
\text { Temp. } \\
\text { (K) }\end{array}$ & $\begin{array}{l}\text { Lower } \\
\text { Temp. } \\
\text { (K) }\end{array}$ & $\begin{array}{l}\text { Inter. } \\
\text { Height } \\
\quad(\mathrm{m})\end{array}$ & $\begin{array}{l}\text { Pyrol } \\
\text { Rate } \\
\text { (kg/s) }\end{array}$ & $\begin{array}{l}\text { Fire } \\
\text { Size } \\
(W)\end{array}$ \\
\hline $\begin{array}{c}1 \\
2 \\
\text { outside }\end{array}$ & $\begin{array}{l}300.0 \\
300 . \odot\end{array}$ & $\begin{array}{l}300.0 \\
300 . \odot\end{array}$ & $\begin{array}{l}2.3 \\
2.3\end{array}$ & $\begin{array}{l}1.40 \odot E-\odot 3 \\
\odot . \odot \odot \odot\end{array}$ & $\begin{array}{l}2.530 E+\odot 4 \\
0.00 \odot \\
0.00 \odot\end{array}$ \\
\hline Time $=$ & $.0 \mathrm{sec}$ & & & & \\
\hline Compartment & $\begin{array}{l}\text { Upper } \\
\text { Temp. } \\
\text { (K) }\end{array}$ & $\begin{array}{l}\text { Lower } \\
\text { Temp. } \\
\text { (K) }\end{array}$ & $\begin{array}{l}\text { Inter. } \\
\text { Height } \\
(\mathrm{m})\end{array}$ & $\begin{array}{l}\text { Pyrol } \\
\text { Rate } \\
\text { (kg/s) }\end{array}$ & $\begin{array}{l}\text { Fire } \\
\text { Size } \\
(W)\end{array}$ \\
\hline $\begin{array}{l}1 \\
2 \\
\text { Outside }\end{array}$ & $\begin{array}{l}1252 . \\
828.7\end{array}$ & $\begin{array}{l}475.1 \\
325.4\end{array}$ & $\begin{array}{r}0.63 \\
1.0\end{array}$ & $\begin{array}{l}\odot .278 \\
\odot .0 \odot \odot\end{array}$ & $\begin{array}{l}4.831+06 \\
0.000 \\
1.609 \mathrm{E}+03\end{array}$ \\
\hline
\end{tabular}

The first column contains the compartment number. On each row with its compartment number from left to right is the upper layer temperature, lower layer temperature, the height of the interface between the two layers, the total pyrolysis rate, and finally the total fire size. The only value given for the outside is the total heat release rate of fires venting to the outside.

\section{Detailed Outputs}

The following sections describe each of the outputs from the model. Each section refers to a specific part of the print out and appears in the order the output appears. A description of each option follows.

\section{Output for Initialization}

This option prints the initial conditions to the output before the actual run starts. This merely mimics the inputs specified by the user in the input data file The initial conditions brake down into seven sections. Each is described below with the section name. The following explanation uses the output from the case STANDARD.DAT which is captured using the program report. STANDARD.DAT is included in the distribution. Please note, there are not mechanical ventilation or horizontal vents in STANDARD.DAT, so below the section saying there are no mechanical ventilation connections, there is an annotated section from additional data files, TESTVVENT.DAT, TESTHVAC.DAT and TESTSPEC.DAT.

Overview: The overview gives a general description of the case. The output is fairly self explanatory. Doors, ..." is the total number of horizontal natural flow vent connections in all compartments of the simulation. "Ceil. Vents, ..." gives the total number of vertical natural flow vent connections in all compartments of the simulation. The last header on the line "MV Connections" has the total number mechanical flow connections to all compartments in the simulation. Times in these outputs come from the TIMES input. All times are in s.

OVERVIEW 


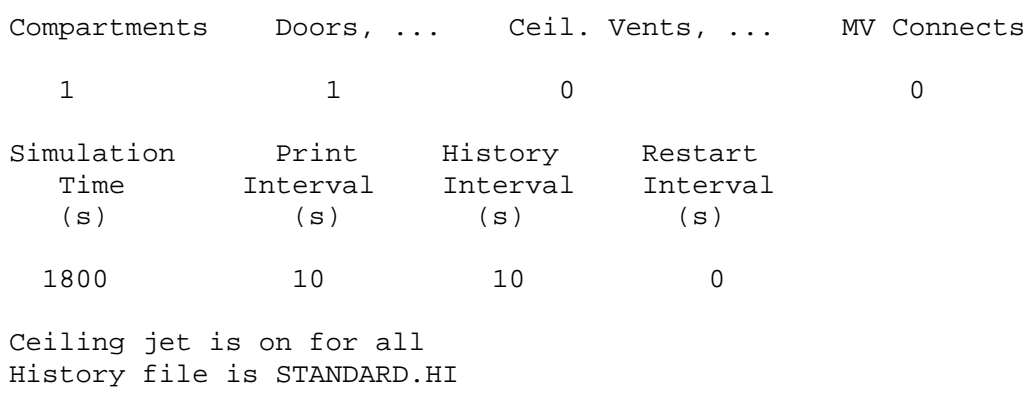

Ambient Conditions: This section, like the overview section, needs little elaboration. It gives the starting atmospheric conditions for the simulation both for outside and inside the structure. Data for these outputs come from the TAMB and EAMB inputs. Temperatures are in $\mathrm{K}$, pressure in $\mathrm{Pa}$, elevations in $\mathrm{m}$, and wind speed in $\mathrm{m} / \mathrm{s}$. Wind Power is the dimensionless power law coefficient from the WIND input.

\begin{tabular}{|c|c|c|c|c|c|c|c|}
\hline Interior & Interior & Exterior & Exterior & Station & Wind & Wind & Wind \\
\hline $\begin{array}{l}\text { Temperature } \\
\text { (K) }\end{array}$ & $\begin{array}{l}\text { Pressure } \\
(\mathrm{Pa})\end{array}$ & $\begin{array}{l}\text { Temperature } \\
\text { (K) }\end{array}$ & $\begin{array}{l}\text { Pressure } \\
(\mathrm{Pa})\end{array}$ & $\begin{array}{l}\text { Elevation } \\
\text { (m) }\end{array}$ & $\begin{array}{l}\text { Speed } \\
(\mathrm{m} / \mathrm{s})\end{array}$ & $\begin{array}{l}\text { Ref. Height } \\
\text { (m) }\end{array}$ & Power \\
\hline 300. & 101300. & 300. & 101300. & 0.00 & 0.0 & 10.0 & 0.16 \\
\hline
\end{tabular}

Compartments: The compartments section gives a summary of the geometry for the simulation. A simple table summarizes the geometry with compartments running down the page in numerical order. The various dimensions for each compartment are on the row with its compartment number. Two columns need explanation. The second to last column "Ceiling Height" gives the height of the ceiling relative to the station height in the Ambient Conditions section. Similarly the "Floor Height" refers to the height of the floor above the station height.

\begin{tabular}{|c|c|c|c|c|c|c|c|}
\hline Compartment & $\begin{array}{l}\text { Width } \\
\text { (m) }\end{array}$ & $\begin{array}{l}\text { Depth } \\
\text { (m) }\end{array}$ & $\begin{array}{l}\text { Height } \\
\text { (m) }\end{array}$ & $\begin{array}{l}\text { Area } \\
\left(m^{\wedge} 2\right)\end{array}$ & $\begin{array}{l}\text { Volume } \\
\left(m^{\wedge} 3\right)\end{array}$ & $\begin{array}{l}\text { Ceiling } \\
\text { Height } \\
\text { (m) }\end{array}$ & $\begin{array}{l}\text { Floor } \\
\text { Height } \\
\text { (m) }\end{array}$ \\
\hline 1 & 9.10 & 5.00 & 4.60 & 45.50 & 209.30 & 4.60 & $\odot . \odot \odot$ \\
\hline
\end{tabular}

- Values for width, depth, height, and floor height come directly from the WIDTH, DEPTH, HEIGH, and HI/F specifications in the input data file.

- Area is calculated as width $\mathrm{x}$ depth in $\mathrm{m}^{2}$.

- Volume is calculated as width $\mathrm{x}$ depth $\mathrm{x}$ height in $\mathrm{m}^{3}$.

- Floor height is the absolute elevation of the ceiling of the compartment and is just station elevation (from the ambient conditions section) + compartment height in $\mathrm{m}$. 
Vent Connections: Vent connections further divides into three distinct parts. Each part has its own sub heading. A description of each follows.

Horizontal Natural Ventilation is the first table in the vent connections sections. Each row in the table characterizes one vent. The first two columns contain the two compartments connected by the vent. Each vent is ordered first by the lower number of the two compartments and then the numeric order of the second compartment. The third column gives the vent number. Column four is the width of the vent. The next two columns report the sill and soffit height for the vent relative to the floor of the first compartment. The seventh and eighth columns have a second listing of the sill and soffit height, this time relative to the station height. Area of the vent is in the last column.

VENT CONNECTIONS

\begin{tabular}{|c|c|c|c|c|c|c|c|c|}
\hline $\begin{array}{l}\text { From } \\
\text { Compartment }\end{array}$ & $\begin{array}{l}\text { To } \\
\text { Compartment }\end{array}$ & $\begin{array}{l}\text { Vent } \\
\text { Number }\end{array}$ & $\begin{array}{l}\text { Width } \\
\text { (m) }\end{array}$ & $\begin{array}{l}\text { Sill } \\
\text { Height } \\
\text { (m) }\end{array}$ & $\begin{array}{l}\text { Soffit } \\
\text { Height } \\
\text { (m) }\end{array}$ & $\begin{array}{l}\text { Abs. } \\
\text { Sill } \\
\text { (m) }\end{array}$ & $\begin{array}{l}\text { Abs. } \\
\text { Soffit } \\
\text { (m) }\end{array}$ & $\begin{array}{l}\text { Area } \\
\left(m^{\wedge} 2\right)\end{array}$ \\
\hline 1 & Outside & 1 & 2.40 & 0.00 & 1.00 & 0.00 & 1.00 & 2.40 \\
\hline
\end{tabular}

- From compartment, to compartment, vent number, width, sill height, and soffit height all come directly from the HVENT specifications in the input data file.

- Absolute sill height and absolute soffit height is the station elevation + compartment floor height + sill height. Absolute soffit height and absolute soffit height is the station elevation + compartment floor height + soffit height

Vertical Natural Ventilation prints out in a similarly simple table. Again each vent is one row of the table. The first column is the upper compartment. The upper compartment is the compartment where the vent opens into the floor. The second column is the lower compartment where the vent is in the ceiling. The third column describes the shape of the vent, which can be either round or square. The fourth column gives the area of the vent. The last two columns are the height of the vent, relative to the floor of the lower room and relative to the station height respectively.

This is the output from STANDARD.DAT

There are no vertical natural flow connections

There are no mechanical flow connections

This is an alternate example that includes a vertical flow connection from TESTVVENT.DAT 


\begin{tabular}{|c|c|c|c|c|c|}
\hline $\begin{array}{l}\text { Top } \\
\text { Compartment }\end{array}$ & $\begin{array}{l}\text { Bottom } \\
\text { Compartment }\end{array}$ & Shape & $\begin{array}{l}\text { Area } \\
\left(m^{\wedge} 2\right)\end{array}$ & $\begin{array}{l}\text { Relative } \\
\text { Height } \\
(\mathrm{m})\end{array}$ & $\begin{array}{l}\text { Absolute } \\
\text { Height } \\
(\mathrm{m})\end{array}$ \\
\hline 2 & 1 & Round & 0.10 & 2.30 & 2.30 \\
\hline
\end{tabular}

which shows a circular hole in the ceiling of area $0.1 \mathrm{~m}^{2}$.

- Top compartment, bottom compartment, shape, and area come from the VVENT specifications in the input data file.

- Relative height is the height of the vent above the floor of the bottom compartment and absolute height is the height of the vent above the station elevation.

Mechanical Flow Connections uses two tables. The first table lists all the connections to compartments and ducts. Each row is either a connection or duct. The first column tells to which system the duct or connection belongs. A system is a set of continuously linked connections, ducts and fans. The example contains only one system. If a second system had been part of the file, a line would have been skipped before starting into the second system. The second and fourth columns give both ends of either the connection or duct. The words "comp" or "node" proceeds the numbers in these two columns. "Comp" means a compartment number. Rows with a compartment number in either the "from" or "to" columns are connections to compartments, which are basically vents. The rest of the rows define ducts. The third and fifth columns give the elevations of the proceeding columns. The sixth column is the length which only applies to ducts. Connections do not have a length so the column is left blank. Next comes the cross sectional area. The last column tells the absolute roughness. This value is the resistance the duct provides to the flow of air. Like the length, this value only has meaning for a duct so it is blank for a connection. Air flows both ways though connections and ducts. The headers "from" and "to" say nothing about the direction of air flow. The headers only provide a convenient way of listing both ends of a duct or connection.

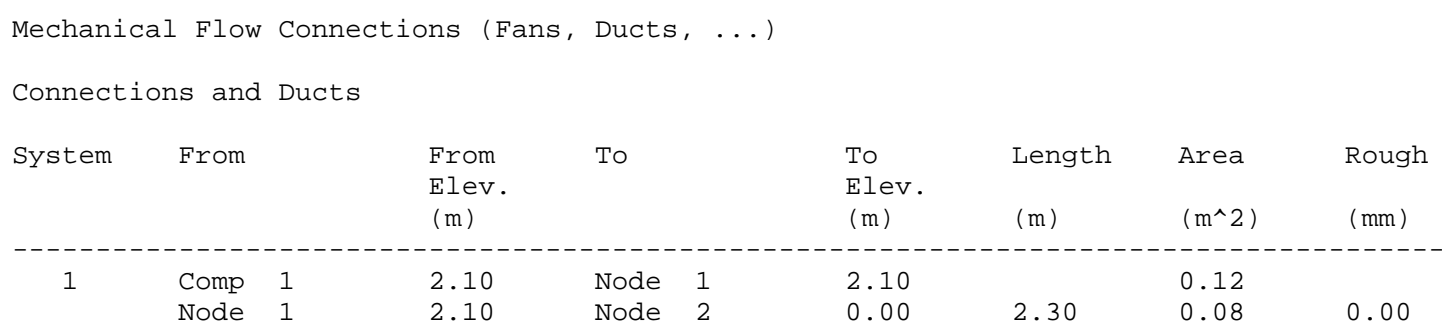

The second table lists the fans. The first five columns in the fan table appear almost the same as the connections and ducts table. The table lists, in order, the number of the system the fan is a part, the "from" node and its height, the "to" node and its height. A fan actually draws air from the first or "from" node and pushes it to the second or "to" node. In the second table, the headers give the direction of the flow of air. The sixth column is the fan number as defined in CEdit. The next two columns are the minimum and maximum pressures at which 
the fan curve is defined. The rest of the row is made up of the two to five fan curve coefficients in the input file.

\begin{tabular}{|c|c|c|c|c|c|c|c|c|c|}
\hline System & From & & $\begin{array}{l}\text { From } \\
\text { Elev. } \\
\text { (m) }\end{array}$ & To & $\begin{array}{l}\text { To } \\
\text { Elev. } \\
\text { (m) }\end{array}$ & $\begin{array}{l}\text { Fan } \\
\text { Number }\end{array}$ & $\begin{array}{l}\text { Minimum } \\
(\mathrm{Pa})\end{array}$ & $\begin{array}{l}\text { Maximum } \\
(\mathrm{Pa})\end{array}$ & Fan Curve \\
\hline \multirow[t]{2}{*}{$\frac{1}{4.33 E-04}$} & Node & 2 & 0.00 & Node 3 & 2.10 & 1 & 0.00 & 300.00 & 0.14 \\
\hline & Node & 3 & 2.10 & Outside & 2.10 & & 0.12 & & \\
\hline
\end{tabular}

Thermal Properties The thermal properties section brakes into two parts. The first part is a table that lists the material for each surface of each compartment. The compartments appear as rows down the page in numerical order. From left to right next to the compartment number comes the material for the ceiling, wall and floor. The second part lists the entries in the thermal data base. The first line gives the database file used. Next comes a listing of each material used. In addition to materials for compartment surfaces, any materials specified for targets are also listed. For each listing of a material, the name is followed by the conductivity, specific heat, density, thickness and emissivity. Additionally, the $\mathrm{HCl}$ constants used to calculate the $\mathrm{HCl}$ deposition for the surface are displayed.

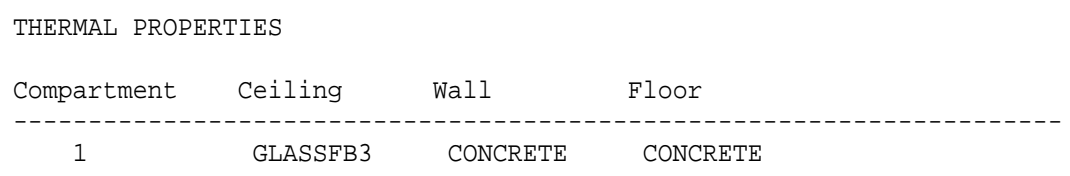

Thermal data base used: THERMAL.CSV

\begin{tabular}{|c|c|c|c|c|c|c|c|c|}
\hline Name & Conductivity & Specific heat & Density & Thickness & Emissivity & \multicolumn{3}{|c|}{ HCL B'S $(1->5)$} \\
\hline GLASSFB3 & $3.600 \mathrm{E}-02$ & 795. & 105. & $1.300 \mathrm{E}-02$ & 0.900 & $0.00 \mathrm{E}+00$ & $0.00 E+00$ & ๑. .००E+००... \\
\hline CONCRETE & 1.75 & 1. $000 \mathrm{E}+03$ & $2.200 \mathrm{E}+03$ & 0.150 & 0.940 & $\odot .00 \mathrm{E}+00$ & $0.00 E+00$ & $\odot .00 \mathrm{E}+\odot \odot \ldots$ \\
\hline PLYWOOD & 0.120 & $1.215 \mathrm{E}+03$ & 545. & $1.300 \mathrm{E}-02$ & 0.900 & $\odot .00 \mathrm{E}+0 \odot$ & $0.00 \mathrm{E}+0 \odot$ & $0.00 \mathrm{E}+00 \ldots$ \\
\hline
\end{tabular}

- Material choices of the ceiling, walls, and floors come from the CEILI, WALLS, and FLOOR specifications in the input data file.

- Materials properties for the chosen materials come from the specified thermal properties file.

- Units for thermal properties are standard S.I. units. For thermal conductivity, $\mathrm{W} / \mathrm{m} \mathrm{K}$; for specific heat, $\mathrm{J} / \mathrm{kg} \mathrm{K}$; for density, $\mathrm{kg} / \mathrm{m}^{3}$; for thickness, m; emissivity is dimensionless.

Targets: The entry for targets shows the orientation of additional targets specified in the data file. Note that the first two are always present. The third one is the target specified in the data file. Each target is numbered based on the order of the target specifications in the input data file. The compartment number, position of the target within the compartment, direction of the front face of the target object expressed as a normal unit vector to the surface, and object material. 
TARGETS

\begin{tabular}{|c|c|c|c|c|c|c|c|c|}
\hline Target & Compartment & Posit & $(x$, & & Dire & $(x$, & z) & Material \\
\hline 1 & 1 & 2.20 & 1.88 & 2.34 & $\odot . \odot \odot$ & $0.0 \odot$ & 1.00 & CONCRETE \\
\hline 2 & 1 & 2.15 & 1.65 & $\odot . \odot \odot$ & -1.00 & $0.0 \odot$ & $0.0 \odot$ & PLYWOOD \\
\hline 3 & 1 & 2.50 & 4.55 & 0.00 & $\odot . \odot \odot$ & 0.00 & 1.00 & CONCRETE \\
\hline
\end{tabular}

- All of the inputs for targets come from the TARGE command in the input data file. Direction is specified as a unit vector as described in the section on target input.

- Units for position and direction are all in $\mathrm{m}$.

Fires: The fire section lists all the information about the main fire and any object fires that might exist. All the information for each fire is listed separately. If there is a main fire, it comes first. Each fire listing has the same form. First is the name of the fire followed by a list of general information. Listed left to right is the compartment the fire is in, the type of fire, the $\mathrm{x}, \mathrm{y}, \mathrm{z}$ position, the relative humidity, the lower oxygen limit, and finally the pyrolysis temperature. A table of time history curves for the fire follows. The table contains all the time history curves for the fire. Each row on the table is a specific time given in the left most column. The rest of the columns give the values at that particular time. The column headers are keywords used in the datafile. The keyword meanings are: fmass is pyrolysis rate; hcomb is heat of combustion; fqdot is heat release rate; fhigh is height of fire; $\mathrm{C} / \mathrm{CO} 2$ is carbon to carbon dioxide ratio; $\mathrm{CO} / \mathrm{CO} 2$ is the carbon monoxide to carbon dioxide ratio; $\mathrm{H} / \mathrm{C}$ is the hydrogen to carbon ratio; $\mathrm{O} / \mathrm{C}$ is the oxygen to carbon ratio; $\mathrm{HCN}$ is the hydrogen cyanide production rate; and $\mathrm{HCl}$ is the hydrogen chloride production rate.

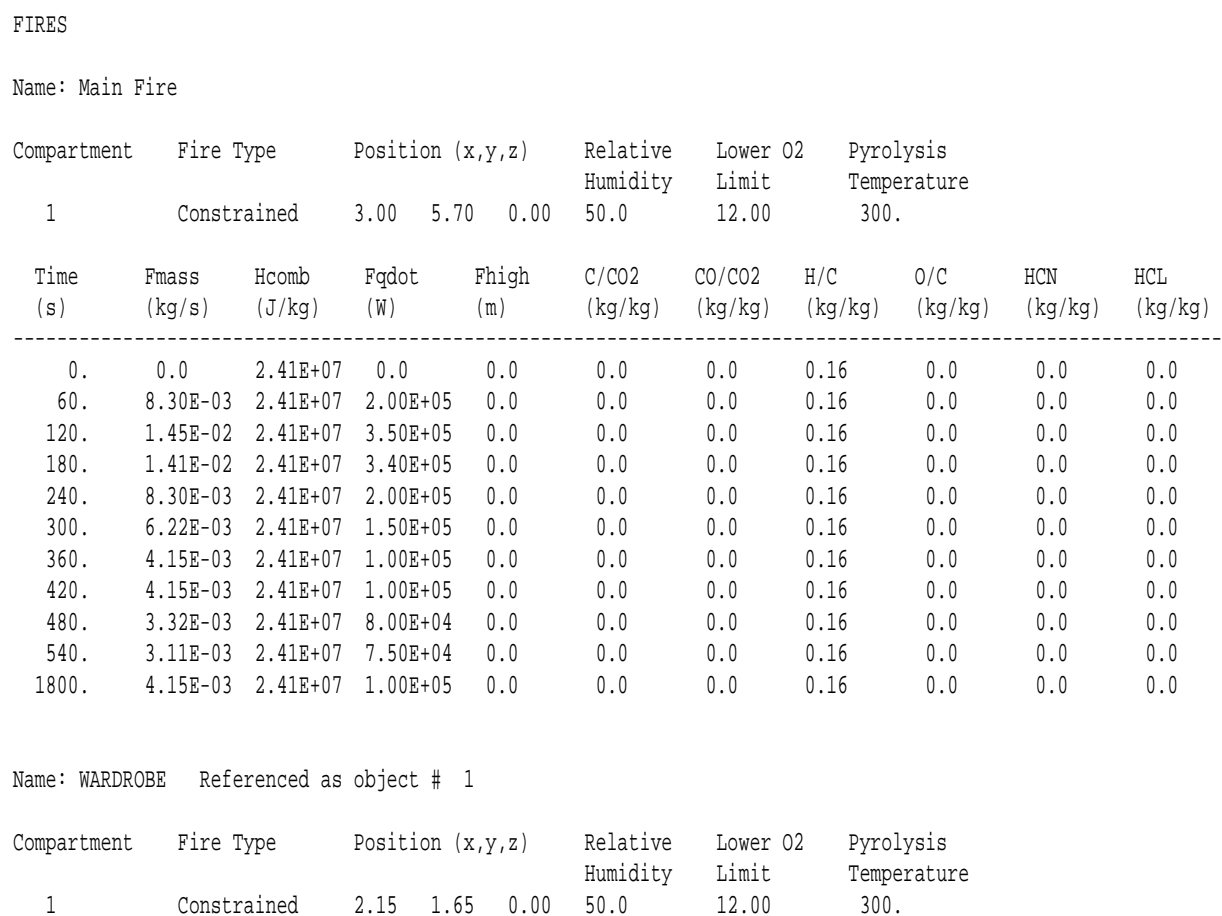




\begin{tabular}{|c|c|c|c|c|c|c|c|c|c|c|}
\hline $\begin{array}{l}\text { Time } \\
\text { (s) }\end{array}$ & $\begin{array}{l}\text { Fmass } \\
(\mathrm{kg} / \mathrm{s})\end{array}$ & $\begin{array}{l}\text { Hcomb } \\
(\mathrm{J} / \mathrm{kg})\end{array}$ & $\begin{array}{l}\text { Fqdot } \\
\text { (W) }\end{array}$ & $\begin{array}{l}\text { Fhigh } \\
(\mathrm{m})\end{array}$ & $\begin{array}{l}\mathrm{C} / \mathrm{CO} 2 \\
(\mathrm{~kg} / \mathrm{kg})\end{array}$ & $\begin{array}{l}\mathrm{CO} / \mathrm{CO} 2 \\
(\mathrm{~kg} / \mathrm{kg})\end{array}$ & $\begin{array}{l}\mathrm{H} / \mathrm{C} \\
(\mathrm{kg} / \mathrm{kg})\end{array}$ & $\begin{array}{l}0 / \mathrm{C} \\
(\mathrm{kg} / \mathrm{kg})\end{array}$ & $\begin{array}{l}\text { HCN } \\
(\mathrm{kg} / \mathrm{kg})\end{array}$ & $\begin{array}{l}\mathrm{HCL} \\
(\mathrm{kg} / \mathrm{kg})\end{array}$ \\
\hline 0. & 0.0 & $1.59 E+06$ & 0.0 & 0.0 & 0.0 & 0.0 & 0.33 & 0.0 & 0.0 & 0.0 \\
\hline 70. & $3.14 \mathrm{E}-02$ & $1.59 E+06$ & $5.00 E+04$ & 0.0 & $1.60 E-02$ & 0.23 & 0.33 & 0.0 & 0.0 & 0.0 \\
\hline 100. & $8.17 \mathrm{E}-02$ & $1.59 \mathrm{E}+06$ & 1. $30 E+05$ & 0.0 & $1.90 E-02$ & 0.13 & 0.33 & 0.0 & 0.0 & 0.0 \\
\hline 140. & 0.33 & $1.59 E+06$ & $5.30 E+05$ & 0.0 & $4.00 E-03$ & $9.00 E-03$ & 0.33 & 0.0 & 0.0 & 0.0 \\
\hline 190. & $1.57 \mathrm{E}-02$ & $1.59 E+06$ & $2.50 E+04$ & 0.0 & 0.0 & $1.60 \mathrm{E}-02$ & 0.33 & 0.0 & 0.0 & 0.0 \\
\hline 200. & $3.77 \mathrm{E}-02$ & $1.59 E+06$ & $6.00 E+04$ & 0.0 & 0.0 & $3.10 E-02$ & 0.33 & 0.0 & 0.0 & 0.0 \\
\hline 340. & $1.57 \mathrm{E}-02$ & $1.59 \mathrm{E}+06$ & $2.50 E+04$ & 0.0 & 0.0 & $6.30 E-02$ & 0.33 & 0.0 & 0.0 & 0.0 \\
\hline 1170. & $3.10 E-03$ & $1.61 E+06$ & $5.00 E+03$ & 0.0 & 0.0 & 0.0 & 0.33 & 0.0 & 0.0 & 0.0 \\
\hline
\end{tabular}

- All of the inputs for the main fire come from the fire specifications in the input data file. Data for the object fire comes from the object data file included with the CFAST software.

- Units for most values are included in the output. Fire position is in $\mathrm{m}$, relative humidity is in \%, lower oxygen limit is in volume percent, and pyrolysis temperature is in $\mathrm{K}$.

\section{Output for Main Output Variables}

An expanded version of the compact default output called the normal print out can be obtained using the /f option. When requested, the normal print out is the first information printed at each interval. The first part of the print out looks similar to the default print out. It is laid out along the same lines, with the calculated values for each compartment listed left to right and compartments listed down. The left most column has the compartment. The next three columns also give the same values as the default output. They are upper layer temperature, lower layer temperature and interface height. The output changes at this point. The fifth column gives the upper layer volume. In the sixth, in parenthesis, is the percent of the total compartment volume the upper layer takes up. The pressure difference from ambient follows in the seventh column. The rest of the columns are the temperature of the bounding surfaces in $\mathrm{K}$.

Time $=1800.0$ seconds .

\begin{tabular}{|c|c|c|c|c|c|c|c|c|c|}
\hline Compartment & $\begin{array}{l}\text { Upper } \\
\text { Temp. } \\
\text { (K) }\end{array}$ & $\begin{array}{l}\text { Lower } \\
\text { Temp. } \\
\text { (K) }\end{array}$ & $\begin{array}{l}\text { Inter. } \\
\text { Height } \\
\text { (m) }\end{array}$ & $\begin{array}{l}\text { Upper } \\
\text { Vol. } \\
\left(m^{\wedge} 3\right)\end{array}$ & $\begin{array}{l}\text { Upper } \\
\text { Absorb } \\
\left(m^{\wedge}-1\right)\end{array}$ & $\begin{array}{l}\text { Lower } \\
\text { Absorb } \\
\left(m^{\wedge}-1\right)\end{array}$ & $\begin{array}{c}\text { Pressure } \\
(\mathrm{Pa})\end{array}$ & $\begin{array}{l}\text { Ambient } \\
\text { Target } \\
\left(\mathrm{W} / \mathrm{m}^{\wedge} 2\right)\end{array}$ & $\begin{array}{l}\text { Floor } \\
\text { Target } \\
(\mathrm{W} / \mathrm{m} \wedge 2)\end{array}$ \\
\hline 1 & 377.0 & 303.8 & 0.7236 & $1.76 \mathrm{E}+02(84 \%)$ & $1.000 \mathrm{E}-02$ & $1.000 \mathrm{E}-0$ & $2-9.483 E-02$ & 437. & 335. \\
\hline
\end{tabular}

The second table of the normal print out has information about the fires. In essence it is two tables joined. The first part lists information by fire. It starts with the main fire, if there is one, and then the object fires down the page. The fires are listed in the second column followed by the plume flow rate, the pyrolysis rate and the fire size. The next three columns are then skipped. The next column with information is the amount of heat given off by each fire convectively, followed by the amount of heat given off radiantly. The second part starts after all the fires have been individually listed. It gives the totals for all fires in each 
compartment. The first column has the compartment number. The compartments start at one and are listed down the page in order. The third to fifth columns are the same as the first part except the values are totals for the compartment and not just for one fire. The sixth column has the total heat release rate that occurs in the upper layer. The next column has the same total in the lower layer. The eighth column has the total size of vent fires in the compartment. The last two columns of the table gives the convective and radiative parts of the fire heat release.

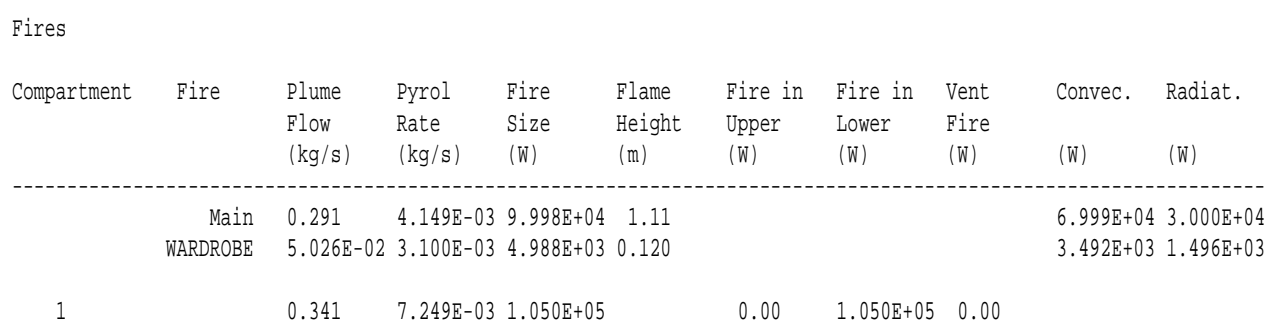

- Flame height is calculated from the work of Heskestad ${ }^{22}$ Valid for a wide range of hydrocarbon and gaseous fuels, the correlation is given by

$$
H=-1.02+0.23 Q_{f}^{2 / 5}
$$

where $\mathrm{H}$ is the average flame height and Qf is the fire size. The mean flame height is defined as the distance from the fuel source to the top of the visible flame where the intermittency is 0.5. A flame intermittency of 0.5 means that the visible flame is above the mean $50 \%$ of the time and below the mean $50 \%$ of the time.

\section{Output for Wall Surface and Targets}

The /f option provides two tables displaying information about wall surface or target temperatures and fluxes, and heat detectors or sprinklers. The left most column specifies the compartment number; followed by four columns providing the temperatures of the bounding surfaces of the compartment in contact with the ceiling, upper wall surface (in contact with the upper layer gases), lower wall surface (in contact with the lower layer gases), and floor, in that order. Next comes information about targets in the compartment, with each target listed on a separate line. Information in the columns includes the surface temperature of the target, net heat flux to the target, and the percentage of that net flux that is due to radiation from the fire, radiation from compartment surfaces, radiation from the gas layers, and convection from the gas surrounding the target. CFAST includes one target in the center of the floor for all compartments. Information on additional targets specified by the user in the input data file are also included, in the order specified in the input file. 


\begin{tabular}{|c|c|c|c|c|c|c|c|c|c|c|c|}
\hline Compartment & $\begin{array}{l}\text { Ceiling } \\
\text { Temp. } \\
(\mathrm{K})\end{array}$ & $\begin{array}{l}\text { Up wall } \\
\text { Temp. } \\
\text { (K) }\end{array}$ & $\begin{array}{l}\text { Low wall } \\
\text { Temp. } \\
\text { (K) }\end{array}$ & $\begin{array}{l}\text { Floor } \\
\text { Temp. } \\
(\mathrm{K})\end{array}$ & Target & $\begin{array}{l}\text { Target } \\
\text { Temp. } \\
\text { (K) }\end{array}$ & $\begin{array}{l}\text { Flux To } \\
\text { Target } \\
(\mathrm{W} / \mathrm{m} \wedge 2)\end{array}$ & $\begin{array}{l}\text { Fire } \\
\text { Rad. } \\
(\%)\end{array}$ & $\begin{array}{l}\text { Surface } \\
\text { Rad. } \\
(\%)\end{array}$ & $\begin{array}{l}\text { Gas } \\
\text { Rad. } \\
(\%)\end{array}$ & $\begin{array}{c}\text { Convect. } \\
(\%)\end{array}$ \\
\hline 1 & 339.2 & 312.3 & 306.3 & 310.8 & $\begin{array}{c}\text { Floor } \\
1 \\
2\end{array}$ & $\begin{array}{l}311 . \\
320 . \\
367 .\end{array}$ & $\begin{array}{l}863.4 \\
1318 . \\
647.8\end{array}$ & $\begin{array}{l}0.0 \\
0.0 \\
0.0\end{array}$ & $\begin{array}{r}27.9 \\
7.7 \\
25.9\end{array}$ & $\begin{array}{r}74.7 \\
71.7 \\
120.5\end{array}$ & $\begin{array}{r}-2.6 \\
20.6 \\
-46.4\end{array}$ \\
\hline
\end{tabular}

The second table provides information about heat detectors and sprinklers included in the input data file. For each output time, the output includes the sensor temperature, whether the sensor temperature has exceeded its specified activation temperature, and the temperature and velocity of the gas adjacent to the sensor. For sensors placed near the ceiling of a compartment with a fire, the temperature and velocity are those of the ceiling jet; for other compartments, it is the upper layer temperature and a default velocity of $0.1 \mathrm{~m} / \mathrm{s}$.

Sensors

\begin{tabular}{|c|c|c|c|c|c|c|}
\hline & & & Sensor & & \multicolumn{2}{|c|}{ Smoke } \\
\hline Number & Compartment & Type & Temp (K) & Activated & Temp (K) & Vel (M/S) \\
\hline 1 & 1 & HEAT & $3.149 \mathrm{E}+0$ & YES & $3.136 \mathrm{E}+02$ & $4.152 \mathrm{E}-01$ \\
\hline
\end{tabular}

- Temperatures are all in $\mathrm{K}$, fluxes in $\mathrm{w} / \mathrm{m}^{2}$, and velocities in $\mathrm{m} / \mathrm{s}$.

- In all cases, the flux to/from a target is net radiation or net convection. That is, it is the incoming minus the outgoing. So while a target or object is heating, the flux will be positive, and once it starts to cool, the flux will be negative.

- Values for radiation from fires (fire rad.), radiation from surfaces (surface rad.), radiation from the gas layers (gas rad.), and convection from surfaces (convect) are expressed as a percentage of the net flux to target (flux to target). Positive values indicate heat gains by the target and negative values indicate heat losses.

\section{Output for Gas Species}

The /f option has two tables displaying information about the amounts of species in each layer. The species information follows the normal print out. The first table gives species concentrations for the upper layers of all the compartments and the second reports the same for the lower layers of all the compartments. Again the compartments are listed down the page and the information across the page. The species are each given in one of several different terms. Below each header is the units for the given value. Most of the headers are simply the chemical formula for the species being tracked. However, a couple are not obvious. "TUHC" is the total unburned hydrocarbons or the pyrolyzed fuel that hasn't burned yet. "OD" is the obscuration density, which is a measure of the amount of smoke. The last four columns, "HCl c", "HCl f", "HCl uw" and "HCl lw", are the amount of $\mathrm{HCl}$ deposition on the ceiling, floor, upper wall and lower wall respectively. 


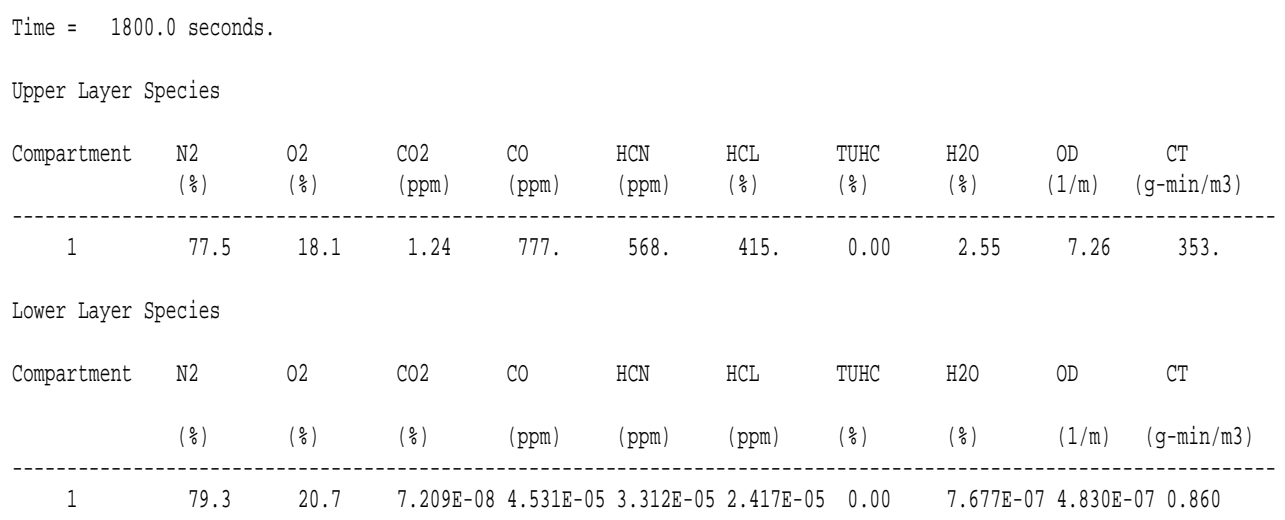

- The report by species for nitrogen, oxygen, hydrogen chloride and the total unburned hydrocarbons (fuel vapor in the layer) are percent by volume. Carbon dioxide, carbon monoxide and hydrogen cyanide are in parts per million, which is also a volume fraction. Optical depth per meter is a measure of the visibility in the smoke. This is covered in detail in the comment on visibility in the section on fires and species specification. The concentration-time (CT) calculation is an integration of the species input for type CT (See section for the input of CT) and is intended to represent a relative dose of toxic gas species ${ }^{23}$

\section{Output for Vent Flows}

Information about hallway and vent flow is obtained by using this option. It includes two sections, one with information about hallway flow specified with the HALL command, and a larger section detailing mass flow through horizontal, vertical, and mechanical vents. For hallway flow, the output begins with the compartment specified as a hallway in the input data file, followed by the time at which gas began to flow into the hallway through the vent that connects the hallway to the main fire compartment. Following the start time are the average gas velocity, the layer depth of the initial flow down the corridor, and the distance from the end of the corridor that the hot layer is estimated to have reached.

Hall Flow

\begin{tabular}{ccccc} 
Compartment & $\begin{array}{c}\text { Start Time } \\
(\mathrm{s})\end{array}$ & $\begin{array}{c}\text { Velocity } \\
(\mathrm{m} / \mathrm{s})\end{array}$ & $\begin{array}{c}\text { Depth } \\
(\mathrm{m})\end{array}$ & $\begin{array}{c}\text { Distance } \\
(\mathrm{m})\end{array}$ \\
\hline 3 & 2.59 & 1.69 & 0.573 & 32.3
\end{tabular}

The section for vent flow is titled "Flow Through Vents (kg/s)." Because flow is always given in positive values, each vent is listed twice. Once for flow going from compartment A to compartment B and a second time for flow from B to A. As the example below shows, the first column lists the compartment. The second column specifies the vent, including the type of vent (an " $\mathrm{H}$ " in this column stands for horizontal flow, such as through a doorway or window; a "V" here would mean vertical flow, such as through an opening in the ceiling, and an "M" stands for a mechanical ventilation connection) and the compartment from which the flow comes. Up to six additional columns detail the flow at this vent. Flow into and out of the compartment through the vent in the upper and lower layers are included, along with mixing between layers at the vent into the upper layer and into the lower layer. 


\begin{tabular}{|c|c|c|c|c|c|c|c|}
\hline \multirow{2}{*}{$\begin{array}{l}\text { To } \\
\text { Compartment }\end{array}$} & \multirow{2}{*}{$\begin{array}{l}\text { Through } \\
\text { Vent }\end{array}$} & \multicolumn{2}{|c|}{ Upper Layer } & \multicolumn{2}{|c|}{ Lower Layer } & \multirow{2}{*}{$\begin{array}{l}\text { Mixing } \\
\text { To Upper }\end{array}$} & \multirow{2}{*}{$\begin{array}{l}\text { Mixing } \\
\text { To Lower }\end{array}$} \\
\hline & & Inflow & outflow & Inflow & Outflow & & \\
\hline 1 & H Outside \#1 & & 0.344 & 0.401 & $6.416 \mathrm{E}$ & & \\
\hline Outside & H Comp $1 \# 1$ & 0.344 & & 6.416 & 0.401 & & \\
\hline
\end{tabular}

- The mass balance is the sum of the flow in minus the flow out. (Note that this is an extended run to achieve results close to steady state.) For any compartment, this is just ("Upper Layer Inflow" + "Lower Layer Inflow" + "Pyrol Rate") ((Upper Layer Outflow + Lower Layer Outflow) with the inflow and outflow summed for each vent. Note that the mixing flows are ignored since they are just exchanged between layers in the same compartment. For the above example, the mass balance is:

$$
\left(0.0+0.401+7.2 \times 10^{-3}\right) \mathrm{kg} / \mathrm{s}-\left(0.344+6.4 \times 10^{-2}\right) \mathrm{kg} / \mathrm{s}=-0.002 \mathrm{~kg} / \mathrm{s}
$$

where the pyrolysis rate (from the"normal” output) is $7.2 \times 10-3 \mathrm{~kg} / \mathrm{s}$. The result is about the right magnitude (about $0.5 \%$ of the mass flow into or out of the vent) for net mass loss. The mass loss should still be slightly negative since the compartment continues to heat.

\section{Spreadsheet Output}

A very important note for interpreting the spreadsheet output. These files capture a snap shot of the modeling data at an instant of time. This instance is determined by the fourth entry on the TIMES line of the data file. HOWEVER, there are events which can occur in between these reporting periods. Examples are the ignition of objects and the activation of detectors or sprinklers. These are NOT reported in these output files.

\section{Primary Output Variables (project.n.csv)}

There are two sets of information. The first is the compartment information such as layer temperature. This is output by compartment and there are seven entries for each compartment:

'Upper Layer Temp', 'Lower Layer Temp', 'Layer Height', 'Volume', 'Pressure', 'Ambient Target', 'Floor Target'/

The second section is for fires. There are five entries per fire. This information is displayed for each fire ( 0 to numobjl)

'Plume flow', 'Pyrolysis rate', 'Fire Size', 'Flame Height', 'Convective flow' 
The units of flow are kg/s, fire size in Watts, temperatures in Kelvin, pressure in Pascals and flux in $\mathrm{W} / \mathrm{m}^{2}$.

\section{Species Output (project.s.csv)}

At present, the eight species, oxygen (O2), carbon dioxide (CO2), carbon monoxide (CO), hydrogen cyanide (HCN), hydrogen chloride (HCL), water vapor (H2O), optical depth (OD), and concentration-time dose (CT) are listed. This set of eight is enumerated for each compartment, and are done sequentially by compartment.

There will be N-1 (number of interior compartments) instances of

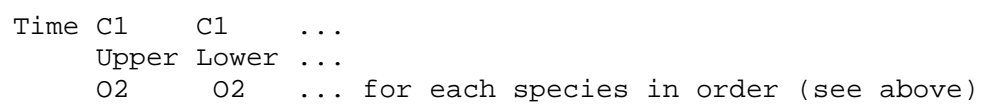

The units are $\mathrm{O} 2$ in \%, CO2 in \%, CO in ppm, $\mathrm{HCN}$ in ppm, HCL in ppm, $\mathrm{H} 2 \mathrm{O}$ in \%, OD in $1 / \mathrm{m}, \mathrm{CT}$ in g-min $/ \mathrm{m}^{3}$.

\section{Vent Flow (project.f.csv)}

First is the horizontal flow through vertical vents such as windows and doors. There are two types of output, first to and from the outside, and second for interior compartments. The flow is broken down to flow in and out of the compartments. For flow to and from the outside (compartment $\mathrm{N}$ ) there are two entries. For interior compartments, there are additional entries for entrainment into the upper and lower layers. Please see the technical reference guide for a detailed description of these flow fields.

Second is the vertical flow through horizontal vents. There are two entries for each compartment, showing the total flow into or out of the compartment.

Third is the mechanical ventilation. Once again, there will be an entry for each node/compartment pair, showing the total flow into or out of the compartment through this node.

An example of horizontal flow for two compartments is

'Time', 'Inflow from 2 to 1', 'Outflow to 2 from 1', 'Mixing to Upper 1 ( 2 )', 'Mixing to Lower 1 ( 2 )'

and for vertical flow

$\checkmark$ outflow from 1 to out, $V$ Inflow from 1 to out 
and for mechanical ventilation

'MV Inflow to 1', 'MV Outflow from 1'

\section{Temperatures and flux (project.w.csv)}

This spreadsheet provides information on surface and target temperatures and flux, and reports on the current state of detectors and sprinklers (as a sub-set of detectors). Flux is reported in Watts/m2, and temperature in Kelvin. Activation of a detector is binary (yes or no). Velocity is in $\mathrm{m} / \mathrm{s}$.

The first line in the spreadsheet is the compartment name or detector number, followed by the second line which is the measure being reported.

'Time' 'burn_room' 'burn_room' 'burn_room' 'burn_room' 'burn_room' ...'
'ceiling'
'upper wall' 'lower wall' 'floor'

Following the compartment and target information is the detector output. The decoding for the type is 1 for a smoke detector, 2 for heat detector and 3 for other. In the activation column, 1 is yes and 2 is no. There will be a set of 10 columns for each compartment following this format.

\section{Error Messages}

In some (hopefully rare) cases, a simulation will fail to complete. In those cases, an error message provides guidance to the user on possible reasons for the failure. The message will contain an error number which provides a reference to additional information from the table below. Most often, these errors result from improper information in the input data files.

During initialization of the program for a simulation, CFAST may stop with an error message if the simulation cannot be initialized due to a missing or incorrect file specification. The error codes are as follows:

- 100 program called with no arguments (no input file)

- 101 code for a free burning fire should not be reachable

- 102 project file does not exist

- 103 total file name length including path is more than 256 characters

- 104 one of the output files is not accessible (for example, if a cfast case with this name is already running) 
- 105 error writing to an output file (openoutputfiles)

- 106 a system fault has occurred. Applies to all open/close pairs once the model is running

- 107 incompatible options

- 108 not used

- 109 cannot find/open a file

- 110 error in handling the status input/output

Error codes from 1 to 99 are from the routine which parses the input and will be reported in the .log file. The first set indicates a command with the wrong number of arguments. These errors indicate an error in a particular input command as follows:

- Code 1, TIMES command

- Code 2, TAMB command

- Code 3, EAMB command

- Code 4, LIMO2 command

- Code 5, THERMAL or OBJECT commands

- Code 7, MAINF command

- Code 8, COMPA command

- 10, HVENT command

- 11, EVENT command

- 12, MVENT command

- 23, VVENT command

- 24, WIND command

- 25, INTER command

- 26, MVOPN command

- 28, MVDCT command

- 29, MVFAN command

- 32, OBJECT command

- 34, CJET and DETEC command

- 35, STPMAX command

- 37, VHEAT command

- 39, ONEZ command

- 41, TARGE command 
- 46, HALL command

- 47, ROOMA command

- 51, ROOMH command

- 55, DTCHE command

- 56, SETP command

- 58, HHEAT command

- 65, HEATF command

The second set of errors related to parsing the input indicate specific errors with a command as follows:

\begin{tabular}{|c|c|c|}
\hline $\begin{array}{l}\text { Error } \\
\text { Code }\end{array}$ & $\begin{array}{l}\text { CFAST } \\
\text { Command }\end{array}$ & Error \\
\hline 9 & compa & Compartment out of range \\
\hline 26 & inter & Not a defined compartment \\
\hline 27 & mvopn & Specified node number too large for this system \\
\hline 30 & mvfan & Fan curve has incorrect specification \\
\hline 31 & & Exceeded allowed number of fans \\
\hline 33 & object & Object must be assigned to an existing compartment \\
\hline 35 & detect & Invalid DETECTOR specification \\
\hline 36 & & A referenced compartment is not yet defined \\
\hline 38 & vheat & VHEAT has specified a non-existent compartment \\
\hline 42 & target & Too many targets are being defined \\
\hline 43 & & The compartment specified by TARGET does not exist \\
\hline 44 & & Invalid TARGET METHOD \\
\hline 45 & & Invalid equation type specified in TARGET \\
\hline 49 & rooma & Compartment specified by ROOMA does not exist \\
\hline 52 & roomh & Compartment specified by ROOMH is not defined \\
\hline 53 & & ROOMH error on data line \\
\hline 54 & & Data on the ROOMA (or $\mathrm{H}$ ) line must be positive \\
\hline 57 & setp & Trying to reset the SETP parameters \\
\hline 61 & hheat & HHEAT specification error in compartment pairs \\
\hline 62 & & Error in fraction for HHEAT \\
\hline 63 & & Fire type out of range \\
\hline 64 & mainf & The fire must be assigned to an existing compartment \\
\hline 66 & heatf & The heat source must be assigned to an existing compartment \\
\hline 67 & mvent & Compartment has not been defined \\
\hline 68 & & Exceed one of the array bounds, ierror=68 (external), 69 (internal) and 70 (fan) \\
\hline 71 & event & Undefined vent type \\
\hline
\end{tabular}




\begin{tabular}{||l|l|l||}
\hline $\begin{array}{l}\text { Error } \\
\text { Code }\end{array}$ & $\begin{array}{l}\text { CFAST } \\
\text { Command }\end{array}$ & Error \\
\hline \hline 72 & inter & Specification for interface height is outside of allowable range \\
\hline 73 & inter & Compartments must be defined in pairs \\
\hline 74 & setp & The requested “SETP” command does not exists \\
\hline 75 & & Incorrect file reference \\
\hline 76 & & Cannot read the parameter file \\
\hline 77 & & Unsupported parameter \\
\hline
\end{tabular}

Errors from 200 to 299 are errors which occur during data initialization as follows:

\begin{tabular}{|c|c|c|}
\hline $\begin{array}{l}\text { Error } \\
\text { Code }\end{array}$ & $\begin{array}{l}\text { CFAST } \\
\text { Command }\end{array}$ & Error \\
\hline 200 & inputmainfire & cannot find the mainfire.o file in either the data or executable directory \\
\hline 201 & inputobject & (read the object databases), too many targets being defined \\
\hline 202 & inputtpp & $\begin{array}{l}\text { (read the thermophysical database) cannot find the thermophysical properties } \\
\text { file }\end{array}$ \\
\hline 203 & & exceeded size of thermophysical properties data structure \\
\hline 204 & & data format in the thermophysical data file is not correct \\
\hline 205 & initwall & name is not defined in the thermophysical database \\
\hline 206 & readinputfile & Incorrect CFAST version specified in input data file \\
\hline 207 & readcsvfile & exceed array bounds for input (nrow) \\
\hline 208 & inputobject & exceed array bounds for object fire (nv) \\
\hline 209 & inputmainfire & exceed array bounds for object fire (nv) \\
\hline 210 & inputobject & object name requested does not match the name in the object file \\
\hline 211 & $\begin{array}{l}\text { spreadsheetnor } \\
\text { mal }\end{array}$ & exceed number of entries in normal output (maxhead) \\
\hline 212 & hvinit & fan not properly defined (mvent command) \\
\hline 213 & inittarg & target points to a non-existent compartment \\
\hline 214 & & target center out of range (outside compartment) \\
\hline 215 & inputobject & cannot find the object file in either the data or executable directory \\
\hline 216 & & normal vector cannot be zero \\
\hline
\end{tabular}

Errors 400 and above are failures while the model is running. In particular, 610 through 685 are failures when IDID $<0$ from DASSL/RESID. 


\section{References}

${ }^{1}$ Jones, W.W., Peacock, R.D., Forney, G.P., and Reneke, P.A., “CFAST - Consolidated Model of Fire Growth and Smoke Transport (Version 5), Technical Reference Guide,” National Institute of Standards and Technology, Spec. Pub. 1030 (2004).

${ }^{2}$ Gross, D., "Data Sources for Parameters Used for Predictive Modeling of Fire Growth and Smoke Spread,” National Institute of Standards and Technology, NISTIR 85-3223 (1985).

3 Jones, W.W. and Peacock, R.D., “Technical Reference Guide for FAST Version 18,” National Institute of Standards and Technology, TN 1262 (1989).

${ }^{4}$ Cooper L.Y. and Forney, G. P., "The Consolidated Compartment Fire Model (CCFM) computer application CCFM-VENTS - part I: Physical reference guide,” National Institute of Standards and Technology, NISTIR 4342 (1990).

${ }^{5}$ Peacock, R. D., Jones, W. W., Forney, G. P., Portier, R. W., Reneke, P. A., Bukowski, R. W., and Klote, J. H., “Update Guide for HAZARD I Version 1.2,” National Institute of Standards and Technology, NISTIR 5410 (1994).

${ }^{6}$ ASTM Standard Guide for Evaluating the Predictive Capability of Deterministic Fire Models, ASTM E1355-04, West Conshohocken, PA (2004).

${ }^{7}$ Forney, G.P. and McGrattan, K.B., "User's Guide for Smokeview Version 4: A Tool for

Visualizing Fire Dynamics Simulation Data.” Natl. Inst. Stand. Technol., Spec. Pub. 1017 (2004).

${ }^{8}$ U.S. Standard Atmosphere, 1976, U.S. Government Printing Office, Washington, D.C., 1976.

9 The CRC Handbook of Chemistry and Physics, David Lide, Editor, CRC Press, Boca Raton (1994).

${ }^{10}$ Klote, J.K. and Milke, J.A., Design of Smoke Management Systems, American Society of Heating, Refrigerating and Air-conditioning Engineers, Atlanta, GA (1992).

${ }^{11}$ ASHRAE Handbook HVAC Systems and Equipment, American Society of Heating, Refrigerating and Air-Conditioning Engineers, Atlanta, GA (1992).

${ }^{12}$ Klote, J. H., A Computer Model of Smoke Movement by Air Conditioning Systems, NBSIR 873657 (1987). 
${ }^{13}$ G. W. Mulholland and C. Croarkin, Specific Extinction Coefficient of Flame Generated Smoke, Fire and Materials 24, 227 (2000).

${ }^{14}$ Jin, T. , "Evaluation of Fire Exit Signs in Smoke," Systems Approach to Fire Safety in Buildings. Volume 2. Session 3. Active Systems Performance and Criteria: Smoke Control, Detection, Sprinklers. Session 4. Passive Systems Performance and Criteria: Combustibles, Fire Resistance. August 29-30, 1979, Tsukuba, Japan, III/73-78 pp, 1979.

${ }^{15}$ Drysdale, D., “An Introduction to Fire Dynamics,” John Wiley and Sons, New York, (1985).

${ }^{16}$ Tewarson, A., "Combustion of Methanol in a Horizontal Pool Configuration," Factory Mutual Research Corp., Norwood, MA, Report No. RC78-TP-55 (1978).

${ }^{17}$ McCaffrey, B.J., "Entrainment and Heat Flux of Buoyant Diffusion Flames," National Bureau of Standards (U. S.), NBS IR 82-2473 (1982).

${ }^{18}$ Koseki, H., “Combustion Properties of Large Liquid Pool Fires,” Fire Technology 25, 241 (1989).

${ }^{19}$ Babrauskas, V. and Grayson, S. J., "Heat Release in Fires” Elsevier Applied Science, London (1992).

${ }^{20}$ Evans, D. D., "Sprinkler Fire Suppression Algorithm for HAZARD,” Natl. Inst. Stand. Technol., NISTIR 5254 (1993).

${ }^{21}$ Davis, W. D. And Notarianni, K. A., “NASA Fire Detector Study,” Natl. Inst. Stand. Technol., NISTIR 5798 (1996).

${ }^{22}$ Heskestad, G., "Fire Plumes, Flame Height, and Air Entrainment" in The SFPE Handbook of Fire Protection Engineering, 3rd Ed., National Fire Protection Association (2002).

${ }^{23}$ Peacock, R. D., Jones, W. W., Bukowski, R. W., and Forney, C. L., "Technical Reference Guide for the HAZARD I Fire Hazard Assessment Method, Version 1.1,” Natl. Inst. Stand. Technol., Handbook 146 (1991). 


\section{Appendix A CFAST Keywords}

All key words are case sensitive and all parameters are required. There are no defaults. If a parameter is missing, the model will terminate with an appropriate stop code.

\section{CJET}

CJET Ceiling_Jet_Flag

This directive tells the model to calculate the effects of a ceiling jet in all compartments containing a fire. The possible flags are OFF, CEILING, WALL, or ALL.

OFF - not calculate ceiling jets effect

CEILING - include calculations for ceiling surfaces only

WALL - to include calculations for wall surfaces only (not recommended)

ALL - to include calculations for both ceiling and wall surfaces

Example:

CJET, CEILING

\section{COMPA}

COMPA Name Width Depth Internal_height Absolute_x_position Absolute_y_position Floor_Height Ceiling_Material Floor_Material_Name Wall_Material_Name

The compartments are numbered internally as they are read in. The other key words which 
refer to compartment numbers then refer to these ordinals. Compartments must be defined before they are referenced by other commands.

Example:

COMPA, hallway, $9.1,5 . \odot, 4.6, \odot ., \odot ., \odot .$, CONCRETE, CONCRETE, CONCRETE

\section{DETEC}

DETEC Type Compartment Activation_Temperature Depth Width Height RTI Suppression Spray_Density

The DETEC keyword is used for both detectors and sprinklers. Sprinklers and detectors are both considered detection devices and are handled using the same input keywords. Detection is based upon heat transfer to the detector. Fire suppression by a user-specified water spray begins once the associated detection device is activated.

For the type of detector, use 1 for smoke detector and 2 for heat detector or sprinklers. If suppression is set to a value of 1 , a sprinkler will quench the fire with the specified spray density of water. If turned off (a value of 0 ), the device is handled as a heat or smoke detector only - values entered for activation temperature, RTI, and spray density are ignored.

The spray density is the amount of water dispersed by a water sprinkler. The units for spray density are length/time. These units are derived by dividing the volumetric rate of water flow by the area protected by the water spray. The suppression calculation is based upon an experimental correlation by Evans, and depends upon the RTI, activation temperature, and spray density to determine the behavior of the sprinkler.

Example:

DETECT $, 2,1,344.2,1.5,1.5,2.29,98,1,7.00 \mathrm{-}-\odot 5$

DTCHE

DTCHE Minimum_Time Count 
The purpose of DTCHE is to prevent excessive computation with a very small time step. This often appears to users as a stalling condition, when it is simply the set of equations has reached a point that requires a very small increment in time for the solver to converge. A negative entry on DTCHECK turns off the time step checking algorithm.

Example:

DTCHECK, 1.E-9, 100

\section{EAMB and TAMB}

EAMB and TAMB Ambient_Temperature Ambient_Pressure Station_Elevation Relative_Hunidity.

This key word is to set the ambient condition, TAMB for the internal and EAMB for outside the building. For the internal ambient, relative humidity sets the initial water concentration in the ambient air. For the external ambient, it sets the water content for air flowing into compartments through vents connecting to the exterior. Temperatures are in Kelvin, pressure in Pascals, and relative humidity in percent.

Example:

EAMB $, 300,101300,0$,

TAMB , 300, $101300,0,5$

\section{EVENT}

EVENT TYPE First_Compartment Second_Compartment Vent_Number Time

Final_Fraction. The " $H$ " indicates a horizontal flow event that changes the vent opening. Final_Fraction is the percent of the full opening width expressed as a fraction.

Used to open or close a vent. This replaces CVENT and applies to all vents for vertical flow $(\mathrm{V})$, horizontal flow $(\mathrm{H})$ and mechanical flow $(\mathrm{M})$. The intent is to allow these events to be triggered by time, temperature or flux as is done with detectors. However, at the moment, time is the only option. 
The form for EVENT is

EVENT H First_Compartment Second_Compartment Vent_Number Time Final_Fraction Decay_time

EVENT V First_Compartment

Second_Compartment V_ID

Time Final_Fraction Decay_time

EVENT M First_Compartment

Second_compartment MVENT_ID

Time Final_Fraction Decay_time

Decay time is the time the event takes to happen and the units are seconds.

Example:

EVENT, H, 1, 2, 1, 10. , $0.3,1$

\section{HALL}

HALL Compartment Velocity Depth Decay_Distance

This command invokes the corridor flow algorithm. For long hallways or corridors, there can be a significant delay time for the initial hot gas layer to travel along the ceiling to the far end of the compartment. By estimating the time required for a ceiling jet to travel in a corridor and the temperature distribution along the corridor, CFAST can delay flow into compartments connected to corridors until the ceiling jet has passed the connections to these compartments.

If the aspect ratio of a compartment (length/width) is greater than about 10, this algorithm should be used.

Example:

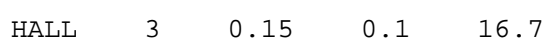

For each of the Velocity, Depth and Decay, using a value of (-1) will bypass this setting. This is so that, for example, the decay distance can be set while using default values for velocity and depth.

\section{HEATF}

HEATF ROOM POS(3) PLUME HRR 
HHEAT First_Compartment Number_of_Parts N pairs of \{Second_Compartment, Fraction\}

Used to allow heat conduction between pairs of compartments which have a contiguous vertical partition between them. There are two forms of this command. The first uses only a compartment number. In this case, the conduction connection

The first form is to use only a compartment number. In this case, CFAST will calculate the conductive heat transfer to all compartments connected to this compartment by horizontal convective flow. The second form specifies the compartments to be connected and what fraction of the compartment is connected to an adjacent compartment. This latter is particularly useful for rooms which are connected to adjacent rooms as well as hallways. The user of the model is responsible for the consistency of these pairings. The model does not check to insure that the specified compartment pairs are located next to one another.

Example:

HHEAT $1,1,2,0.5$

specifies that compartment one has one connection to compartment two and the fraction of wall surface through which heat is transferred is $1 / 2$ of the wall surface of compartment one.

\section{HVENT}

HVENT First_Compartment Second_Compartment Vent_Number Width Soffit Sill Wind_Coefficient First_Compartment_Offset Second_Compartment_Offset FACE Initial_Opening_Fraction.

Vent which allows horizontal flow of gases, through vents such as doors and windows. Compartment offsets are triplets from the compartment origin. FACE is an integer from 1 to 4 counterclockwise from the origin defining which wall face to place the vent on when visualizing with Smokeview. It doesn't affect the dynamics of the calculation, just the way it looks. The size of the opening can be modified by EVENT. This changes the Opening_Fraction from the initial value (set above) to some other value. Typical use is to start with the door open (Initial_Opening_Fraction =1) and use EVENT to close the door $($ Final_Fraction $=0)$.

Example:

HVENT, 1, 2, 1, 2.4, 1.๑, $., 0 ., 0 ., 0 ., 1,0.9$ 
INTER

INTER Initial_Interface_Height_1 Initial_Interface_Height_2 ... Initial_Interface_Height_N

This is used to set the initial interface height below the top of the compartment. A great deal of care is needed to use this, as the model has only rudimentary checks for the limits imposed (for example, the initial value must specify a height not greater than the compartment height. This does change the nature of a zone in the context of a zone model.

Example:

$\begin{array}{llll}\text { INTER } 2 & 1.2 & 3 & 2.0\end{array}$

\section{LIMO2}

LIMO2 Lower_Oxygen_Limit

This is the limiting oxygen index for gaseous combustion. In version 5 and earlier, it was on the CHEMIE line. It is global and applies to gaseous combustion in all plumes. Please read the technical reference manual for the meaning and implication of setting this parameter.

Example:

LIM02, 6

would set the lowest limit for gaseous combustion to $6 \%$

MAINF

MAINF ROOM POS(3) PLUME

A simple fire. The key word refers to the mainfire.o file. POS is the three dimensional 
position vector, relative to the front, lower, left corner of the compartment.

Example:

MAINF,2,.1,.1,.1,1

\section{MVENT}

MVENT From_Compartment To_Compartment ID_Number From_Opening_Orientation From_Center_Height From_Opening_Area To_OpeningOrientation To_Center_Height To_Opening_Area Flow Begin_Dropoff_Pressure Zero_Flow_Pressure initial_fraction

This replaces the more complex mechanical ventilation commands with a constant flow fan connection. The original commands MVOPN MVFAN MVDCT and INELV are not supported in this version. The command specifies a pair of openings connected by a constant volume flow fan. The fan flow can be modified with the EVENT key word.

Example:

MVENT $, 5,7,1, \mathrm{~V}, 0.50,1.00, \mathrm{H}, 2.40,1.10,2.00,200 ., 300 ., 1.0$

\section{OBJECT}

\section{OBJECT NAME ROOM POS (3) PLUME IGNITION_TYPE IGNITION_CRITERION NORMAL (3)}

This key word places a fire (designated objects for version 6) into a compartment. The NAME on the object line should match the name in the file. While the main fire (MAINF) places a very simple fire in a compartment, mimicking a sand burner, OBJECTs are intended to simulate real burning items and must have attributes such as an orientation. The format for the fire objects is shown in "V6 Fire Format.xls." A position vector of $(-1,-1,-1)$ puts the object in the center of the compartment on the floor. A pointing vector of $(0,0,1)$ is facing upward.

Example: 
OBJECT, WARDROBE $, 1,-1,-1, \odot ., 1, \odot, \odot . \odot \odot,-1,-1,-1$

\section{ONEZ}

ONEZ Compartment

For tall compartments or those removed from the room of fire origin, the compartment may be modeled as a single, well-mixed zone rather than the default two-zone assumption. A single zone approximation is appropriate for smoke flow far from a fire source where the two-zone layer stratification is less pronounced than in compartments near the fire. This is used in situations where the stratification does not occur. Examples are elevators, shafts, complex stairwells, and compartments far from the fire.

Example:

ONEZ, 2

\section{ROOMA and ROOMH}

\section{ROOMA and ROOMH Compartment Number_of_values Area(or Height)}

These key words allow the user to define non-rectangular rooms by specifying crosssectional area as a function of height. One set of values is included for each compartment that has a variable cross-sectional area. The format in both cases is the key followed by an index of the number of values. These key words must be used in pairs.

Example:

$\begin{array}{lllll}\text { ROOMA } 1 & 3 & 10.0 & 5.0 & 3.0 \\ \text { ROOMH } 1 & 3 & 0.0 & 1.0 & 2.0\end{array}$

specifies that compartment 1 has a cross-sectional area of $10 \mathrm{~m}^{2}, 5 \mathrm{~m}^{2}$ and $3 \mathrm{~m}^{2}$ at elevations $\odot .0 \mathrm{~m}, 1.0 \mathrm{~m}$ and $2.0 \mathrm{~m}$ respectively. 


\section{THRMF}

THRMF Thermophysical_Properties_File

By default, thermophysical properties are obtained from the thermal.csv which is located in the directory where the model executables reside. This allows for another file to be used.

Example:

THRMF, NEWTHERMALFILE

\section{STPMAX}

STPMAX Maximum_Time_Step

This specifies the largest time step that the model will take. The default value is one second. In most cases, the numerical routines adjust the time step appropriately; however, for long simulation times and slowly varying conditions, a larger value is appropriate. In cases where the fire height and vent soffits interact, the time step may need to be smaller.

Example:

STPMAX, $\odot .2$

\section{TARGE}

TARGE Compartment Depth Breadth Height Normal_Depth Normal_Breadth Normal_Height) Material Method Equation_Type

CFAST can track and report calculations of the net heat flux striking arbitrarily positioned and oriented targets and the temperature of these targets. A non-zero normal vector must be specified as must a material from the thermophysical database. Method can be one of STEADY for steady state solution, XPLICIT for explicit solution, and MPLICIT for an implicit solution. 
Example:

TARGE $, 1,2.20,1.88,2.34,0 . \odot \odot, \odot . \odot \odot, 1 . \odot \odot$, CONCRETE, IMPLICIT, PDE

\section{TIMES}

TIMES Simulation_Time Print_Interval History_Interval Nornal_Output_Interval WallandTarget_Output_Interval Vent_Flow_Output_Interval Species_Output_Interval.

Example:

TIMES, $360,-120,130,140,150$,

Printed output will be on the screen or in a file named project.out. The binary history output (for use with the DLL package) will be in project.hi. The four spreadsheet listings are in project. \{n.csv, w.csv, f.csv and s.csv\}. Please see Appendix ??? for a discussion of the format of each of these files.

\section{VERSN}

VERSN,version number, Title

The header is \$ $\$$ CF \$ and is case sensitive. The major version number from the file must match the major version number kept internally (6 at the moment).

Example

VERSN, 6,"Simple test of the object file input"

\section{VHEAT}

VHEAT First_Compartment Second_Compartment 
Heat transfer between the ceiling and floor of specified compartments can be incorporated with the VHEAT key word. Ceiling to floor heat transfer occurs between interior compartments of the structure or between an interior compartment and the outdoors. The model checks to make sure that the ceiling and floor are reasonably contiguous (within 0.01 $\mathrm{m}$ ), and the assumption is made that this is true for the entire ceiling and floor.

Example:

VHEAT $, 1,2$

The floor properties of the top compartment ( 1 in this case) and the ceiling properties of the bottom compartment ( 2 in this case) must be defined by COMPA and included in the thermophysical file.

\section{VVENT}

VVENT from_compartment to_compartment area shape initial_fraction

Combined buoyancy and pressure driven (i.e., forced) flow through a horizontal vent (vertical flow) is possible when the connected spaces are filled with gases of different density in an unstable configuration, with the density of the top space larger than that of the bottom space. This type of flow is inherently different from horizontal flow (vertical vent) in that there is not layer to layer mixing from inverted plumes. This key word describes those horizontal openings between the compartments through which this type of flow occurs. Each VVENT line in the input file describes one horizontal vent. There are four parameters, the connected compartments, the shape of the opening, and the effective area of the vent.

Example:

VVENT $, 1,2,4.0,2,0.9$

\section{WIND}

WIND Wind_Speed Scale_Height Power_Law_Coefficient 
The wind speed, scale height, and power law are used to calculate the wind coefficient for each vent connected to the outside. The wind velocity is specified at some reference height. The power law then provides a lapse rate for the wind speed. An assumption is that the wind speed is zero at the surface. This is the same format as in version 5 . Please see the technical reference guide on the formula used in this calculation.

Example:

WIND, $3 ., 10 ., 0.16$ 